


\section{Smithsonian Institution}

Sibraries

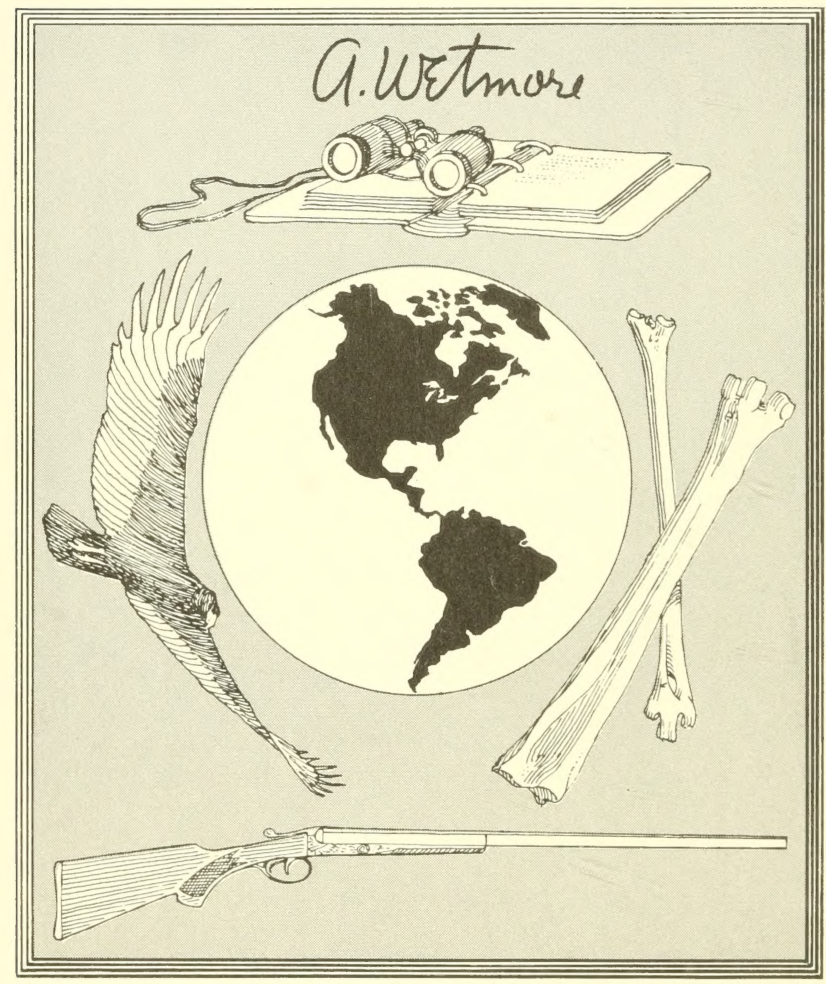

Alexander Wetmore

1946 SixthSecretary 1953

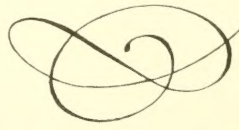


Q. Wrtmaxe

Jue calezh

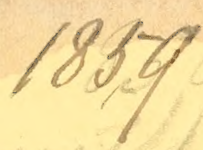

thubum 1294 
$2) 6$ 
THE

\section{TAXIDERMIST'S MANUAL。}




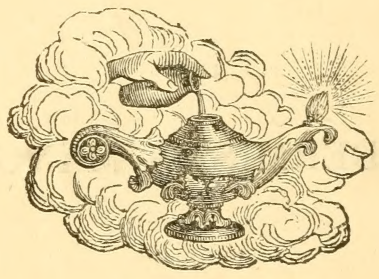




\title{
TAXIDERMIST'S MANUAL;
}

\author{
OR THE
}

ART OF COLLECTING, PREPARING, AND PRESERVING OBJECTS OF

\section{NATURAL HISTORY.}

DESIGNED FOR THE USE OF

TRAVELLERS, CONSERVATORS OF MUSEUMS, AND PRIVATE COLLECTORS.

B Y

\section{CAPTAIN THOMAS BROWN, F.L.S.,}

conservator of the Manchester musenM of Natural history, LATE PRESIDENT OF THE RUTAL PHYSICAL SUCIETY, ETC., ETC., ETC.

ELEVENTH EDITION.

LONDON, EDINBURGH, AND DUBLIN :

A. FULLARTON AND CO.

1853. 
EDINBURG

FUIJARTON AND MACNAB, FRINTKR3, LWTH WALK 


\section{PREFACE.}

There are few individuals who have not, in the course of their lives, met with objects of Natural History, which they considered worth preserving, but, from the want of knowledge how to proceed, have been unable to do so. Indeed many fine specimens have been lost from this cause alone. To remedy this, in some degree, is the intention of the following little book, which will be found to contain almost all that is already known on the methods of Collecting and Preserving Objects of Natural History, including several things which are not generally known.

In the year 1819, the Senatus Academicus of the Edinburgh University, did me the honour to request me to proceed to France, to inspect the splendid Museum of Mons. Dufresne, chief of the preserving department, at the Jardin des Plantes, Paris, which was then for sale; and, if I approved of it, to purchase the collection for the College. I found the collection to consist of many rare and valuable specimens, and, as a whole, in a high state of preservation, as might be expected, from the ability of its distinguished possessor; and that it was worth more, in my estimation, than the sum asked: I accordingly made the purchase. 
The intimacy that I then formed with M. Dufresne, one of the best naturalists in Europe, and, situated as he was at the head of the laboratory of preservation, afforded me ample opportunity of inspecting and becoming acquainted with all the different processes employed in the preservation of animals. This I was the more anxious to acquire, that I might be of use to our own Museum, which had, by this magnificent purchase, been increased by an addition of sixteen hundred Birds, twelve thousand Insects, two thousand six hundred species of Shells, amounting to upwards of five thousand individuals. There were besides upwards of two thousand Fossils, and a beautiful collection of upwards of eight hundred eggs, accurately named, with numerous other things, such as Quadrupeds, Corals, Echini, \&xc.

In the following treatise, it has been my object to attend more to rendering the meaning clear, than to - elegance of language; and, besides, to get the work up in a style at once creditable and moderate in price, so that it might be generally useful. At the same time, I have preferred avowing myself the author, to publishing the work anonymously, being firmly of opinion, that no man should publish on a subject which he is ashamed to acknowledge.

Naturalists and travellers are frequently greatly at a loss, on going abroad, to know what instruments are necessary to be carried along with them, so that they may be effectually prepared for every kind of research; and, as they are also at a loss to know who are the best makers of these, I have pointed out Mr. Alexander Adie of Edinburgh, a gentleman long distinguished for the excellence of his instruments, 
and whose inventive genius has led to many improvements on them. I reed only remark, that he has made nearly the whole instruments which were used by our late highly distinguished Professor of Natural Philosophy, Sir John Leslie, as also those used by Sir David Brewster, in his experiments on Natural Philosophy, and more particularly such as were comnected with his admirable discoreries concerning the polarization of light.

When Travellers and Naturalists go into foreign lands, or even traverse the more remote districts of Britain, or the continent of Enrope, they should not confine their rescarches to the collecting of natural olyects alone; their attention should be extended to geographical and meteorological olserrations, the altitude of mountains, lakes, and sources of rivers, above the level of the sea; the moistuie and particular state of the atmosphere in those situations; the temperature of lot springs; their relation to volcanic causes : for all which purposes instruments are made, by which these things can be easily determined.

On these interesting points, much yet remains to be done even in Great Britain. 


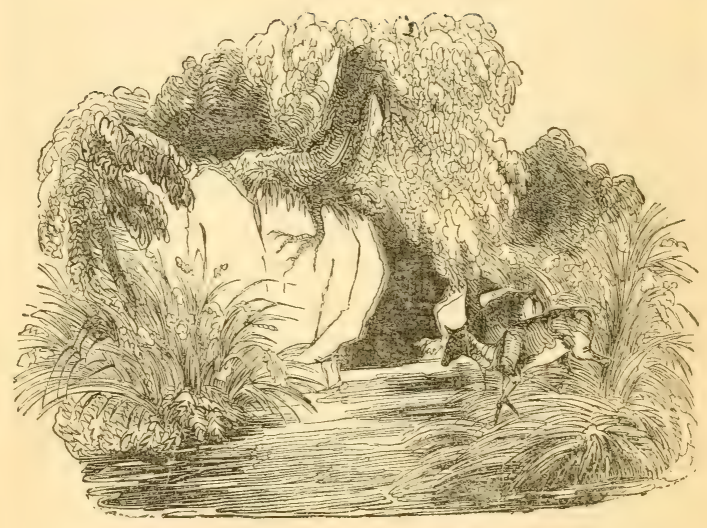




\section{CONTENTS.}

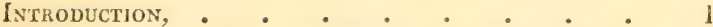

Chap. I. - Of skinning, preparing, and mounting the

Mammalia or Quadrupeds, . . . 6

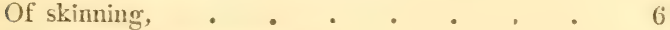

Of stuffing Quadrupeds, \&c. . . . . . 8

Order I.-Bimana, . . . . . . 14

Order II.-Quadrumana, . . . . . 15

Apes and Monkeys, . . . . . 15

Order 1II.-Cheiroptera, . . . . . 15

The flying Lemur, . . . . . 15

Bats, . . . . . ค . 16

Order IV.Feræ, - . .

Hedgehogs, . . . . . . . 16

Bears, . . . . . . . 16

Order V.-Marsupialia, . . . . . . 18

Order VI.-Glires, . . . . . . 18

The Porcupine, . . . . . . 19

Hares, . . . . . . . 19

Order VII.-Edentata, . . . . . . 19

The Sloths, . . . . . . 19

Armadillos, . . . . . . . 19

Ant-Eaters, . . . . . . 20

The Duck-Billed Platypus, . . . . 20

Order VIII.-Fachydermata, . . . . 20

The Elephant, . • . . . . 20

Order IX.-Ruminantia, . . . . . 23

Deer, Antelopes, and Goats, \&e. . . . 23

The Elk, . . . . . . . 23

The Urus, Bison, llulialo, . . . . 23 
Order X.-Cetacea, . . . . . . . 24

The Dolphin, Porpoise, \&c. . 24

Chap. II. - Of skinning, preserving, and mounting Birds, 25

Skinning, . . . . . . . . 25

Manner of skinning Birds, as practised at the Jardin des Plantes, Paris, . $\quad . \quad . \quad . \quad . \quad 28$

On stuffing Birds, . . . . . . 32

Mr Bullock's method of stuffing Birds, . . . 36

M. Becœur's method of stufling Birds, . . 37

M. Mauge's method of stuffing Birds, . . 38

Mr Waterton's method of stuffing Birds, . 39

Method of mounting dried skins, . . . . 44

Of mounting Birds feather by feather, . . 45

Order I. - Rapaces, or Birds of prey, . . . 48

Vultures, . . . . . . . . 48

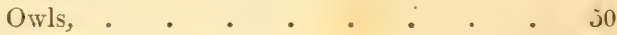

Order II.-Omnivorous Birds, . . . . 50

Order III.-Insectivorous Birds, . . . 51

Order IV.-Granivorous Birds, . . . . . 51

Order V.-Zygodactylous, or yoke-footed Birds, 51

Order VI.-Anisodactyli, . . . . . 52

Order VII.-Alcyones, . . . . . 53

Order VIII.-Chelidones, . . . . 53

Order IX._Columba, . . . . . 53

Order X.-Gallinæ, . . . . . . 53

Order XI.-Alectorides, . . . . . . 54

Order XII,-Cursores, . . . . . 5 t

Order XIII.-Grallatores, • . . . . . 56

The Flamingo, • . . . . . 56

Order XIV.-Pinnatipedes, . . . . . 57

Order XV.-Palmipedes, . . . . . 57

Order XVI.-Inertes, . . . . . . 58

Of the nests and eggs of Birds, . . . 58

Chap. III - On skinning, preserving, and setting up Re'p-

tiles, Fishes, and Molluscous Animals, dic. 69

Class III.-Reptiles, • • • • • • (i)

Tortoises and Turtles, . . . . 6 6il

Crocodiles and Lizards in gencral, . . . 61

Serpents in general, . $\quad . \quad$. $\quad . \quad 61$ 
Frogs and T'oads,

Lampreys, Eels, and other Fisil of similar form,

Of skinning Fish in general, . . . . 63

Stuffing Fish, . . . . . . 63

Division II._-Invertebrate Animals, . . . 67

Mollusca, . • • • • • . 67

Of polishing Shells, . $\quad$ • . 69

Class VI.-Crustacea, . . . . . 70

Chap. IV.-Of preserving Spiders, Gally-Worms, and

Insects, . $\quad . \quad 0 \quad$ • $\quad$ • 72

Class VII.-Arachnides, . . . . . 72

Class VIII._Myriapoda, . . . . . 74

Class IX.-Insects, • • . . . . 74

Setting and preserving Insects, . . $\quad$. 79

Method of relaxing dried Insects, . . 83

The eggs of Insects, • • • • • 86

The Larvie, or Caterpillar, . . . 86

The Pupa, . . . . . . 87

Method of breeding Insects, . . . 87

Class X.-Echinodermata, . • . • 90

Asterias-Star Fish, . . . . . 90

Echini and Spatangus-Sea Urchins, . . 91

Class XI.-Entozoa; and Class XII.-Acalepha, 92

Class XII.-Polypi, . . . . 92

Class XIII.-Infusoria, • . . . . . 93

Chap. V.-Of preparing Skeletons, . . . 9 1.

Cleaning and preparing bones in general, . . 91

Of natural Skeletons, . . . . . 95

Of artificial Skeletons,

Chap. VI.-Of the chase, and manner of collecting

Animals, . . . . . .

Shells, . . . . . . . . 104

Of the Gangui, . . . . . 106

Of the Rake, . . . . . . 106

Of the Dredge, . . . . . . 107

Molluscous Animals, . . . . . 110

Insects, . . . . . . . . 111

British Insects, . $\quad . \quad+\quad \cdot \quad$. 112 
Chap. VII.--Receipts for various articles used in the preservation and setting up of Animals,

Solution of Corrosive Sublimate, • • • 115 Arsenical Soap, . . . . . . 116

Arsenical composition, . . . . . 117

Solution of Pearl Ashes, . . . . . 117

Annealed Iron Wire, . . . . . 117

Gum Paste, . . . . . . 118

Flour Paste, . . . . . . 118

Solution of Gum Arabic, • • • • • 118

Paper Paste gummed, . . . . . 118

Pollen Powder, . . . . . . . 119

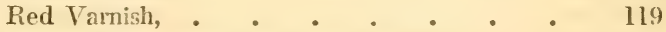

Luting for rendering bottles air tight, . . . 120

Tow and flax Slivers, . . . . . 320

Methol of making Enamel Eyes for Animals, - 120

Second method of making Eyes, . . 122

Third method of making Eyes, . • • • 122

Articles required for skinning and motasing Quad-

rupeds, Birds, Fishes, and Reptiles, . . 124

Chap. VIII.-Instructions to Travellers, . . . 125

The Animal Kingdom, • . . . . 125

Of the Vegetable Kingdom, . . . . 130

General remarks on Botany, . . . . 133

Geology and Mineralogy, • • • • . 135

Explanation of the Plates, . . . . 137

Appendix, . . . . . . . . 142

List of Books for attitudes of Quadrupeds and Birds, 143

Meteorology, • • • • . . . 143

List of Geographical and Meteorological Instru-

ments, \&c., with their prices, . . . 144

Index, . . . . . . 147 


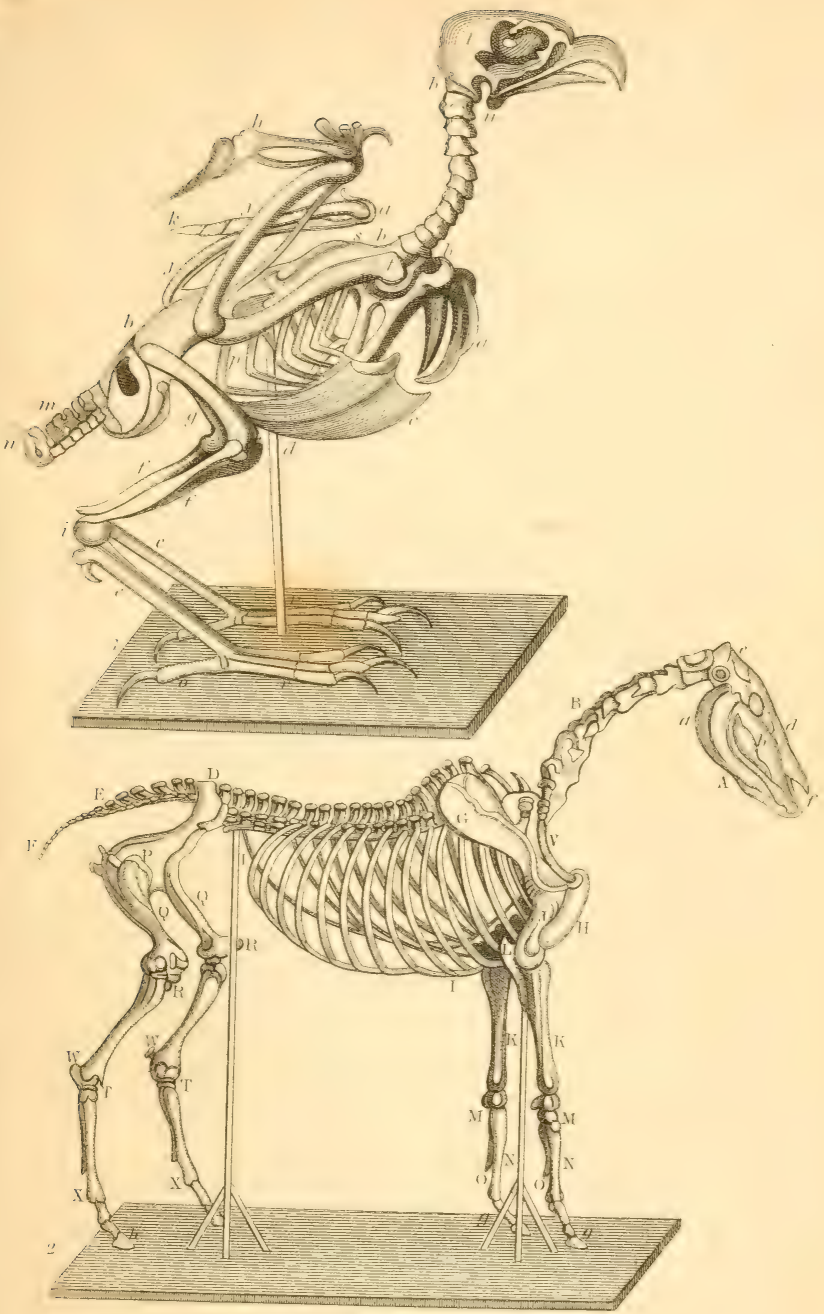





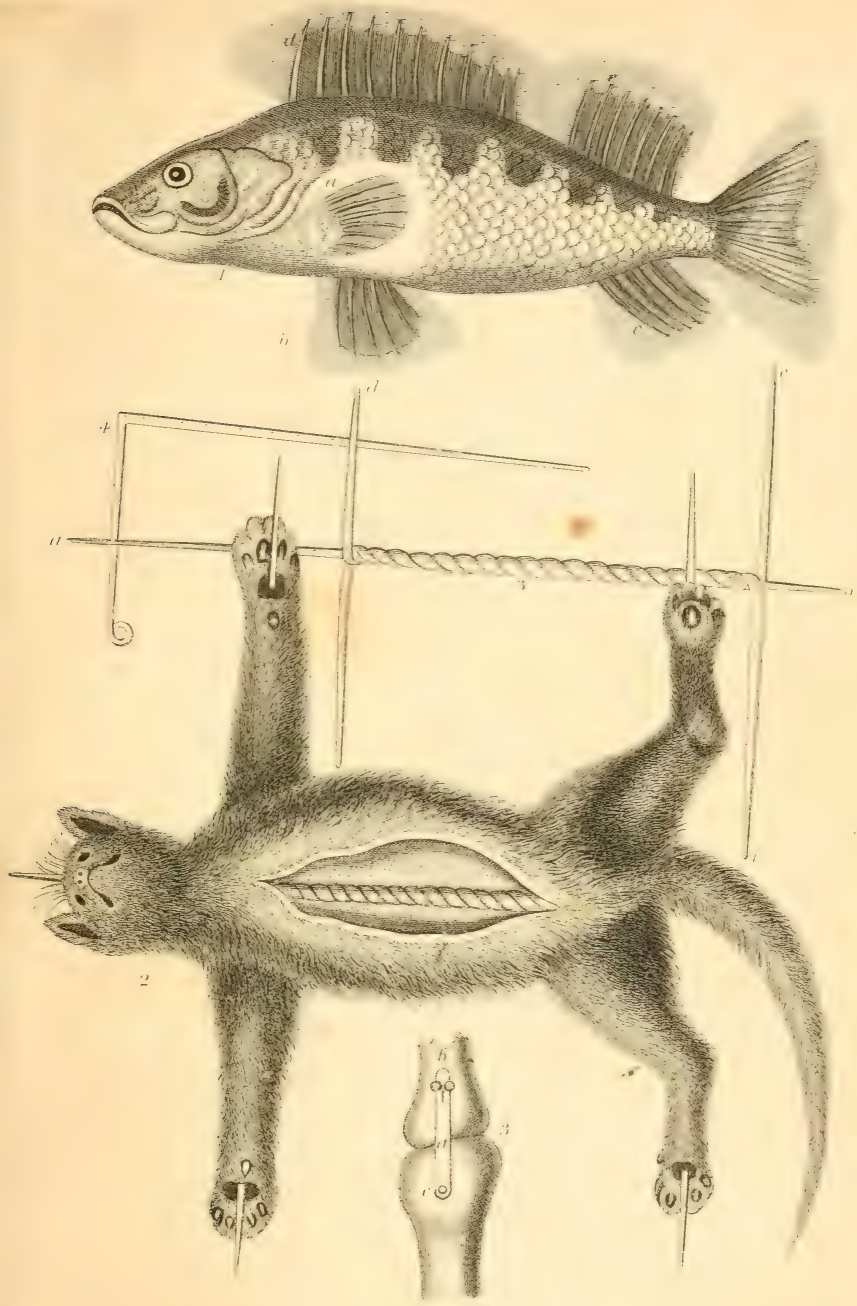





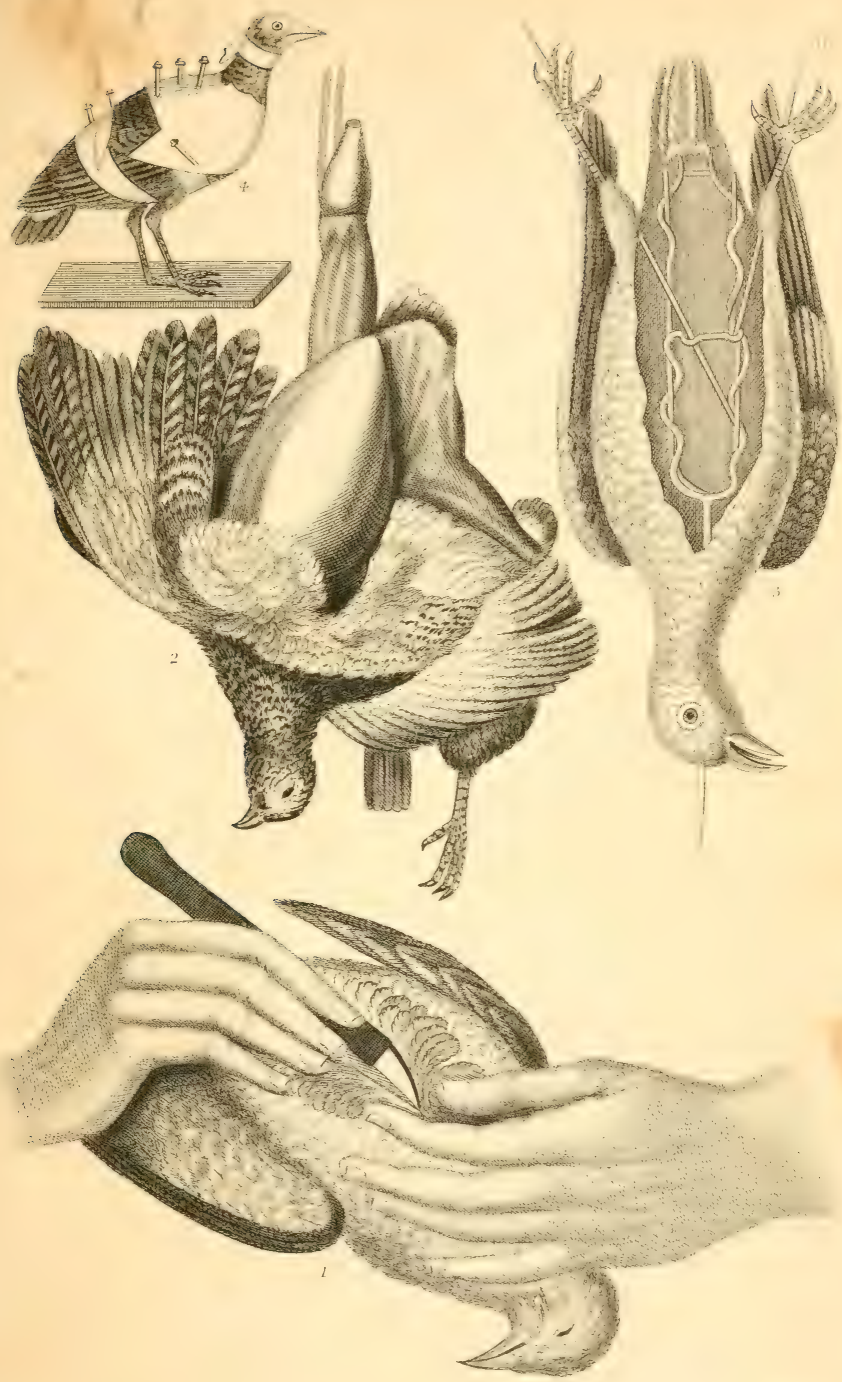





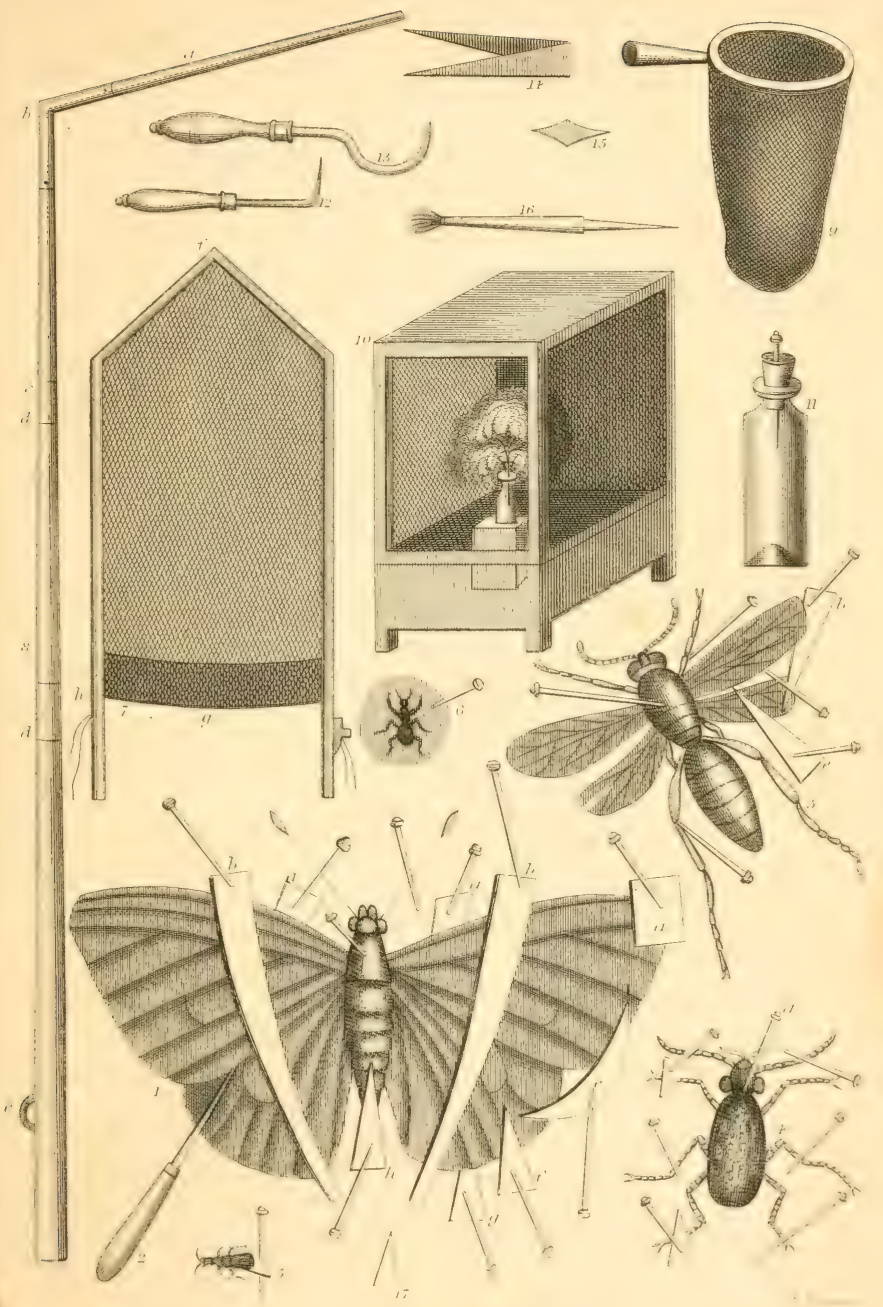




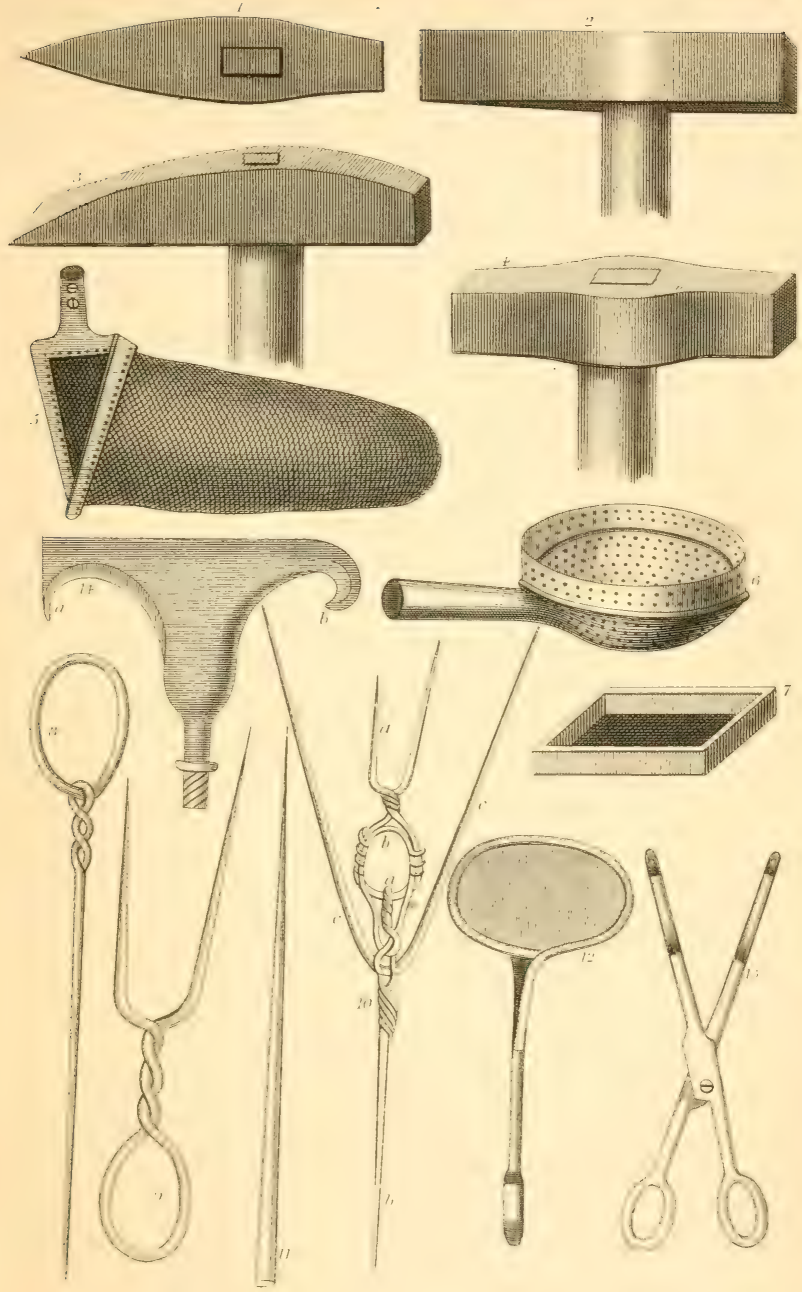



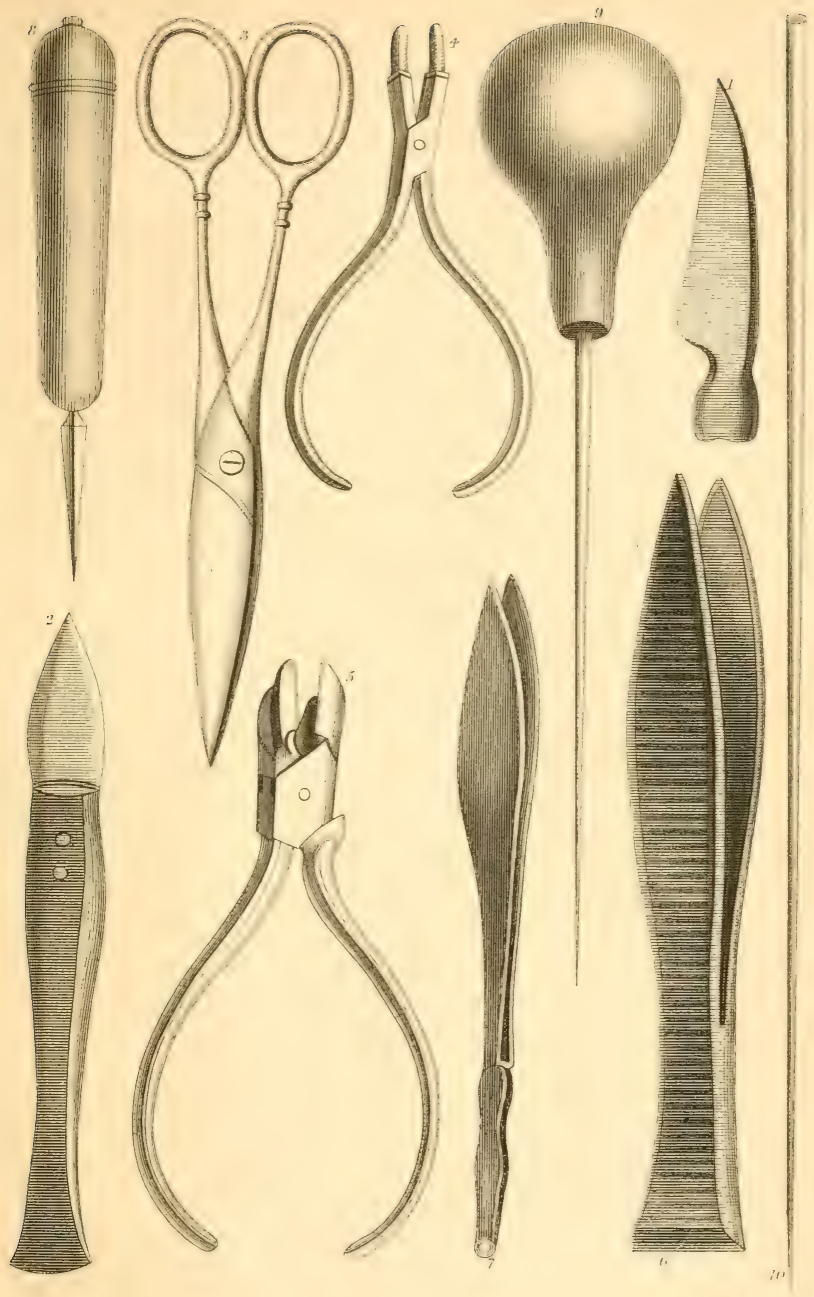





\section{INTRODUCTION.}

The advantages to be derived from a collection of objects of Natural History, are too apparent to require any illustration ; and their beauty and variety of their forms have, in a preserved state, ever attracted the admiration of mankind, as being. next in point of interest to the living animals. Although good drawings and engravings will give us a perfect knowledge of the general appearance of animals, still they are deficient in many pariculars; for by them we cannot be made acquainted with the texture of the skin, nor the structure of the hair or feathers.

The naturalist, on all occasions, prefers a reference to the stuffed animal to that of a pictorial representation, as by this means he is enabled to trace, compare, and decide, on the creature in its several characters and relations.

In museums and cabinets are brought together natural ol)jects of all kinds, from the most extreme points of the globe, and presented in a form that enables us, as it were, to look upon the mighty field of nature at one view; with the additional advantage of having the various Classes and Genera placed in systematic order, to investigate which, in their native wilds, would be the business of several lifetimes. Besides, we can here contemplate, without dread, the mosi destructive and furious quadrupeds, and the most noxious reptil: s. Here we can muse upon and study the animals which latse created in us the highest of sentiments while realing the tale of the traveller, or the singularity of organization, pointel out by the naturalist. 
He who has attended to any branch of Natural History, will best know how dificult it is to collect even the animals, plants, or minemls of Britain; because some of the individuals are extremely local in their habitats.

To instruct in the manner of Collecting, Cleaning, Preparing, and Preserving these, is the object of the following Treatise. This art has bien practised in a certain degree from very early times, but it was not till after the midule of the last century, that Taxidermy, or the art of preserving objects of Natural History, had reached any degree of perfection, and it is still susceptible of much improvement.

We have seen that attempts at the preservation of animal substances were practised by the Egyptians in the instance of Mummies and the Ibis, which they always preserved along with their chiefs. But these were prepared in such a manner as to produce no pleasurable sensations in examining them; being remarkable only for their great antiquity.

It is to be lamented, that even to the present day chemists have not discovered means of effectually resisting the universal law of decay, which, by certain fixed operations, reduces every kind of organised matter to its original elements. Methods have been devised of arresting for a time the progress of decay, but these seem gradually to lose their effect, and ultimately become mutilated and decomposed. Animal substances are subject to the ravages of thousands of minute animals. This is probably brought about by the varied changes and penetrating powers of the atmosphere, caused by its gases, heat and moisture. We do not mean by this that the atmosphere creates minute beings, only its influence is favourable and indispensable to their reproduction. On unorganised substances, these are found to be ever acting and destructive agents.

To derise the means of preventing these effects is the business of the Taxilermist, and upon his success the excellence of his art will depend. It will, therefore, easily be imagined h. w important and indeed indispensable to his art is a thorough knowledge of chemical science, for by experimenting on preservatives on established chemical principles, he may discover the best method of averting the progress of 'Time's destroying hand.

Although considerable advanes have been made of late 
years in the art of Taxidermy, it is still far from perfection. This is to be attributed, in a great measure, to the education of the persons who practise this art; for among all I have met with employed in the preservation of animals, none have had the advantage of anatomical study, which is quite indispensable to the perfection of stuffing. One or two individuals, it is true, have attended to the structure of the skeleton of Man, and a few of the more common animals, but this is far from the information which they ought to possess ; for nothing short of a general and extensive knowledge of comparative anatomy can qualify them sufficiently for an art which is so comprehensive and varied in its application.

These observations are particularly applicable to Quadrupeds and Reptiles, for what are even the best stuffed specimens of the first museums in the world compared to the living subject? Nothing better than deformed and glaringly artificial productions, devoid of all the grace and beautifully turned points of living nature. A knowledge of drawing and modelling are also indispensable qualifications, to enable the stuffer to place his subject in a position both natural and striking. It is the too frequent practice for the stuffer to set about preserving the animal withont having determined in what atitude he is to place it, so that it will appear to most advantage, and be in character with the ordinary habits of the creature. This he leaves to the last efforts of finishing his work, and, consequently, its proportions and character are likely to be devoid of all appearance of animation.

The first thing, therefore, to be attended to in all great national natural history establishments, is to choose young persons who are yet in their boyhood, to be instructed in this art, most important to science. Their studies should be commenced by deep attention to drawing, modelling, anatomy, and chemistry, while they, at the same time, proceed with the practical part of their art. Every opportunity of examining the habits and actions of the living subject should be embraced, and its attitudes and general aspect carefully noted. Without strict attention to these points, so manifestly obvious, the art of preserving animals never will attain that degree of perfection which its importance demands. On the other hand, if this art is pursued in the manner here recommended, artists may be

A 2 
produced who will fulfil the objects of their profession vith honour to themselves and advantage to their country. Would any person expect to arrive at eminence as a sculptor if he were unacquainted with the established preliminaries of his art, namely, drawing and anatomy? The thing is so self-evident, that I am only surprised it has not long ago been acted upon. Upwards of twelve years have elapsed since I pointed out these facts to the Professor of Natural History in the University of Edinburght, but tings continue as they were before that time.

Although these observations apply with their full force to the preservation of the MAMmalia, or Quadrupeds, they are equally applicable to Birds and Fishes. It is quite true, that defects in ill-stuffed birds are not so obvious as in quadrupeds, because the feathers assist in a great measure to conceal such deformitios; and in fishes, imperfections are also less observable, owing to the smooth and unmarked appearance of their exterial surface, from the circumstance of their bones being principally small towards their outside, and the larger bones being deeply concealed uncler tine muscles.

I am happy to find that the ingenious MIr Waterion agrees with me on this important subject. "Were you," says he, "to pay as much attention to birls as the sculptor does to the human frame, you would immediately see, on entering a museum, that the specimens are not well done.

"This remark will not be thought severe, when you reflect, that that which was once alive, has probably been stretched, stuffed, stifiened, and wired, by the hand of a common clown. Consider, likewise, how the plumage must have been disordered by too much stretching or drying, and, perhans, sullied, or at least deranged, by the pressure of a coarse and heavy hand,plumage which, ere life had fled within it, was accustomed to by touched by nothing rougher than the dew of heaven, and the pure and gentle breath of air.

"In dissecting, three things are necessary to insure success, viz., a penknife, a hand not coarse or clumsy, and practice. The first will fumish you with the means, and the second will enable you to dissect, and the third will cause ycu to dissect well. These may be called the mere mechanical requisites.

"In stuffing you requixe cotton, a needle and thread, a litle 
stick the size of a common knitting-needle, glass-eyes, a solution of corrosive sublimate, and any kind of a common temporary box to hold the specimen. These also may go under the denomination of the former. But if you wish to excel in the art, if you wish to be in Ornithology, what Angelo was in sculpture, you must apply to profound study and your own genius to assist you. And these may be called the scientific requisites.

"You must have a complete knowledge of Ornithological anatomy. You must pay close attention to the form and attitude of the bird, and know exactly the proportion each curve or extension, or contraction, or expansion of any particular part bears to the rest of the body. In a woid, you must possess Promethean boldness, and bring down fire and animation as it were, into your preserved specimen.

" Repair to the haunts of birls on plains and mountains, forests, swamps, and lakes, and give up your time to examine the economy of the different orders of birds.

"Then you will place your Eagle, in attitude commanding, the same as Nelson stood in, in the day of battle, on the Victory's quarter deck. Your Pie will seem cratty, and just ready to take fightit, as though fearfui of being surprised in some mischievous plunder. Your Sparrow will retain its wonted pertness, by means of placing his tail a little elevated, and giving a moderate arch to the neck. Your Vulture will show his sluggish habits by having his boly nearly parallel to the earth; his wings somewhat drooping, and their extremitie: under the tail instead of above it,-expressive of ignoble in dolence.

"Your Love will be in airless, fearless innocence, looking mildly at jou, with its neck not too much stretched, as if uneasy in its situation, or dramn too close into die shoulders, like one wishing to avoid discovery; but in moderate, perpendicular lengths, supporting tire head liorizontally, which will set off the breast to the best advantage." *

To the traveller who wanders in search of knowledge, but

- Wauderings in Sonth America, \&ec by Charles Waterton, Eiq, a work that cannot be two highly commended, from the many remarkible incidents contained in it, aud the highly poetic and zealous warmth of its dic. tiun. 
without the means of conveying skins of quadrupeds or birds, we would say a word or two. When he has killed and examined an animal or bird, which appears new to him, after having noted down all its characters, he ought to attempt a drawing of the object, as the next best substitute for the skin.

The indefatigable Wilson, whose unbounded zeal led him to explore the mighty wilds of America, in search of information regarding the feathered tribes, but who, without either money or patronage, could not transport their skins across these nearly bomiless wildernesses, was compelled to adopt these, the ouly means he had, and to delineate their forms and features, in their native colours, as faithfully as he could, as records at least of their existence.

Audubon adopted this method. He pinned the bird to a tree in some natural position, held out loy wires, \&c., then made a drawing while the animal was yet warm. By this means he could imitate those beatiful tints which are alone to be found in living nature; and the forms being still those of the real subject, were likely to surpass those of stuffed speci. mens.

\section{H A P. I.}

OF SKINNING, PIEPARING, AND MOUNTING TIE MAMMALIA, OR QUADRUPEDS.

\section{OF SKINNING.}

WHEN a qualimped is killed, and its skin intended for stuffing, the preparatory steps are to lay the animal on its back, and plug up its nostrils, mouth, and any wounds it may have received, with cotton or tow, to prevent the blood from disfiguring the skin. A longitudinal incision is then made in the lower yart of the beliy, in front of the pubis, and extended from tience to the stomach, or higher if necessary, keeping in as straight a line as possible, and taking care not to penetrate so deep as to cut into the abdominal muscles. In some in- 
stances, the incision is made as high as the collar bone. In this operation the hairs must be carefully separated to the right and left, and none of them cut, if possible. The skin is also turned back to the right and left, putting pads of cotton or tow between it and t'le nuscles, as the skinning is proceeded with. If any fatty or oily substance should be noticed, it must be carefully wiped away. The skin being remored as far in every direction as the extent of the incision will admii of, each of the thighs must be separated at its junction with the pelvis, that is, by the heal or ball of the $O s$ femoris, * or thigh bone. The intestinal canal is then cut across, a litile way ahove the anus, and then the tail is separated, as close to the animal as possible. Afier this the pelvis is pulled out of the skin, and the skin separated from the back by inserting the handle of the scalpel cutting-knife between it and the carcase. It is pulled gradually upwards until the operator reaches the shoulders. The whole hinder parts and trunk of the houly being thus out of the skin, the next operation is to remore the fore-legs, by separating them from the boly at the shoulderjoint, or the base of the Os humeri. When the joint of one shoulder has been separated from the borly, the leg is again put into the skin, and the animal then turned in order to repeat the same with the other side, the limb of which is also returned. The skin is then removed from the neck. The next thing is to separate the skin from the head by the assistance of the scalpel. It is taken off as far as the point of the nose ; while great care must be taken not to injure the eyelids, and to cut the ears as close to the skull as possible; and also to avoid cutting the lips too close.

All this having been performed, the head and trunk of the animal are completely separated from the skin. The next operation is to remove the head of the animal from the trunk, at the upper bone of the vertebræ. The external muscles of the head and face are then carefully cut off with a scalpel, and the bones left as free from flesh as possible. The occipital bones are next enlarged by means of a strong knife, or oiher instrument; and the brain all carefilly remored. The fore legs

* Those who are unacquainted with the names of the different hones of the skeleton, will find a full detail of these of buth Quadrupeủs azd Birds, in our description of Plate $I$. 
ure now pulled out of the skin, by drawing the legs one way and the skin another, as far as the claws of the foot. All the miscles are then cut off the bones, while care is taken not to injure the ligaments and tendons. They should be left adhering to the knee. They are then returned into the skin again. The hind legs are treated in the same manner. The tail is the last part which is skinned, and this is a more difficult task than the other parts of the body. Two or three of the first joints or vertobr:e are first laid bare by pulling the skin back; they are then tied firmly with a strong cord, which must be attiched to a strong nail or hook on the wall. A clefi stick is introduced between the vertebrie and the skin, the stick is then forced to the extremity, and the tail-bones come out of their enveloping skin or sheath.

The skeleton head, having been divested of all its fleshy matter, tongue, palate, external muscle, and brain, is now returned to its place in the skin, which is in a condition for commencing the operation of stuffing.

\section{OF STUFFING QUADRUPEDS, \&c.}

Let us suppose the animal which we intend to stuff to be a Cat. Wire of such a thickness is chosen as will support whe animal by being introduced under the soles of the feet, and rumuing it through each of the four legs. A piece of smalles. dimensions is then taken, measuring abont two feet, for the purpose of forming, what is termed by stuffers, a tail-bearer. This piece of wire is bent at nearly a third of its length, into an oral of about six inches in length; the two ends are twisted together, so as to leave one of them somewhat longer than the other; the tail is then correctly measured, and the wire is cut to the length of it, besides the oval. The wire is thrn wrapped round with flax in a spiral form, which must be increased in thickness as it approaches the oval, so as to be nearly equal to the dimensions of the laryest vertebric, or ront of the tail. The thickness can be very nearly initated from measuring the bones of the tail which have just been rumoved, and for this purpose a pair of callipers should be used. When fitished it should be rubbed thinly over with fonir-paste, to 
preserve its smooth form, which must be allowed to dry thoroughly, and then the surface should receive a coating of the preservative. The sheath of the tail must now be rubbed inside with the preservative. This is applied with a small quanity of lint, attached to the end of a wire, long enough to reach the point of the tail-sheath. The tail-bearer is then inserted into the sheath, and the oval part of the wire placed within the skin of the belly, and attached to the longitudinal wire, which is substituted for the rertebrie or back bone.

Four pieces of wire, about the thickness of a crow-quill, are then taken, which must be the length of the legs, and another piece a foot or fifteen inches longer than the body. One end of each of tirese is siarpened with a file in a triangular shape, so that it mily the more easily penetrate the paris. At the blunt end of the longest piece a ring is formed, large enough to admit of the point of a finger entering it; this is done by bending the wire back on itself a turn and a half, by the assistance of the round pincers. On the same wire another ring is formed in a similar manner, consising of one entire turn. and so situated as to reach just between the animal's shoulders. The measurement should be carefully made from the animal itself. The remaining part of this wire should be perfectly straight, and triangularly pointed at the extremity.

Another method of forming the supporting wires, as practised by M. Nicolas, is to take a central wire, which must be the length of the head, neck, body, and tail of the Cat, as in plate II., that is, from $a$ to $b$, but tise tail at $b$ is shortened owing to want of room in tine plate; two other pieces are then taken and wwisted round the centre piece, in the mamer represented in plate II. $c, d, e, f$; these extremities being left for the leg wires. After the wires are thus twisted together, the central one is pulled out; and the feet wires of one sitle are pushed through the legs of one side from the inside of the skin, and, the other two leg pieces are bent and also forced through the legs, and afterwards made straight hy a pair of pineers : the centre piece, having been previously sharpened at one end with a file, is now forced through the foreneat and down the neck, till it enter the centre of the twisted leg wires which it formerly occupied, and pushed forward to the extremity of the tail, leaving a small piece projecting out of the 
forehead, as represented in the Cat, plate II. fig. 2. After which, the completion of the stuffing is proceeded with.

We think this mode unnecessary for the smaller animals, and that it should only be adopted for quadrupeds the size of Deer, \&c. These wires are besides much more difficult to insert by this than by the other method.

All the wires being adjusted, the operation of stuffing is next proceeded with. The skin of the Cat is now extended on a table; and the end of the nose seized with the left hand, and pushed again into the skin, till it reaches the neck, when we receive the bones of the head into the right hand. The skull is now well rubbed over with the arsenical soap, and all the cavities which the muscles before occupied are filled with chopped tow, flax, or cotion, well mixed with preserving powder. The long piece of wire is now passed into the middle of the skull, and after it is well rubbed over with the preservative, it is returned into the skin. The inner surface of the neck-skin is now anointed, and stuffed with chopped flax, taking care not to distend it too much. Nothing like pressure should be applied, as the fresh skin is susceptible of much expansion.

Observe that it is always the inner surface which is anointed with the arsenical soap.

Take care that the first ring of the wire, which passes into the head, is in the direction of the shoulders, and the second corresponding with the pelvis, or somewhat towards the posterior part. One of the fore-leg wires is then inserted along the back of the bone; and the point passed out under the highest ball of the paw. When this is accomplished, the bones of the leg are drawn up within the skin of the body, and the wire fastened to the bones of the arm and fore-arm with strong thread or small twine. Brass wire, used for piano-forte strings, makes it more secure, and is not liable to rot. These are well anointed, and flax or tow slivers wrapped round them, so as to supply the place of the muscles which have been removed. The common stuffing employed by the French taxidermists, at the Jardin des Plantes, is chopped flax; but it must be quite evident that for such parts as the legs of animals or birds, that flax or tow slivers are far preferable; and can be wound on with more nicety. Whereas, 
chopped fax or tow is apt to make inequalities. To give the natural rise to the larger muscles, a piece of sliver should be cut of the length of the protuberance required, and placed in the part, and the sliver wrapped over it. This gives it a very natural appearance.

The mode of fixing the legs, is by passing one of their pieces of wire into the small ring of the horizontal or midtle supporting wire. Pursue the same plail with the other leg; and then twist the two ends firmly together, by the aid of a pair of flat pincers. For an animal of the size of a Cat, the pieces left for twisting must be from five to six inches in length. After being twisted, they are bound on the under side of the body wire, with strong thread: the two legs are then replaced, and put in the form in which we intend to fix them. The skin of the belly and top of the shoulders is then anointed; and a thick layer of flax placed under the middle wire. The shape is now given to the scapulie on both sides, and all the muscles of the shoulders imitated. These will be elevated or depressed, according to the action intended to be expressed. The anterior part of the opening is now sewed up, to retain the stuffing, and to enable us to complete the formation of the shoulders and junction of the neck. This part of the animal is of great importance, as regards the perfection of its form: and much of its beaty will depend upon this being well executed.

If the animal has been recently skinned, the best plan possible is to imitate, as nearly as possible, the muscles of the carcase; by which many parts will be noticed which might otherwise have been neglected. Even to the comparative anatomist, I address this recommendation: Copr Nature WHENEVER YOU HAVE IT IN YOUR POWER.

It must be observed as a general rule, that the wires for the hind legs of quadrupeds should always be longer than those of the fore legs.

The next thing is to form the hind leggs and thighs, which must be done, as above described for the fore legs; but with this difference, that they must be wound round with tirread, drawn through the stuffing at intervals, to prevent it slipping up when returned into the skin of the leg. They are then fixed, by passing the leg wires into the second ring of the centre 
body wire, which is situated at, or near the pelvis; the two ends are then bent, twisting them to the right and left around the ring: and to make them still more secure, they should be wound round with small brass wire or packthread: the tail bearer is then attached in the manner formerly described.

Having completed this part of the iron work, the skin of the thighs is coated inside with the presurvative, and the stuffing completed with chopped flax or tow. The whole inner parts of the skin whici can be reached are again anointed, and the body stufing completed with chopped tlax. Care must be also paid not to stuff the belly too much, as the skin very easily dilates. The incision in the belly is now closed by bringing the skin together, and then sewed within and without; while attention is paid to divide the hairs, and not to take any of them in along with the thread; but should any of them be inadrertently fixed, they can be picked out easily with the point. (Plate VI. fig. 10.) When this is completed, the hair will resume its natural order, and completely conceal the seam.

The seam should now be well primed, on both sides, with the solution of corrosive sublimate, to prevent the entrance of moths.

The articulations of the legs are then bent, and the animal placed on its feet; and pressure used at the natural flat places, so as to make the other parts rise where the muscles are visible.

I camnot take leave of this part, without mentioning a plan which I invented, for giving full effect to the muscles of the shoulders. Having skimed a Dog, immediately on removing the carcase, I took a plaster of Paris cast off, from each of the shoulders; and from these moulds I cast a pair of shoulders. After having completed the internal stuffing, I applied these casts on the top of the tow, and on the skin being brought over them, they had the best effect imaginable; and gave the complete appearance of the shoulder in the living animal. This method may be extended to the other visible muscles of the body with great effect; and it is very easily and speedily accomplished. In short, every legitimate means of this kind should be thought of and adopted, at whatever expense and trouble it may be, to obtain the end in view ; namely, as close 
an imitation of the living sulject as possible; for one well mounted specimen is worth fifty indifferently executed.

A board is now prepared, on which to place the Cat. But before fixing it permanently, the animal should be set in the attitude in which it is intended to be preserved, and the operator having satisfied himself, then pierces four holes for the admission of the feet wires, which must be drawn through with a pair of pincers till the pars rest firmly on the board. Small grooves are then made for the reception of the pieces of wires which have been drawn through, so that they may be folded back and pressed down in them, and not be beyond the level of the back of the board; wire nails are now driven half in, and their heads bent down on the wires to prevent them from getting loose, or becoming moreable.

The stufier next directs his attention to the position and final stuffing of the head and neck. The muscles of the face must be imitated as correctly as possible, by stuffing in cotton at the opening of the eyes, as also at the mouth, ears, and nostrils. To aid in this also, the inner materials may be drawn forward by the assistance of instruments, such as are represented at plate $I V$. figs. 12 and 13 , and also small pieces of wood formed like small knitting meshes.

Our next care is the insertion of the eyes, which must be done while the eyelids are yet fresh. Some dexterity and skill are required in this operation; and on it will depend most of the beauty and character of the head. The seats of the eyes are supplied with a little cement, the eyes put in their place, and the eyelids properly drawn over the ejeballs; but if rage or fear are to be expressed, a considerable portion of the eyeballs must be exposed. The lips are afterwards disposed in their natural state, and fastened with pins. If the mouth is intended to be open, it will be necessary to support the lips with cotton, which can be remored when they are dry. Two small balls of cotton, firmly pressed together, and well tinctured with the arsenical soap, must be thrust into the nostrils, so as to completely plug them up, to prevent the air from penetrating as also the intrusion of moths; and besides it has the effect of preserving the natural shape of the rose after it has dried. The same precaution should be adopted with the ears, which, in the Cat, require but little attention in setting. 
We must again recommend the stuffer to see that he has sufficiently applied the preservative soap; and the nose, lips, errs, and paws, being very liable to decay, must be well imbued with spirits of turpentine. This is applied with a brush, and must be repeated six or eight times, at intervals of some days, until we are certain of the parts being well primed with it; and, after all, it will be adviseable to give it a single coating of the solution of corrosive sublimate.

The methods of stuffing, which we have pointed out in the preceding pages, are applicable to all animals, from a Lion down to the smallest Mouse. Animals of a large description, require a frame-work suited to their dimensions; these we will point out in their systematic order. They are also some animals, whose peculiarity of structure requires treatment differing a a little from the ordinary course.

\section{ORDER I.-BIMANA.}

The only species of this order is MaN, who justly ranks at the head of the animal kinglom. Numerous have been the attempts of mankind to preserve the skin of their fellow-creature. The very best of these have been most disgusting deformities, and so totally unlike the "human form divine," that none of them have found a place in collections, with the exception of some parts of man, which form part of the European anatomical collections. In the museum of the Jardin du Roi, at Paris, there is one of the best things of this kind which we have seen-a human head injected, and preserved in spirits of turpentine. This curious preparation was the production of Ruitch, a Dutch physician, highly celebrated for his pathological skill. The precise manner this interesting preparation was originally preserved is not known. However, it retains to the present day, all the original and natural colours. In winter, the cold affects the spirit so much, in which it is preserved, that the head cannot be distinguished, until the return of warm weather, which dispels its cloudy appearance.

The new Zealanders have a method of drying and preserving the heads of their chiefs, with the flesh entire. Many of these 
are to be found in museums; but they are of little nse, and by no means calculated to produce pleasurable sensations.

We may safely predict, that no method will ever be discovered, by which Man can be preserved, so as to be fit for placing in a Museum.

\section{ORDER II.-QUADRUMANA.}

The animals which approach nearest to Man, are the nu merous tribes of Apes and Monkeys, and their congeners.

\section{APES AND MONKEYS.}

One of the chief difficulties to contend with, in setting up Monkeys and Apes, is the preservation of their hands, and hind hands, or what are commonly called their feet; because we must not attempt to deprive these limbs of their flesh, as we never could again supply its place, any thing like what it is in nature. The hand must therefore be dried, and then well imbued with turpentine, and the solution of corrosive sublimate, repeated eight or ten times at least, at intervals of four or five days. The other parts of the stufing should be exactly similar to that recommended for quadrupeds generally. The paws of several will require to be coloured with the different rarnishes, and, when dry, slightly polished with fine sand paper, to remove the gloss. The callosities, on the hinder parts of many of them, will also require to be coloured, and treated in the same way as the face. We may instance the Manurill (Cynocephalus Narmon), the Atys Monkey (Cercopithecus Alys), the Fair Monkey (Jacchus Argentatus), and others.

\section{ORDER III.-CHEIROPTERA.}

\section{THe FLying hemur (Galeopithecus Volans),}

Has a large flexible membrane, which envelopes the feet and extremities, and even the fingers and tail. This membrane silould be laid open from within, and the preservative flenti- 
fully supplied to it, and then dried. Wires are afterwards introduced, to keep the different parts distended; but we have found that, by introducing buckram or stiff parchment, they are much more natural and pliable. They are to be stuffed and mounted as other quadrupeds.

\section{BATS.}

The wing-membranes of this varied and numerous tribe do not require either wire or parchment to set them. They are very easily dried by distention. They are laid on a board of soft wood, the wings extended, and pinned equally at the articulations; and when dry they are removed from the boarl.

\section{ORDER IV.-FERE.}

\section{HEDGEHOGS.}

When it is wished to preserve Hedgehogs, rolled into a ball, which is a very common position with them in a state of nature, there should be much less stuffing put into them than is usual with quadrupeds, so that they may the more easily bend. No wires are required in this case. The head and feet are drawn close together under the belly; then place the animal on its back, in the middle of a large cloth, and tie the four ends firmly together; suspend it in the air till thoroughly dry, which finishes the operation.

If Hedgehogs are wished, with the head and limbs exposed, the usual method of mounting is adopted. The skins of Shrew Mice, Moles, \&c., having a very offensive smell, it will be necessary to add a considerable portion of the tincture of musk to the solution of the corrosive sublimate, with which the skins are imbued. The same applies to Badgers, Wolverenes, Polecats, and Skunks, all of which are strong smelling animals.

\section{BEARS。}

The structure of the wires requires to be different in these larger animals, from any we have beiore describer. 
Procure a bar, one inch thick, two inches broad, and as long as to reach horizontally from the shoulders to the connexion of the thighs, or os pubis. A hole is bored, four inches distant from one of its ends, from which a comnecting groove must be formed, extending on both sides to the end of the plank next the hole; this groove must be cut out with a hollow chissel, deep enough to receive the wire. The wire is then passed through it, one end of which is just left long enough to be twisted with the other, at the end of the plank. The wire on both sides is now pressed down into the grooves, and twisted firmly together, by the aid of a pair of strong pincers. Pierce some holes obliquely into the groove, and insert some wire nails into them, which must be firmly driven home, and then bent over the wires to keep them firm. The longest end of the wire should be at least eighteen inches beyond the bar, so as to pass through the skull of the animal.

The use of this bar, it will be observed, is as a substitute for the central or supporting wires of the body. Two other holes are now bored into it, the one two, and the other three, inches from the end which we first pierced; these are for the reception of the wires of the fore-legs : and two similar holes must be made at the other extremity of the bar, for receiving the wires of the hind legs.

Bears always support themselves on the full expansion of their dilated paws, so that it is necessary to bring the leg-wires out at the claws. The leg-wires are bent at right angles, for a length of five inches from the upper end. These are put through the holes in the bar, and when they have passed through they are curved again. Two small gimlet-lioles are then made for the reception of smaller wire, by which the leg-wires must be bound together close to the bar. The fore-leg wires are fixed in the same manner, which completes the framework.

Tiis seems to be the most simple manner which could be devised, for obtaining the end in view, and is that practised at the Laboratory of the Jardin des Plantes, at Paris. No other means are used for middle-sized animals, such as the Lion, 'Tiger, Leopard, \&c. The stuffing is completed as in other quadrupeds.

As the Dog, Wolf, Hyrna, Fox, sc. belong to this orlur, B:3 
we beg again to refer to what we have already said on tisc subject at page 0 .

The Walrus, Seals, and other amphibious animals of this order, are treated in the manner of quadrupeds generally, only that leg-wires are unnecessary, except in the fore-feet; the tail, which represents the hind feet, has merely to be dried and kept properly stretched during this process, which precaution also applies to the fore-feet. They are the easiest stuffed of all animals, only the skins are very oily, they should be well rubbed with the arsenical soap, and also with the preserving powder.

The stuffing of the Walrus (Trichecus rosmarus), the Sea Elephant (Phoca proboscidea), and other large animals of this family, should consist of well dried hay for the interior parts, and tow for the surface next the skin.

\section{ORDER V.-MARSUPIALIA.}

Considerable nicety is required in the preparation of animals of this order. The females of several of them, such as the Kangaroo, Opossum, \&c., have abdominal pouches in which they carry their young, and others have membranes which project from their sides. In drying the pouches, they require to be well prined with the preservative, and attention must be paid to show them properly in the stuffed animal. The membranes should be kept out by buckram, or strong parchment, as before recommended in the Flying Lemur: page 16.

\section{ORDER VI.-GLIRES.}

This Order contains the Beaver, Musk Rat, Common Rat, and other animals whose skins have a strong smell. These require to be plentifully supplied with the preservative. The tail of the Beaver should be cut underneath, and all the flesh removed, then stuffed with tow or chopped flax, and afterwards thoroughly dried and well primed with the arsenical soap to prevent patrefaction, to which it is very liable. It 
should also have repeated washings with oil of turpentine The back should be round and short.

\section{THE PORCUPINE.}

In stuffing this animal considerable and varied expression may be given, both from the attitude and disposition of the quills. Great attention is therefore required in gुiving these a proper set during the process of drying. They will require to be looked at several times during the first and second day after they have been stuffed, and any of them that may have fallen out of the position required, to be adjusted.

\section{HA RES.}

A very pretty attitude for the Hare is to have it seated in its form in an upright position, as if alarmed at the noise of dogs, \&c. An oval is formed of wire and attached to the interior frame work, after having passed one end of it through the anus, which must be passed through a hole in the board on which the animal is to be fixed. The wires of the hind legs must be forced through the posterior part of them, and also fixed into holes formed for their reception in the board.

\section{ORDER VII.-EDENTATA.}

\section{THE SLOTHS}

Must be mounted in an upright posture, as they are seldom or never to be seen walking horizontally, except in finding their way from one tree to another. The great length of their fur makes it a comparatively easy task to mount them.

\section{ARMADILLOS}

Are also easily set up, owing to the bands preserving the ordinary shape of the animal. The French Taxidermists do not use any of the preservative for the skin, but merely dry it. We are, however, of opinion, that they are wrong, as all sorts 
of hides are liable to the attacks of insects, unless preserved in some way. We would, therefore, recommend the use of the arsenical soap as in other skins.

\section{ANT-EATERS.}

The great Ant-Eater (Myrmecophega jubata), has a long prehensile tail, with long flowing hairs. The tail must be supported by a much longer tail-bearer than that of other quadrupeds generally. The tongue is very long and protractile, and ought to be drawn out of the mouth as if in the act of catching Ants.

THE DUCK-BILLED PLATYPUS (Ormithorinchus rufus.)

In stuffing this animal, attention must be paid to showing as much as possible its cheek pouches, a characteristic of the genus.

\section{ORDER VIII.-PACHYDERMATA.}

The animals of this Order are mostly of gigantic size, and nave very thick skins. At the head of this Order is

\section{THE ELEPHANT.}

Various methods have been devised for the mounting and stuffing of Eleplants. The best plan is that which was adoptell, with the elegant specimen now in the Jardin du Roi at Paris.

The dead Elephant being extended on the ground, the dimensions were all taken, and correctly noted at the time. M. Lassaigne, cabinet-maker to the establishment, invented a large rule for that purpose, which was somewhat like a shoemaker's size-stick. The different curves of the back, belly, neck, \&c., were taken by bars of lead of three quarters of an inch in thickness. This metal is much better adapted than any other for that and similar purposes, as it has no elasticity, it retains any shape into which it is put.

M. Demoulins made a drawing of the animal from these: 
measurements, on the wall of the workshop where the model was constructed of its natural size.

The Elephant was placed upon its back by means of four-corded pulleys fastened to the platform. An incision, the form of a double cross, was then made in the lower side, the central line reaching from the mouth to the anus; the two otier cuts were made from the left leg on both sides to the opposite right legs. The trunk was longitudinally opened in its under side; the soles of the feet were now taken out to within an inch of their edge, and the nails allowed to remain attached to the skin-this was effected by the aid of a chisel and mallet, and was one of the most difficult operations of the whole.

Several persons wrought at a time at the operation of skinning, and four days were necessary to effect it. When removed from the carcase, the skin was weighed, and found to be five hundred and seventy-six pounds.

It was extended on the ground, so that the cutaneous muscles of the head and other parts might be cut away from its interior. The skin was then put into a tub, and covered six inches deep with water which had been saturated with alum.

The model which was to fill the skin was made as perfect as possible in its shape. To insure this, models were made of half the head in plaster, as also a fore and hind leg. This structure was made of linden-wood, and so ingeniously constructed by $\mathrm{M}$. Lassaigne, that almost the whole parts could be separated. He opened a pannel on one side of the body, whereby he introduced himself into its interior, so that he might make its parts more perfect within. Even the head and proboscis were hollow, which rendered this stupendous model so light that it could be moved from one part to another with comparative ease.

The model being completed, the alum water in which the skin had been all the time immersed, was now taken out and made boiling hot, and in that state poured on the skin, which was then allowed to soak in the warm liquor for an hour and a half, when it was taken out still warm and placed upon the model, which they accomplished with some difficulty. But jutge of their mortification when it was foumd that the model was rather 
too large. To diminish the wood-work they foresaw would run the risk of putting its parts out of proportion. It then occurred to them, that the best thing to be done under these awkward circumstances, was to take off the skin again and reduce its thickness with knives; they removed all the internal thicknings which came in their way. In this operation five men were occupied for four days, during which time they cut out one hundred and ninety-four pounds weight off the internal surface. During this process the skin had dried, and required again to be immersed in cold soft water; after allowing it to remain twenty-four hours to soak, it was then put on the model and found now to cover it completely; the edges were brought together, and secured with wire nails deeply driven home, and large brads. Except at the edges, the nails and brads were only driven in half-way to keep the skin down to the different sinuosities and hollows until dry, when they were again all pulled out.

The alum with which the water was saturated gave the skin an ugly gray appearance, in consequence of its becoming crystallized. But this was soon remedied, by first rubbing the skin with spirit of turpentine, and afterwards with olive oil.

By the admirable and well executed contrivance here adopted, a specimen has been mounted with all the appearance of life, which, with a little attention, may resist for ages the influence of Time's destroying hand. It is the only specimen of an Elephant in Europe worth looking at, all others being great misshapen masses, completely devoid of all appearance of nature.

The Rhinoceros, Tapir, Horse, ard its congeners, should all be mounted in the same manner. At the Jardin du Roi, a fine specimen of the Quagga has been mounted in this way.

\section{ORDER IX.-RUMINANTIA.}

The same plan should be adopted with all the larger animals of this order, as with the Elephant described in Order VIII. At the Jardin des Plantes, Paris, the Giraffe is mounted in the same way as the Elephant: as are also some of the larger Antelopes. 


\section{DEER, ANTELOPES, AND GOATS, \&c.}

These animals should be mounted on the same principles as recommended for the Bears, in Order IV. A different mode must, however, be adopted in skinning the animals, which the horns render necessary. It is performed in the ordinary manner until the operator reaches the neck. After cutting as near the head as possible, another incision must be made, commencing under the chin, which is continued to the bottom of the neck, or from eight to ten inches in length. By this opening, the remainder of the neck is separated from the head; the tongue is cut out, and the occipital orifice enlarged, and the brain extracted thereby. The lips are now cut as near as possible to the jaw-bones, and the operator must continue pro gressively ascending towards the forehead, and in this manner all the skin will be separated from the head, except at the nose, or point of the muzzle. All the muscles are next removed by the scalpel, and the skull well anointed with arsenical soap. The muscles which have been cut out are then imitated with chopped flax or cotton, which may be attached to the bones with cement. When this is done, the head must be replaced within the skin. The orifice under the neck must now be sewed up with fine stitches, so that the hair may spread over them to conceal the seam. The whole other parts of the mounting is completed as directed for the Bear.

\section{THE ELK}

Being an animal of stupendous size, should be mounted on a model the same as the Elephant.

Some of the smaller species of Antelopes may be put up in the same manner as the Cat, but using stronger wires.

\section{THE URUS, BISON, BUFFALO}

And other large animals, to be mounted in the same maner as the Elephant. But their skins should be deeply inbued with turpentine. 


\section{ORDER X.-CETACEA}

THE DOLPHIN, PORPOISE, \&c.

The structure of these animals, as well as of the other species of the first family of this orler, differs but little in general structure.

In skinning these, an incision is made under the chin, and continued to the extremity of the tail; the skin is then detached right and left with the scalpel, or a sharp knife. When the skin has been cut back as far as possible, disengage the vertebre at the tail, and this will enable the $o_{1}$ serator to detach the skin from the back; the vertebrie are now cut close to the head, and the whole carcase removed.

All this tribe have a thick layer of fat under their skin. In the operation of skinning it requires considerable dexterity to leave this fat, or blubber, adhering to the carcase. Practice alone will obviate this. When this has not been properly managed in the skinning, the only thing to be done afterwards is to scrape it thoroughly with a knife. The oil which flows from it, during this operation, must be soaked up with bran, or plaster of Paris.

There being no muscular projections in the skin of the Porpoise, there is no use for wires in mounting it. A narrow piece of wood the length of the body is quite sufficient to keep the skin stretched, and stuffed either with tow or hay. Some months are necessary to render it perfectly dry and stifi, from its greasy nature. The grease almost always leares some disagreeable looking spots on the skin. To remove these, and prevent a recurrence of them, powdered pumice-stone steeped in olive oil, is rubbed thickly on the skin with a hand-brush. It is then gone over a second time with emery and oil. It is rubbed in this way till the skin has a glossy appearance, when it may be rubbed dry with a woollen cloth; and to complete the polish, a clean woollen cloth may be applied with some force to complete the gloss, which is natural to the skin in a living state.

Where a very glossy appearance is wished, varnishes become necessary, but some difficulty has been experienced in 
getting these to remain attached to the skin in all weathers, because the humidity of rainy seasons melts gum Arabic when it is used as a varnish, and when white varnish is applied, both it and the gum Arabic fall off in pieces. To prevent the gum from falling off in this way, by its contracting, the solution should have about an eighth part of ox-gall mixed with it, and the surface of any body to be varnished should be washed with ox-gall and water before the varnish is applied, which will, almost to a certainty, prevent it from cracking and falling off. It must, however, be thoroughly dried before the varnish is applied.

We may here state, that an animal the size of a Fox or a Cat, may be skinned, prepared, and finally set up, in the space of four or five hours, by a person who has had a little practice in the art of Taxidermy, and that from ten to fifteen minutes are all that will be required to skin an animal of the size just mentioned.

\section{CHA P. II.}

UF SKINNING, PRESERVING, AND MOUNTING BIRDS.

\section{SKINNING.}

Immediately after a Bird is killed, the throat and nostrils should be stuffed with tow, cotton, or fine rags, and a small quantity wound round the bill, to prevent the blood from staining the plumage; but should any get on the feathers, notwithstanding this precaution, the sooner it is removed the better, which should be effected by a sponge which has been merely moistened in water. Too much dispatch cannot be used in removing the skin, if the bird is shot in a warm climate; but, in temperate regions, the bird may be allowed to cool.

In proceeding to skin the Bird, it should be laid on its back, and the feathers of the breast separated to the right and left, when a broad interval will be discovered, reaching from the top to the bottom of the breast-bone. (See plate III. fig. I., 
for the manner of separating the feathers, and using the scalpel.) A sharp pen-knife, or scalpel (see plate IV. fig. I and $z)$, must be inserted at the point of the bone, and cut the outer skin from thence to the vent, taking care not to penetrate so deep as the flesh, or upon the inner skin which covers the intestines. The skin will then easily be separated from the flesh ; in larger specimens, by the fingers, or, in smaller ones, by passing a small blunt instrument betwixt the skin and body, such as the end of the scalpel landle: with this you may reach the back. The thighs should now be pressed inwards, as in the common method of skinning a rabbit, and the skin turned back, so far as to enable you to separate the legs from the body, at the knee-joint. The skin is tien pulled downwards, as low as the rump, which is cut close by the insertion of the tail, as shown at plate III. fig. $2, a$; but in such a manner as not to injure its feathers. The skin is now drawn upwards the length of the wings, the bones of which must also be cut at the shoulder-joints (see plate I. fix. 1, a.) ; it is then pulled up, till all the back part of the skull is laid bare, when the vertebre of the neck are separated from the head, from $b$. in plate I. fig. 1.; and the whole body is now separated from the skin. You next proceed to remove the brain, through the opening of the skull, for which purpose it may be enlarged by a hollow chissel, or other iron instrument. The ejes must then be taken out, by breaking the slender bones, which separate the orbits from the top of the mouth, in which you may be assisted by pressing the eyes gently inwards, so as not to break them. In skinning the neck, great care must be taken not to enlarge the opening of the ears, and not to injure the eyelids. The whole of the flesh is next to be removed from the under mandible.

Several species will not admit of the skin being thus pulled orer their heads, from the smallness of their necks; some Woodpeckers, Ducks, Coots, \&c., fill under this description; in which case a longitudinal incision is made under the throat, so as to admit of the head being turned out, which must be neatly sewed up before stuffing. The flesh from the hearl, wings, legs, and rump, must then be carefully removed with a knife or scalpel, and the cavities of the skull filled with cotton or tow. The whole inside of the skin, head, \&c., must 
be well rubbed with arsenical soap, or preserving powler, or spirit of turpentine, or the solution of corrosive sublimate. When it is wished to stuff the bird, it may now be immediately done, as it will easily dry, if in a warm climate; but in low damp countries, it will require artifcial heat to do it effectually.

When the skins are merely wished preserved, the bones of the legs and wings should be wrapped round with cotton or tow, so as to sumply the place of the flesh; the skin is then inverted and hung ain to dry, afier using the arsenical soap, as ahove directed ; before doing which, in larger birds, a threat or small string may be drawn through tile rump, and passed up the inside of the neck, and drawn through the bill, to prevent the heal from stretching too mucel by its own weir!t. In larger specimens, where cotion or tow is not easily to be met with, well-dried hay may be used.

The incision for removing the skin is frequently made under the wings. This may be done with marine birds to advantage. The Penguins and Divers inaj be skinated, by making the incision in the back.

The tongue should either be kept in the mouth, or sent home separately with the birds.

The greatest care must be taken to prevent the fat and oily matter, so common to sea-birds, from getting on the feathers : pounded chilk will be foml an excellent absorbent, for applying to these birds.

In sending home specimens of birds, they should be each wraped in paper, and closely packed in a box; and camplior, preserving powcler, and strong aromatics, strewed amongst them, to prevent diem from being attacked by insects; and Lhe'y onght to be kept in a very dry part of the ressel.

It is of the utmost consequence to know the colour of the eyes and legs of birts, and these things should be carefully noted the moment tires are killed; and it should also be mentione whether they are male or f'male: such a memorantum ought to be attached to the birls by a ticket. The santial of the year, in which the birl is killed, must also be mentioned. It is also of much consequence to have good sheletons, and, for this purpese, the carcaves may be sent home in a barrel, edifere in spirits or a s!rong solution of salt and water. 
MANNER OF SKINNING BIRDS, AS PRACTISED AT THE JARDIN DES PLANTES, PARIS.

First, a needle, full of thread, is passed across the nostrils, and tied under the lower mandible. A little cotton is introduced into the mouth, and every care taken, that neither blood nor oily matter is allowed to soil the feathers of the hear, as it is no easy matter to remove it from that part.

The bird is laid on a table, on its back, and the feet from you, with the head placed towards your left hand. The feathers of the breast and belly are then divided right and left with a pair of forceps, and the down which covers the belly is pulled off. An incision is then made in the skin with the scaipel, from the upper edge of the sternum, or breast-bone (see plate I. fig. 1. c.), until you reach the micldle of the belly (see plate I. fig. 1. d.) The skin of one side is then lifted with the forceps, and separated from the muscles of the breast, by the point and end of the scalpel, used alternately, until you reach as near as possible the wings. Having accomplished this, a small quantity of cotton, dusted over with flour, or powdered whitening, is placed on the flesh, to prevent the skin from adhering to it. The thighs are then forced forward, and cut through between the femur and tibia (plate I. fig. l. e. and f.) ; the femur is then returned into its place, in the skin. You then separate the skin from the rump, by the use of the scalpel and the fingers: this part being left to support the feathers of the tail. The part of the carcase which is now denuded of its skin, is taken into the left hand, and the skin separated from the sides; in which operation, small scissors are used for cutting any of the tendons which may be met with. The wings are now separated from the trunk, by the end of the os humeri (plate I. fig. 1. g.), and again pushed back into their place. The neck and head are skinned, as we have described at page 26 , and the same method formerly pointed out, is employed in removing the brain; while cotton and flax are applied, and any moisture absorbed by means of plaster of Paris or dry earths, which prevent the feathers from adhering.

The wings are now removed, properly cleaned of their flesh, and restored to their place, after being rubbed with the arsenical 
soap, and dusted with the preserving powder. The flesh is removed from the thighs, the bones being carefully preserved, and restored to their proper places, afier being treated in the same manner as the thighs.

In the larger species of birds, all the muscles and fatty matter, which adhere to the skin, are carefully clit off. Any gुun-shot holes in the skin are next sewed up from within; a piece of thread is then attached to the first joint of both wings, and they are by means of it drawn together, to such a distance as they may be supposed to have been apart, when the muscles were on the body. This gives the wings a set, so that when the bird is stuffed, they naturally fall into their proper place and position, if the bird is in a quiescent posture.

When birds are of a large size, take a piece of cord about a yard long, one end of which should be made fast to a large hook or nail in the wall, from which the bird should be suspended; then, with a ruming noose fastened round one of the thighs, as represented in plate III. fig. 2., the bird is suspended in such a manner as enables it to be turned in any direcion without injury. 'ilhe resistance afforded assists greatly in the operation of skinning:

The insides of the wings should have an incision made in them, and as nuch flesh taken away as possible, and some preserving powder introduced; a little tow or oakum should be put slightly in to fill the skin, but not to extend it. If the bird is large, lay may be substituted for the above. The feathers must now be placed smootil, the wings laid in their natural position, closed, and the subject pat in a clean dry place, and exposed to the air for a few days, till all moisture has evaporated from it; after which the stuffing may be withdrawn, and many skins may be packed flat on each other.

If the feet are large and Heshy, as in some of the Gulls, Geese, Eagles, \&c. an incision should be male along the sole oi each foot, so as to expose the muscles to the action of the air, and also a quantity of preserving powcler applied to it, otherwise they run every risk of becoming putrid and rotten. This latter precaution is not required in small birds, in which the small quantity of cotton, that is put into them while drying, may be retained, unless the traveller is restricted for want of roon, in which case they may be packed quite flat. 
Mr Salt, while in Albyssinia, parked his bird-skins between sheets of paper, in the same manner as a hortus siccus, or herbarium, and they reached this combry in perfect safety, and made excellent specimens when set up. In warm climates, the boxes shonld be well closed, and the seams filled with warm pitch, on the outside, to prevent the intrusion of insects; and the inside should be supplied with camphor, musk, or tobacco-dust, which will prevent the attacks of the smaller insects.

Till practice has given facility to the operator, it will assist in keeping the feathers clean, if, as he opens the skin of the breast, he pins pieces of paper or linen cloth on the outside; but, after a few trials, this will be unnecessary.

Some of the marine fowls are so fat, that there is much trouble in separating it from the skin, and, in warm weather, great attention will be required to prevent it from ruming on the feathers. As much as possible should be scraped off, in the first place, with a blunt table-knife or palate-knife, and a quantity of powdered chalk applied, to absorb what remains, which, when saturated with the oily matter, should be scraped off, and a fresh supply used ; after which, a much larger proportion of the preserving powder should be applied, than in other birds which are not fat.

When shooting on the seacoast, if the Ornithologist is not provided with these requisites for absorbing the oil, which flows quickly from any wounds of the skin, he will find dry sand a tolerable substitute.

If, however, after every precaution, the oily matter should get on the feathers, the sooner it is removed the better, as, in birls where the plumage is white, if it is allowed to becume hardened, it will produce a very disagreeable appearance; and, besiles, render that part particularly liable to the attack of insects. There are several effectual methods of removing the greasy stains; the first, safest, and best, is, by taking a quantity of diluted ox-gall-or where it cannot be commanded, sheep's-gall, or that of any other animal-mix it with about double the quantity of water, and apply it with a sponge to the place which the fatty matter has touched, when it will immediately remove it. The next is by using a solution of salt of tartar, or potash, or soda. This must be made 
rery weak, not exceeding half a tea-spoonful to a cup of water; which will have the same efrect as the gall. Whichever of these are used, the place must be immediately afterwards washed with pure water, so as to leave none of the gall or alkaline substance remaining. The gall has a gummy tendency, and will glue together the fibres of the feathers; and, besides, it has a great attraction for moisture, and, in humid weather, will become damp, and therefore produce mould; the other alkaline substances must also be used with much caution and quickness, because they have the power of changing the colours of the plumage, so that they are most useful in white plumage, and therefore should only be used on coloured feathers, wilere gall cannot be procured.

One general observation applies to the preservation of all animal skins, which is, they must be made perfectly dry, so that the sooner they are exposed to a fire current of air the better; and unless they are speedily and thoroughly dried, the skin will become putrid and rotten, and the hair or feathers will consequently fall off. If a skin is properly dried, soon after it is killed, it will keep a considerable time withont any preservative whatever, only it will be the more liable to be attacked by insects afterwards.

The following excellent general directions for skinning, are given by $\mathrm{Mr}$ Waterton:- "While dissecting, it will be of use to keep in mind, that in taking off the skin from the body, by means of your fingers and little knife, you must try to shove it, in lieu of pulling it, lest you stretch it.

"That you must press as lightly as possible on the bird, and every now and then take a view of it, to see that the feathers. \&c., are all right.

"That when you come to the head, you must take care that the body of the skin rest on your knee ; for if you allow it to dangle from your hand, its own weight will streich it too much.

"That, throughout the whole operation, as fast as you detach the skin fiom the body, you must put cotton immediately betwixt the body and it, and this will effectually prevent any fat, blood, or moisture, from coming in contact with the plumage.

" As you can seldom get a bird withont shooting ii, a line or two on this head will be necessary. If the bird be still alive, fress it hard, with your finger and thmul, just behind the 
wings, and it will soon expire. Carry it by the legs, and then the body being reversed, the blood cannot escape down the plumage and througin the shot-holes. As blood will have often issued ont, before you have laid hold of the bird, find out the shot-holes, by dividing the feather's with your fingers, and blowing on them; and then, with your pen-knife, or the leaf of a tree, carefully remove the clotted blood, and put a little coiton on the hole. If, after all, the plumige has not escaped the marks of blood, or if it has imbibed slime from the ground, wash the part in water, without soap, and keep gently agitating the featlers with your fingers, till they are quite dry. IVere you to wash them, and leave them to dry by themselves, they would have a very mean and shrivelled appearance.

"In the act of skinning a bird, you must either have it upon a table, or upon your knee, probably you will prefer your knee, because, when you cross one knee over the other, and have the bird upon the uppermost, you can raise it to your eye, or lower it, at pleasure, by means of the foot on the ground; and then your knee will always move in unison with your body, by which much stooping will be avoided, and lassitude prevented."

\section{ON STUFFING BIRDS.}

The first thing to be rone in stufing is to replace the skull, after it has been well anointed with the arsenical soap, and washed with the solution of corrosive sublimate inside. The thread, with which the beak is tied, is taken hold of by the lêf $\mathrm{t}$ hand, and the head is repassed into the neck with the forefinger of the right hand, while the thread is pulled on the opposite side; and we are careful that the feathers, at the margin of the opening, do not enter with the erlges of the skin. The bird is now laid on the table, with the head turned towards the lefi hand; and the legs and wings adjusted to their proper situation. A flat piece of lead, about a pound in weight, is laid on the tail, while the feathers of the margins of the opening are raised by the forefinger and thumb of the lef ham to prevent their being soiled. Tie inside of the neck is now couted with the arsenical soap; flax is stuffed into it, but not too tightly. The back and rump are anointed, and hise boly should then be stuffed with tow, to about a third 
of the thickness required, so that the wire may have a sort of cushion to rest on.

Four pieces of wire are then prepared, of a thickness proportionate to the size of the bird to be stuffed. The centre-piece should be somewhat longer than the body of the bird. At about a fourth of its length a small ring is formed, by the assistance of the round pincers, or plyers (plate VI. fig. 4), and the other end is pointed with a file. This wire is oiled, and introduced across the skull, and passed into the neck, through the centre of the flax or tow with which it is stuffed; the ring being situated towards the anterior part of the skull, for the purpose of receiving the points of each of the wires that are passed through the feet and thighs.

The following is the mode in which this perforation is effected. A hole is bored wilh a brass awl (see plate VJ. fig. 8), the calibre of the wire which it is intended to use. The wire, which is to continue in the leg, is passed across the knee, and brought out interiorly, and, placing it into the ring above mentioned, the same operation is performed on the other side. The extremities of the wires of the legs, and the end of the central wire beyond the ring, are all twisted together with flat pincers, and then bent towards the tail. The tail-bearer is next formed, which consists of the fourth piece of wire, with which an oval is formed, by twisting the two ends two or three turns, so that they may form a kind of fork, with the oval nearly the length of the body of the bird; the two points of the fork must be sharpened with a file, and near enough to enable them to enter the rump, through which they must pass, and their points will be concealed by the rectrices, or large straight tail-feathers, while the oval is within the borly of the bird. If the bird is large, the tail-bearer must be firmly attached to the interior wires, by twisting a smail wire several times roumd both. But unless the birds be large, it may remain quite free. The several wires are figured on plate $V$, of which see a description at the references to the plates, at the end of the work.

All the parts of the skin at which we can come must be thoroughly rubbed with the preserving soap, the rump in frarticular, which should besiles be soaked with the solution of corrosive sublimate. The stuffing is now proceeded with, by inserting chopped fiax or tow, till it las attinined its proper 
dimensions. The skin is brought together, and sewed up, while we take the greatest care to separate the feathers at every stitch.

The orbits of the eyes are next finished, by inserting, with small forceps (plate VI. fig. 7 ) and a short stufing stick, a small quantity of chopped cotton, while attention is paid to round the eyelids properly. The glass eyes are now inserted, taking care to place them properly unler the eyelids. But, before fixing the 'ye, a litile calcareots cement must be used, to prevent them from coming out. If any part of the nictitating membrane is visible below, it must be pushed up wih the steel point. (See plate VI. fig. 9. and 10.)

The stuffing of the bird being now completed, the next thing is to phace it either on a branch, or if a bird which does not sit on trees, on a piece of plank; whicherer of these it is, two l:oles are bored for the reception of the wires, which have been allowed to proirude from the soles of the feet, for fixing the bird. (See plate III., fig. 3.) These, of course, are pierced in such situations as are necessary for the attitude or position of the legs. The wires are put through these hoies, and twisted so as to secure the bird in its yosition. The attitude of the bird will, of course, depend upon the fancy and taste of the operator, and ought to be in conformity with the manners of the bird in a living state.

A general notion will be gathered of the position of birds' legs, by studying the skeleton which we have represented in plate I., fig. J. It will be noliced that the three bones, which compose the legs, are articulated somewhat in the form of the letter $Z$, varying, of course, in the inclination of the various bones, according to the species of bisd. A fiult in most stuffed birds is the great and unnatural length of leg seen under the feathers, from the circumstance, that tire bones are too siraight. Even in the division of birds called Waders, such as Cranes, Storks, Herons, \&c., where the legs are straighter than in most other orders, the upper joint of the thigh is sthject to a considerable inclination. This natural position of the bones of the leggs must never be lost sight of in setting un birds after stuffing.

The bird being now placed on its support, and the logs reaty to receive their fual position, the furst thing to be done 
is to press the two thumbs on the lower limbs or tarsi, (plate I., fg. $1, e$.) to give them a backward inclination from twenty to sixty degrees, according to the mamer of sitting, natural to the bird. The tibia, or second bone, (plate I., fig. $1, f$,) is next bent forward, by which these bones will now have a position similar to those of plate I., fig. I. The head, neck, and wings, are then bent, and fixed according to the expression intended to be given to the bird. On the disposition of these, much of the beauty and character depend. The habits of the bird require to be well known, to enable the operator to perform this important part with life and spirit. If the living habits of the bird are without the reach of his study, he should devote himself to the accounts given of it by naturalists, and also examine the best plates in which the species is represented.

Having fixed on the atitude, it now only remains to put the feathers into their natural order as smoothly and regularly as possible, and to keep them in this state, they should be bound round with small fillets of muslin fastened with pins, in the manner represented in plate III., fig. 4 . The bird should then be thoroughly dried, which must be done by placing it in some airy situation, if in summer; or if in winter, near the fire, but not so close as to affect the natural oil contained in the feathers. The want of proper attention in drying is the ruin of many a fine specimen; because, if they are long kept damp, putridity will ensue in spite of all the preservatives; when the skin will become rotten, and the feathers will soon fall ofr; besides, the mould and damp long continued change the chemical properties of the ingredients used as preservatives.

After the bird has been thoroughly ditied, the fillets are removed; the wire which protruded from the head is cut off as close to the skull as possible with the wire-cutting-pincers figured in plate VI., fig. 5. It must then be attached to a circular, or other shaped piece of wood, with the generic and specific name and sex, as well as its country and locality attached to it, on a small ticket, when it may be placed in a museum.

The wire frame-work, above described, is the most simple of any in its construction, and is better adapted for small than large birds. Indeed, it will hardly suit those of the larger species. The following is another method of construct- 
ing the frame-work, which may be used either in large or small birds :-

Like the former it is constructed of four pieces of wire. The centre piece should be double the length of the bird; it is bent at a third of its length of an oval form, and twisted two turns, the shortest end being passed into the oval, and then raised against the longer end, so as to produce a ring at the end, outside of the oval, large enough to admit the two wires which pass from the feet to the inside of the bird. It is now twisted a second time, and firmly united to the longer end, which ought to be straight, with a sharp point, effected by neans of a file. As before directed, it is rubbed with oil, and forced through the stufing of the neck. It oight to be so constructed by measurement, that the oval part of the wire shall be in the centre of the body inside. The wires of the feet and legs, as before directed, ought to be straight and pointed, and passed through the soles of the feet as before. When the point has penetrated, the other end of the wire may be bent, se that by means of it we may be able to assist in forcing up the remainder of the wire. The two internal ends of the foot-wires are twisted together, and curved within, so as to pass through the small circle, or ring of the middle branch above the oval, to each side of which the are now attached with a piece of small string.

The tail-bearer is constructed on the same principles, and attached in the same manner as before described, and the latter apparatus is introduced after the neck and back are finished in the stuffing.

This practice of introducing the neck-wire, after the neck is stuffed, was first adopted at the Jardin des Plantes at Paris, and is now invariably adopted in that establishment in preference to introducing it before the neck is stuffed. The neck of a swan or other long-neeked and large birds, are even done so. It is unquestionably the best plan which has hitherto been discovered, as it preserves the cylindrical shape of the neck.

\section{MR BULLOCK'S METHÓD OF STUFFING BIRDS.}

Mr Bullock of the London Museum, Egyptian Hall, had another method of arranging the wires, which, after what we 
have already said, will be easily comprehended by a reference to plate III., fig. 3, where we have given a figure of his mode. After the skin is taken off and prepared, different sized, nealed, iron-wires are procured according to the size of the bird they are to support. The skin is laid on its back without stretching it ; cut two pieces of wire, the one rather longer than the bird, and the other shorter, so as not to reach to the head of the bird; twist them together, sharpen the ends of the longer by means of a file, and pass one end through the rump, and the other through the crown of the head, near the base of the bill. Care must be taken not to extend the neck beyond its ordinary length, - a very common fault in most preservers. Lay a little tow along the back of the skin for the wire to rest on, then take two other pieces of strong wire and file them to a point at one end these are passed through the soles of the feet and uip the centre of the leg-bone, or tarsus. When within the body, they are to be fastened to the first wires by twisting them together, which, when accomplished, may be supposed to represent the back bone. The wire should be left two or three inches out of the soles of the feet, to fasten them in a standing position, as before directed. Two smaller wires are then passed through the wings, as in the legs, and afterwards fastened to the back-wires a little higher up than the legwires, taking care that no part of the skin is extended beyond its natural position.

\section{MR BECGEUR'S METHOD OF STUFFING BIRDS.}

Becœur, the best apothecary in Metz of his day, the inventor of that truly uscful preservative the A rsenical soap, had a method of mounting birds peculiar to himself, which he successfully practised. He stuffed recent specimens in very high perfection. And in support of the fact that they were well preserved, many specimens preserved by his own hand, still enrich the cabinets of France, and these were set itp sixty-five years ago.

A little attention and practice will enable any one to follow his method. He skinned his bird in the ordinary manner. He extracted the body by this opening, without cutting any of the extremities. The muscular parts were then extracted by a scal- 
pel, while every endeavour was made to preserve all the liga. ments. He then anointed the skin with the arsenical soap, and also the skeleton, and then returned it to its place within the skin, and carefully disposed of the feathers on either side. He formed a ring on a piece of iron-wire at nearly a third of the length of the wire, and passed this wire through the head; the smallest side passed into the rump in such a manner, that the iron-ring came under the sternum; a leg-wire was then passed through each leg, so that the ends of them united to pass into the little ring in the midlle of the back bone, where they were secured with a string. The flesh of the muscles was replaced by flax, or chopped cotton; and when he had satisfied himself with the form, it was then sewed up, placed on a foot-board, or support of wood, where he gave it the attitude intended, of which he was always certain, for a bird mounted in this mamer can only be placed in a natural attitude.

Becœur mounted quadrupeds in the same manner, and with equal success.

\section{MAUGE'S METHOD OF STUFFING BIRDS.}

This naturalist had a method of preparation and stuffing, of which he was the inventor, and which he practised with considerable success. It was as follows:-(The bird is supposed to be a small one.)

He took two pieces of wire, in length and thickness required for the birl he was about to stuff. One of these was somewhat longer than the other. The longer piece he pointed at both ends with a file, and the shortest piece at one end only. One end of each wire was held under the fore finger and thumb of the left hand; he then twisted the other parts five or six times round, about three quariers of an inch from the point of the other wire with the finger and thumb of the right hand, leaving an untwisted space large enough for a finger to pass chrough; he now twisted it four or five times more, leaving a second space untwisted for the purpose of passing the feet-wire through, and also of producing a triangular form with the first interval he had left untwisted, the smaller opening being one turn above the triangle.

'ihe wires for the feet were straght, and pointed at one end 
in the ordinary form. When the head and neck were stuffed, he introduced the long end of the centre wire through the neck and skull, and the other exiremity which was forked, and passed it across the rump to sipport the tail feathers. He then forced up one of the leg-wires, and brought the end of it through the small hole which was sicuaced above the triangle. and then gave it an inclination towarls the opposite parts, and united the two with threads; the same method was then adopted with the other leg.

For larger birds, II. Inauge substituted the oval for the triangle.

We shall now describe the new method invented by the ingenious Mr Waterton.

\section{MR WATERTON'S METHOD OF STUFFING BIRDS.}

"You will observe," says Mr Wrate"ion, "how beautifully the feathers of a bird are arranged, one falling orer the other in the nicest order ; and that, where this charming harmony is interrupted, the defect, thomg not noticed by an ordinary spectator, will appear immediately to the eje of a naturalist. i'hus, a bird not woninded, and in perfect feather, must be procured if possible, for the loss of the feathers can seldom be made good; and where the deficiency is great, all the skill of the artist will avail him little in his attempt to conceal the defect, because, in order to hide it, he must contract the skin, bring down the upper feathers and shove in the lower ones, which would throw all the surrounding parts into contortion.

"You will observe, that the whole skin loes not produce feathers, and that it is very tender where the feathers do not grow. The bare parts are admirably formed for expansion about the throat and stomach, and they fit into the different cavities of the body at the wings, shoulders, rump, and thighs, with wonderful exictness; so that in stuffing the bird, if you make an even rotund surface of the skin where these cavities existed, in lieu of re-forming them, all symmetry, orter, and proportion, are lost for ever.

"You must lay it down as an absolute rule. that the bird is to be entirely skinned, otherwise jou can never succeed in forming a true and pleasing specimen. 
"You will allow this to be just, after reflecting a moment on the nature of the fleshy parts and tendons, which are often left in: 1st, They require to be well seasoned with aromatic spices; 2dly, They must be put into the oven to dry; $3 d l y$, The heat of the fire and the natural tendency all cured flesi has to shrink and become hard, renter the flesh withered, listorted, and too small; 4thly, The inside then becomes like a ham, or any other dried meat; ere long the insects claim it as their own, the feathers begin to drop of, and you have the liideous spectacle of death in ragged plumage.

"Wire is of no manner of use, but, on the contrary, a great nuisance, for where it is introduced a disagreeable stifiness and derangement of symmetry follow.

"The heal and neck ean be placed in any attitule, the body surported, the wings closed, extended, or elevaied, the tail depressed, raised, or expanded, the thighs set horizontal or oblique, without any aid from wire. Coiton will effect all this.

"A very smal! proportion of the skull bone, say, from the imepart of the eyes to the bill, is to be left in, though even this is not absolutely necessary. Part of the wing-bones, the jaw-bones, and half of the thigh-bones remain; every thing else, flesh, fat, eyes, bones, brins, and tendons, are all to b: taken away.

"Introduce the cotton for an artificial body by means of a little stick like a knitting neelle, and without any other aid or substance than that of this little stick anl cotton, your own genius must produce those swellings an! caviites, that just pioportion, that elegance and harmony of the whole so much admired in animated nature, so little attended to in preserved suecimens. After you have introduced the cotton, sew up the orifice you originally made in the belly, beginning at the vent. And from time to time, till you arrive at the last stitch, keep adding a little cotton, in order that there may be no deficieiscy there. Lastly, Dip your stick into the solution, and pur it down the throat three or four times, in order that every pari may receive it.

"When the head and neck are filled with cotton quite to your liking, close the bill as in nature. A little bit of bees wax at the point of it will keep the mandibles in their proper 
place. A needle must be stuck into the lower mandible perpendicularly, jou will shortly see the use of it. Bring also the feet together by a pin, and then run a thread through the knees, by which you may draw them to each other as near as you julge proper. Nothing now remains but to add the eyes, with your little stick make a hollow in the cotton within the orbit and introduce the glass eyes into it. Adjust the orbit to them as in nature, and that requires no other fastner."

Great attention must be paid to the size of the orbit, which will receive within it an object much larger than the eye, so that it must be drawn together with a very small delicate needle and thread, at the part farthest from the beak.

A small quanticy of the solition is now applied to the bill, orbits, and feet.

Take any ordinary box large enough for holding the bird, and fill three-fourth of it from the top at one end, and the other end forming an inclined plane; make a hollow in it sufficient for the reception of the bird, place it in the box with its legs in a sitting posture; take a piece of cork into which three pins have been stuck for legs, like a three-footed stool; place it under the bill of the bird, and the needle which was tormerly run through the bill is stuck into the cork, which will act as a support to the bird's head. If the neck is wished to be lengthened, put more cotton under the cork, or vice ver$s a$; and if the head is wished to be projecting forward, it has only to be brought nearer the front of the box, humouring the cork, so as to place it in the position you require.

As the back part of the neck shrinks mose in drying than the fore part, a thiread must be tyed to the end of the box, and fastened to tile beak, to prevent the face from looking too much upwaris. If the wings are wished elevated, support them with cotton; and if to be very high, place a piece of stick under them.

Sinould you desire to expand the wings, the order of the feathers must be reversed, commencing with the two millle ones. When perfectly dry, place them in the natural order, and they will ever afterwards continue as you wish them. If the crest is wished to be erect, the featilers must be moved in a contrary direction for a day or two, when they will soon take the position wished for. 
The box must now be placed out of the reach of the sun, air, or fire, so that the skin may dry slowly. The corrosive sublimate is of much service in this respect, for it renders the skin moist and flexible for many lays. The bird should be lifted every day, so that any faults may be corrected which take place while drying.

The small wing-coverts are apt to rise, owing to the skin coming in contact with the wing-benes. The part which rises should be gently pulled with the finger and thumb for a day or two, and the feathers pressed down.

The feathers should be frequently adjusted so as to render them distinct and visible.

The legs begin to stiffen in three or four days, when it will be time to place them in the desired position; and the toes either arranged, or curved, so as to hold a branch, in which two sikes must be placed for the reception of the fect, whereon they are to be stuck, and can afterwards be removed at pleasure. All the threads which kept the different parts in their laces may now be removed.

Mr Waterton touches the whole feathers with the solution of corrosive sublimate, so as to preserve them from the attack of moths. He says, "The surest way of proceeding is to immerse the bird in the solution of corrosive sublimate, and then dry it before you begin to dissect it."

We must now describe the mode of setting up a bird with extended wings. After having proceeded with the stufing as formerly directed, and the central supporting wires have been put in their places, pointed wires are to be thrust from the inside through the wings, reaching as far as the metacarpus and the cari)us, (sce plate I., fig. $h \& s$ ), that is, to the arms and fore arms; the ends which remain in the body are formed into ovals, of the same size as those of the central wires, and firmly attached to them either with threads, or small wires. The wings may now be raised to any height wished, and disposed agreeably to the taste of the operator; and should he feel a difficulty in pleasing himself, a good engraving may be copied.

If it is intended to represent the bird flying, its wings are extended to their utmost stretch, the tail placed horizontally, and expanded, the neck forced forward, the legs and feet drawn up close to the breast, with the toes closed. It may then 
the suspended from the ceiling, by a piece of very fine brass wire, such as is used for piano-forte strings. This may either he attached to a hook in the back, placed betwixt the wings, or drawii through the body with a very long slender needle. The best plan, if jou have determined on t'ie flying position, previous to stuffing, is to fix this small wire to a transverse piece of strong wire, attached to the oval inside, which should be placed pretty far forward, so as to balance the bircl.

A very spirited and striking position is, when the bird is about to take flight. In this attitude, it is placed with the body reclining forward, and the wings slightly raised, which ean be managed without the assistance of external wires, by merely placing a little cotton or tow under the wings, while the skin is yet wet.

The moment of alarm is also an interesting attitude. To express this, the one foot must be placed stretched forward, and the other drawn near the body, and considerably bent. The body must be thrown to one side, with the wing on that side much elevated and spread out, while the other is placed lower and less diffuse; the tail must be expanded, thrown down at the point, and arched; the neck should be elevated, and inclined to the sile next the foot which is drawn up; the head turned to one side, and the eyes rivetted on the object of its terror; the bill must also be open.

In Eagles, Vultures, and other birds of prey, a farourite attitude is the position of seizing their prey. This varies according to the species. The Golden Eagle, when he has seized his quarry, expands his wings and tail, like a curtain around the birl, gazes upwards, and throws his head backwards, in an attitude of triumph and defence; the feathers of his crest and neck stand nearly erect, and he gazes around in every direction, to observe if he is safe from the intrusion of an enemy before he devours his victim.

Descriptions of this kind are endless; let those who intend stuffing birds study nature in its various details, and, where this cannot be come at, good books and prints will be found an $e x-$ cellent substitute. 'These we shall point out in their proger place. 


\section{METHOD OF MOUNTING DRIED SKINS.}

Having treated of all the different modes, which we know can be successfully practised, in stuffing recent specimens, we must now say something respecting the setting up of skins which have been preserved by travellers, and sent home from distant parts.

The general method is exactly the same as in stufing recent specimens. There are, however, some preliminary steps, which it is necessary to know.

If the specimen sent home has been partially stuffed, our first business is to undo the stitches, if it has been sewedwhich was an unnecessary process. We then remove the whole cotton or tow from the inside, by the assistance of forceps, and from the neck with a small piece of wire, twisted or hooked at the end. Having finished this, small balls of wet cotton are placed in the orbits of the eyes, and the legs and feet are wrapped round with wet cotton or linen rags. A damp cloth is then thrown over the bird, and it is allowed to remain in this state till next day. The neck and body are then filled with wet linen or cotton, and it will be ready for commencing setting up in four or five hours.

The eyes are now put in, as directed in the recent subjects, and then stuffed in exactly the same manner. Some difículty will, however be experienced with respect to the leg-wires, and it will require more time and care, from the dryness of the legs, to get the wire to penetrate. Having proceeded so far as to get the bird generally formed, the wings are next adjusted: this also is frequently difficult, owing to the stiffuess of the tendons, and want of proper attention in skimning and drying them at first. Indeed with some of the South American birds, a proper adjustment of the wings is found impracticable, owing to the attempts of the native Indians of Guyana, who seldom dispose them properly. There is something extremely curious in the efiorts of man in a savage state. Whether this arises from want of observation, or a vitiated taste, it is difficult to say; but it is a notorious fact, that any attempt at art, by an uncivilized people, is generally widely different from what the object is in nature: and yet the opportunities of these people 
are much greater, in studying or even observing natural objects, than that which is enjoyed by man in a civilized state.

We have seen a bird entirely mounted by the Indians of Guyana, which was placed in an attitude so fantastic, and so out of all possibility of the birl's assuming in a natural condition, that we could only suppose it to be the harlequin of birls.

When these skins-frequently exceedingly valuable from their rarity-are unlone, to be remounted, it is oftentimes found utterly impossible to get the wings to take a natural set; in which case, there is no other remedy but cutting them off close to the body, and fixing them anew. 'Tlie scapulars are separated, they are softened with damp cloths, and then wrapped up with bands of sheet lead, to give them a proper set. When we have got them in their natumal shape, they must be fixed to the sides by cement and cotton, and a long pin through each, with the head concealed amongst the feathers. The scapulars, which we have cut off, must then be cemented on, and they will efrectually cover the joining of the wings. The bird being now arranged, and all the feathers adjusted, it is wrapped round with small bands of fine linen or muslin, and set aside till thoroughly dry.

Should any feathers be disengaged, during the mouning, they must be kept, and, when the bird is dry, we can replace them in their proper situations with a pair of forceps, after they have been touched on their shafts with the cement; the feathers around the place in which we intend to insert th: $m$, must be held up with the probing-needle (plate VI. fig. 10).

If any of the feathers are deranged in mounting, and have got a wrong set, the only way to remedy the desect is to pull them out with forceps, and re-insert them witl cenent.

\section{OF MOUNTING BIRDS, FEITHER BY FEITHER.}

Rare birds are frequently received from foreign countries, the skins of which are in such a state of decay, that it is impossible to mount them by the ordinary processes above described. The only way in which they can be preserved, is to mount them feather by feather, which lowerer is a very tedions method. It is as follows.

Procure a piece of soft pliable wire, such as is used by ball- 
hangers; or take some of the ordinary wire used, and make it red-hot in the fire, and allow it to cool gradually, when it will become quite pliable. Take five pieces of this, of different lengths; and form them into the skeleton of a body; namely, two for the back, one on each side, and one to represent the breast-bone. Imitate the shape of the bird's body, as nearly as possible. The wires must be roughened with a file, at the place where all the wires nect, at the neck and rump; and first wrap the place next the neck round with strong thread or fine brass wire. The two pieces intended for the back musi bend gently downwards, and be gradually separated from each other to wards the centre, and brought together again at the place in tended for the rump, whither they must intersect each other, and be twisted two or three times, to keep them in their place; they are then spreed out as supports for the tail; the sirle pieces are next formed, so as to represent the natural bulge of a bird's body, and attached to the rump; the piece representing the breast is then formed, joined at the rump, and afterwards continued as long as the other tail-pieces, to support the centre of the tail ; while at the front extremity a piece is left, for the purpose of forming a neck to which to attach the head. Two leg-wires are attached to the side-wires, by being rolled round them for several turns. These will be better understood from the following figures. No. 1. is a profile of the skeleton wire boily, and No. 2. a section of it viewed from above.

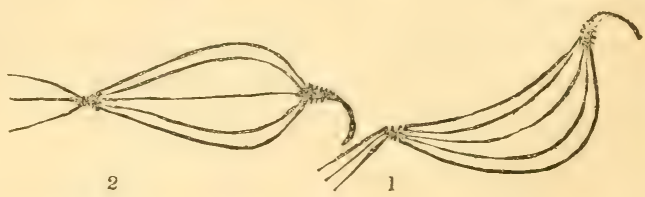

A fier this body has been properly formed, it must be wrapped round with tow-sliver (see Articles used in Stuffing), and the neck thickened to its required dimensions. When this is ac:complished, the head, legs, wings, and tail are softened in the usulal manner; the eyes are then fixed in with some cotton nitoduced into the orbits, with a little of the cement. The wings und tail are now placed on a table, with a flat leaden weight 
above each, to restore them to therr natural shape. The legwires are then passed through the legs, commencing at tise top, and bringing them out at the soles of the feat, and left with a piece extending beyond the claws.

The tail is now fixed on, by first attaching to it a quantity of cotton with the cement, and, when dry, it is fixed to the part intended as the rump.

The feet of the bird must be fixed into a piece of wood, as a perch, the ends of which must be left some inches beyond the body. 'The end next the tail is fixed into a table-vice, with the helly upwards, and the head pointing towards the operator. The feathers are now put on, commencing, under the tail, or crissum, with what are termed the under-tail coverts : a coating of cement must be previously laid on, to attach the feathers with. It is proceeded with upwards to the breast, and finally the length of the neck, taking care to put the proper feathers on their respective sides, as the side-feathers have all an inclination to one side. The bird is now turned with the back up, still keeping the head towards the stuffer; and the wings are fixed on with cement, and pins forced through the beards of the feathers to conceal the heads. When this is done, put on the feathers of the rump, and proceed upwards, as has been done with the belly. After reaching the top of the neck, the head is then fixed on with some cotton immersed in the cement, and allowed to dry before attempting to put on the feathers.

In this mode of mounting a bird there are several things which must be attentively adhered to ; these are-first, not to put the feathers too thick, for there is a danger of running short; secondly, all the shafts of the feathers must have a small bit cut of the tip, so as to admit the cement and to give them a firmer hold; and thirdly, that the feathers should all occupy their respective parts; and fourthly, that they should be arranged as they are in nature on these parts, as the disposition of every part of the body is peculiar to itself:

At first, this mode of setting up birds will be found a difficult task, but, by a little practice and experience, it will become familiar and comparatively easy, althongh it will always be found a tedious process. We have seen some specimens set up in this way, which we could hardly detect from those mounted in the ordinary manner. 
Besides, what we have already said concerning the stufing and preparing of birds, there are many details connected with particular species which demand our attention, and which can only be described as regarding that speeies. It will, however, be impossible for us to enter into all these minutely, but onty give a few examples as general guides. We shall take these in systematic succession.

\section{ORDER I.-RAPACES, OR BIRDS OF PREY.}

In the preservation of the feathers of Birds, little else is required to prevent the dissipation of their colours than to keep them as much as possible from air and light. These two agents, which were indispensable to their beauty and perfection in a living state, now exercise their inthence as destroyers, and that influence will sooner or later work its ends according to the quality, texture, or colour of the object with which it is contending. The feathers are now deprived of two agents, which in a living state contributed to their vigour and their beauty, namely, the internal circulating juices which they received from the body of the animal, and the external application of oil by the bill of the bird, supplied from a gland which is placed over the rump of all birds.

The colours of the rapacious tribes are not so evanescent as those of many others, as they, for the most part, are composed of intense browns and blacks, which are not so easily absorbed by light or air, so that they continue for a very long period without any sensible difference. There are, however, certain other parts which are liable to almost immediate cliange of colour after the death of the animals, and these are the cere and skin of the legs and feet, and the naked skin on the heads and necks of Vultures and their congeners. We shall treat of these individually.

OF VULTURES.

The birds of the genera Vultur and Cathartes of Temminck's arrangement, are distinguished from their heads and generally the upper paris of their necks and a spot 
on the breast being naked. Now, this naked skin usually loses colour and becomes of a dirty brown or yellow. It is evident, therefore, that if we wish to give these parts in our stuffed specimen the appearance they exhibited while alive, artificial means must be employed; and this can only be done by the application of paints or coloured varnishes. It is well known, that during life these naked skins on the head and neck, were liable to change of colour from the influence of the passions of the bird, as either excited by love, fear, or rage; all of which must be considered in preserving. For example, the skin of the ash-coloured Vulture (Vultur cinereus), is of a livid blue colour when the bird is in a quiescent state, but under the influence of love or rage, becomes of a bright reddish hue ; so that either of these must be adopted in our preserving, according to the character we intend giving.

The King of the Vultures (Cathartes Pajn), has a fleshy cere of a bright orange colour, or rather inclining to vermilion, which is prolonged above and between the nostrils to an elevated comb, a scarlet circle surrounds the eye, the remainder of the head is purplish black. The back of the head is corered by a patch of short blackish down, and behind the eye on either side are several broad and deep wrinkles of skin, giving origin to a thick and prominent fold, which extends ob. liquely downwards along the whole of the neck. This fold, when the bird is in an unexcited state, is of a reddish-brown, mingled with blue, and is traversed by numerous lines of minute black hairs. From the upper part of the neck, which is of a bright red, the colour gradually becomes less intense, and fades into orange and yellow as it descends towards the lower part. The legs and claws are of a dusky black, but sometimes the former are reddish, and at other times of a dirty white. This depends on the age of the bird.

Now, as all these colours, which we have described, are lia ble to change, immediately after death, it is evident that considerable nicety will be required to give the preserved specimen the appearance of nature. These must, therefore, be supplied artificially with the varnish colours, which we have Darticularly described in their proper place; as also the combinations for the formation of compound colours. The reddish- 
brown cclour mentioned, of which the fold is composed, must be touched by a mixture of the scarlet varnish, with a litlle powdered burnt-umber, and the blue streaks with which it is traversed, coloured above with cobalt blue. All the varnish colours have a tendency to shine, which, it will be evident, is not the character of any part of the skin, or caruncle of the bird described. As soon, therefore, as it is thoroughly dry, which will be in about an hour, the whole surface must be gently rubbed with very fine sand paper, which will completely remove the gloss, and give the appearance of nature.

Some nicety will be required in painting betwixt the hairs, but it can be easily managed with a little caution. Sometimes these hairs are liable to become brown, in which case they can be touched with the black varnish.

As these birds are inhabitants of warm climates, some care is requisite, after killing them, to prevent decay; the tendons of the legs should be extracted to prevent their being attacked by moths, and their place supplied by some cotton and preservatives. The tendons are extracted by means of a longitudinal incision made behind the tarsus. The edges of this incision can easily be brought together when the bird is under the process of preparation.

\section{OWLS.}

In skinning the different species of the Owl genus, much care is to be exercised in drawing the skin of the neck over the head, as it is generally so very large in proportion to the thickness of the neck, that it is no easy task to get it to pass over without either tearing or stretching the skin; this must be assisted by the use of the nails of the thumb, and easing it all round with the end of the scalpel handle.

The attitudes of these birds are always very simple. They are generally sitting in an upright posture, or devouring their prey, in which little energy is expressed.

\section{ORDER II.-OMNIVOROUS BIRDS.}

Jirds of this Order will admit of much more variety of attitude in the stuffing than those of the former. For the 
most part they are gregarious, and many of them predatory, and generally cumning and intelligent. To give them attitude and expression corresponding with their habits, is the business of the stuffer. The Paradisea, or birds of Paradise, are of this Order, for the manner of mounting which, we refer to the plan of setting up birds feather by feather.

\section{ORDER III.-INSECTIVOROUS BIRDS.}

A rich field for the display of taste is to be found in setting up the Insectivorous birds. Here we have every variety of action, the species for the most part being lively and active in their habits, contention in seizing their prey, hopping from twig to twig, watching the movements of insects, and suspended from the points of the most slender twigs in the act of seizing them. Many of these are also songsters of the grove, who delight us with melody, so that putting them in the act of singing has always a pleasing effect.

\section{ORDER IV.-GRANIVOROUS BIRDS.}

The same variety will be found in this as in the above Order. Many of them have, however, peculiar interest from the singular construction of their nests; and if stuffed in connection with these they have always an excellent effect.

\section{ORDER V.-ZYGODACTYLOUS OR YOKE- FOOTED BIRDS.}

Here agnin the prevailing dispositions and habits of the birds are widely different from any of the former Orders. They have two toes before and two behind, but the exterior hind toe is sometimes reversible; that is, it can be turned considerably to the front, or be spread horizontally along a branch.

Their food consists chiefly of caterpillars, worms, and insects, hut some species live on solt fruits. The construction of their toes gives them considerable powers in assuming attitudes on $\mathrm{E} 2$ 
branches; but they are devoid of all the playful agility of the Insectivorous and Granivorous birds. In this genus are the Parrots and their congeners, remarkable for their powers in climbing branches, and in suspending themselves in various positions by the limbs, Great latitude may be used with the setting up of this tribe-their colours are for the most part very brilliant, but they should not be too much exposed to the light. Those having purple, orange, or liliac tints, are particularly liable to change.

The legs, cere, and naked parts of the face of Parrots, and their congeners, will require, for the most part, to be refreshed with the coloured varnishes. Their limbs and bills have frequently the appearance of being powdered. In these species, this appearance is to be given by washing the bill, \&c. with mastic ramish and dusting the Pollen powler through a pepperbox over them. This powder is described in the Chapter of Receipts.

In this Order are also the Woodpeckers (Picus), which are true climbing birds, and should be attached to the trunks or branches of trees,-they seldom expand their wings,-they are assisted in climbing by their tail, consequently, it almost always forms an inclined plane to the back of the bird.

\section{ORDER VI.-ANISODACTYLI.}

The habits of this Order are much like the former, all of them being climbers and insectivorous. Their tongues are more or less extensibie,-they have three toes before and one behind, always of unequal length, hence the name of the order.

Many of the species possess the most splendid and gorgeous plumage; for example, the Creepers (Certhia), and the Humming-birds (Trochilus), the beauty of whose plumage, in general, baftes all description. Those having the purple or orange in their feathers, should be specially protected from air and light, as these colours are exceedingly evanescent. 


\section{ORDER VII.-ALCYONES.}

This Order is also remarkable for the beauty of the colours of its species, which admit of considerable extent of attitude. They, however, neither walk nor climb; they take insects while on the wing, and frequently on the surface of the water. It contains the Bee-Eaters (Merops), and the Kingfishers (Alcedo), \&c.

\section{ORDER VIII.-CHELIDONES.}

These birds are entirely insectivorous, and take their food always on the wing. They sometimes perch on trees, but admit of little variety in point of attitude, and are not remarkable for the beauty of their colours. The Swallow (Hirundo), Swift (Cypselus), and Goatsucker (Cuprimulyus), are of this order.

\section{ORDER IX.-COLUMBA.}

This Order contains but one genus, namely, Pigeons ( $C o$ lumb(e). The members of this genus are proverbial for the general elegance of their form, the variety and beauty of their plumage, and gentleness of their manners; they, however, admit of but little variety in point of attitude, the principal thing to be attended to is the plumpness and general beautifully rounded contour of the body, more especially the breast.

\section{ORDER X.-GALLINÆ}

In this varied genus there is much to exercise the skill of the Taxidermist. It comprehends the various Peacocks (Pavo), the domestic poulry (Gallus), the Pheasant (Phusiamus), the Turkey (Meltagris), the Grouse (Tetrao), Partridge (Perdix), and other genera.

The comb of the Cock and its wattles will require to be 
coloured with the red varnish, to which must be added a little lake; as also the comb of the Guinea fowl (Numidu). The particular passion of the animal at the time must also have to be studied, and the colour of his head and throat, which is liable to great change under different impulses. The male pinnated Grouse has a large, skinny membrane on each side of its neck, which it inflates during the season of love, and which is in size and colour similar to a ripe orange. This must be coloured with the red varnish, mixed with either gamboge, or chrome-yellow.

The general habits of these birds are familiar to most people.

\section{ORDER XI.-ALECTORIDES.}

The birds of this order frequent, some of them, open countries, while others inhabit the banks of streams. The former are continually in search of serpents and lizards; in which pursuit they may be very appropriately preserved. Those of the latter kind live principally on insects and worms. Little can be said as to their attitudes: these must be left to the taste of the operator.

\section{ORDER XII.-CURSORES.}

The birds of this order live mostly in the fields, in desert places remote from woods; feeding on herbs and seeds. They seldom fly, trusting to their speed of foot for safety. At the head of it stands the Ostrich (Struthio Camelus). This stupendous bird, the largest of the feathered kind, reaches from eight to ten feet in height. It falls to the lot of few to preserve this bird; but as the frame-work for it must necessarily be commensurate with its size, the manner of constructing it we shall describe :-

A piece of wood eighteen inches long, and four inches in circumference, is first taken, and a hole bored eight inches from one of its ends, from which form a groove, to the shortest end, both above and below; four inches from the other extremity two holes are pierced, at four and six inches from the end. The wire which is to support the head of the Ostrich is 
passed through the perforation, which is eight inches from the end ; it must extend eight inches out of the hole ; the two ends of the wire are now pressed flat down into the furrows, which have been formed for their reception. Strong wire nails are put in obliquely to keep the wires in their places; the heads of the nails crossing above the wires; and by the addition of strong iron wire they can be still more firmly bound down. The long end of the wire, which has been left uncut, must now be cut off, corresponding to the length of the neck, head, and bill, of the Ostrich, which must be accurately measured. The wire must be at least a quarter of an inch in diameter. It must be inserted into the neck previous to putting in the stuffing. The head and neck are now filled with chopped tow, and when properly stuffed, as well as part of the back, the wood must be placed in the middle of the body to supply the place of the oval in smaller birds. The leg-wires must be at least threeeighths of an inch in diameter. When the first one has been forced up, it must now be extended to the hole, which was six inches from the end, passed through it for the length of six or eight inches; curve it back to the end, and fix it down with two nails. The same is done with the wire of the other leg, which must be passed through the other hole. The whole are now firmly wrapped round with cord. The other parts of the stuffing are done as directed for smaller birds.

Besides a strong application of arsenical soap, we wou'd recommend Mr Waterton's plan of touching all the feathers with the solution of corrosive sublimate, and the roots of the feathers should be well soaked with turpentine, which ought to be repeated at intervals of some months.

The same method of stuffing is adopted with the Emu (Dromiceus Nova Hollundia), the Galeated Cassowary (Cassuarius Galeatus), and other large birds. The head of the latter bird is of a fine vermilion behind, and also the wattle on the throat, with its appendages; these must be coloured with the red varnish; the sides of the face and throat are of a beautiful violet tinge, which is composed of lake and Antwerp blue, in combination with the white vamish. When dry, these must be dimmed with sand paper, as formerly directed; the legs must get a coating of the same colour, with the addition of some white-lead to render it paler. 


\section{ORDER XIII.-GRALLATORES.}

This order consists of birds which frequent the sea-shore, margins of lakes and rivers, feeding on fish, worms, \&c. In stuffing, they must necessarily always be placed in standing or walking postures. They walk with a slow and measured step. Many of them enter the water without swimming, and hence their designation, Waders. As we recommended in the Vulture tribe, the tarsi must be opened, and the tendons taken away to prevent putridity, to which they are very liable.

Birds of this order must be placed on flat boards, or circles of wood tumed for the purpose. Their skins are of a very greasy nature, and require to be particularly well primed with the arsenical soap, and after they have absorbed this, with the solution of corrosive sublimate. We must particularly notice

\section{THE FLAMINGU.-Phanicopterus ruber.}

This bird is one of those, whose head cannot be passed within the skin of the neck during the operation of skinning, so that a different mode of treatment becomes necessary. When obstacles of this nature come in our way, we must, in the first place, bare the neck as high as possible, by introducing the scalpel-handle betwixt the skull and the skin. The neck is then cut off as high as we can reach, and the skin pulled straight while it is yet soft. It now becumes necessary to make an incision behind the head, by which to remove the remaining vertebræ and the brain of the bird; the skin must be laid back to the right and left, and cut as low as the first vertebræ. The occipital hole is then enlarged, that we may more easily extract the brain; and the eyes are taken out by the same opening. The orifice is then sewed up with very fue stitches, taking care to separate the feathers at every stitch.

The wire of the ncck must be placed before the stuffing is commenced. The other parts are stuffed in the ordinary way. The leg-wires are next put in. The bone of the tarsus is pierced near the heels with a triangular bodkin (plate VI., fig. 8). The point of the leg-wire is now introduced into the perforation. When the point has reached the knee-joint, we must 
press pretty hard while we turn it round and round, till it penetrates the apophysis of the tarsus, after which, it will easily be forced to the top of the thigh. The feet being palmated, must be spread, so that the membrane which connects the toes may be distinctly seen, and the webs put down with small pins.

The same mode of treatment is pursued with the Jabiru's (Mycteria, Australasia, and Americana).

\section{ORDER XIV.-PINNATIPEDES.}

The birds of this order are all swimmers; they are covered with a very thick, glossy, and close plumage; their legs are placed far behind. They are but ill adapted for any variety of form in stufing. The Grebes (Podicepes), when out of the water, can hardly walk, and sit quite erect with the point of their toes merely seen beyond their feathers. An error very common in stuffing this bird, is exposing the tarsus too much, which, in a living state, is harlly ever visible while sitting. They are very easily prepared, as the thickness of the feathering conceals most defects.

\section{ORDER XV.-PALMIPEDES.}

Alnost the whole of this numerous order are sea-birds. Their plumage is very thick, and, consequently, they are easily stuffed, but susceptible of little variety of attitude. The chief thing to be attended to is the placing of the legs. They are, for the most part, set far back. Some of the bodies are erect when sitting, with the legs almost entirely concealed, and others, such as the swan, goose, \&c., have their bodies placed horizontally. The thigh-bone (plate I., fig. $f$.), should be forced close to the breast in front, with an angle of forty-five degrees below. The body should be nearly horizontal, and the neck in the form of an S.

The Duck tribe have, in general, large heads, and, like the Flamingo, cannot be passed through the neck, so that it 
fiequently becomes necessary to make an incision at the nape for extracting the brain and eyes.

Others of this order have very fat skins inside, so that great eaution is necessary to prevent it from soiling the plumage while taking off the skin. A very large proportion of cotton and tow, therefore, becomes necessary.

\section{ORDER XVI.-INERTES.}

Little can be said respecting this orler; but what we have just remarked concerning the former order, will apply also to this.

\section{OF THE NESTS AND EGGS OF BIRDS.}

Few objects of Natural History are more interesting than the nests of birds. To the reflecting naturalist, they open up a wide field for inquiry. Speaking of the examination of birds, in the exercise of their mechanical aris of constructing nests, professor Remie says, "This work is the business of their lives-the duty which calls forth that wonderful ingenuity, which no experience can teach, and which no human skill can rival. The infinite variety of modes in which the nests of birds are construeted, and the exquisite adaptation of the nest to the peculiar habits of the individual, offer a subject of almost exhaustless interest." The number and variety of the eggs of birds are curious subjects of contemplation, and should be carefully noted whenever opportunity offers. They are as essential to the personal history of the species, as any other part of our inquiries.

Professor Rennie's interesting work on the architecture of birds needs only to be read, to excite in those, who are unacquainted with the subject, sufficient interest to induce an attentive notice of them. He has arranged them in systematic order, according to the construction of these nests, under the following heads; namely:- Mining birds, Ground-builders, Mason birds, Carpenter birds, Platform-builders, Basket-making birds, Weaver birds, Tailor birds, Felt-making birds. Cementers, Dome-builders, and Parasice birds. It 
only requires an examination of the nests themselves, which he has thus arranged, to convince us how appropriate the terms are, which he has applied to their several structures.

The eggs are emptied of their contents by making a rery small hole at each end with the triangular borer (plate VI, fig. 8), or with the point (fig. 9, or 10). By blowing at one of the ends, the contents will escape by the other, unless the young has been already formed; in which case a larger hole must be made in the side of the egg, and the contents removed with a small hook. The hole should then be stopped up by pasting a little gold-beater's leaf over it. At the Jardin des Plantes, Paris, glove-leather, or linen, are used for this purpose. The eggs are then either returned to their nest, in which they ought to be cemented, or should be fixed domn by one side to cards, with the name and locality attached.

The best mamer of conveying loose eggs to a distance, is to put some cotton at the bottom of the nest, and then another layer above them. The nests should all be put in separate boxes if possible, and so packed that the pressure of the lid may not injure the eggs, or a box with several compartments should be used, taking care that each is carefully marked. It would also be of consequence to have the nests attached to the branches, with those species which build on trees, which will enable us to trace the ingenious means employed by those little animals in constructing their habitations. In sending home specimens from a foreign country, the seams of the box should be covered by pitched cloth to protect them from the influence of moisture.

In foreign countries, strict attention should be paid to the different localities in which the various species consiruct their nests, and the trees, or plants, or kinds of soil, carefully noted; and also, whether the same species invariably fix upon the same trees and soils for building, or what are the kinds of trees or soil which they choose; besides, whether the same materials are invariably used. All these will throw linht upon some curious deductions that may be lrawn from a contemplation of this part of their economy. 


\section{H A P. III.}

CN SKINHING, PRESERVING, AND SETTING UP REPTILES, FISHES, AND MOLLUSCOUS ANIMALS, \&C.

\section{CLASS III.-REPTILES.}

\section{TORTOISES AND TURTLES.}

THE bodies of this tribe are enveloped in two plates, or shields, the upper one is formed of the ribs, and the under one of the sternum, or breast-bone.

SkInving. - The first operation is to separate the back and breast shells with a strong short knife, or chisel. If the force of the hand is inadequate, a mallet may be used, taking care not to strike so hard as to crack the shell.

These two bony plates being covered by the skin, or by scales, the scapula, and all the muscles of the arm and neck, in place of being attached to the ribs and spine, are placed below, from which cause the tortoise has been termed a retroverted animal. The vertebral extremity of the scapula is articulated with the shield, and the opposite extremity of the clavicle with the breast-plate in such a manner, that the shoulders form a ring for the passage of the trachea and osophagus.

After the Turtle is opened, all the flesh which adheres to the breast-plate, and also to the upper shell, is removed, while attention is paid to the parts as above described. The head, fore-feet, and tail are skinned as in quadrupeds; but none of these must be removed from the upper shell, but left attached.

All the fleshy parts being removed, the shells are washed out with a sponge, and carefully dried. They are then slightly rubbed with the arsenical soap.

STUFfing.-Wires are now passed through the middle of the legs, after the skin has been rubbed with the preservative. 
The skull is returned to its place, and the whole of the head, neck, and legs stuffed with chopped flax or tow. The parts of the skin, which have been cut, are then sewed together. The back and breast plates are then united by four small holes, being bored at their edges, and united by strings or small wires. The junction of the bones may then be attached with the cement, coloured so as to correspond with the shell.

If the calipash is dirty, it may be cleaned with a slight solution of nitric-acid and water; afterwards clean washed, oiled, and then rubbed hard with a woollen rag, to give it a polish.

\section{CROCODILES AND LIZARDS IN GENERAL.}

Skinving. - All this tribe are skinned in the same manner as quadrupeds. Care is, however, required in skinning the tails of the smaller species, as they are very liable to break. The skins being of a dry nature require but little of the preserrative. After they are thoroughly dried they will keep a very long time without decay.

Stufrivg. - Stuff them as directed for quadrupeds. They admit of but little variety of attitude. The small species are exceedingly apt to change colour in drying; which must be imitated with the coloured varnishes, and afterwards dimmed with sand paper. To keep them in their natural colours, they should be preserved in spirits.

The skins of such as are glossy shoudd be varnished after they are perfectly dry.

\section{SERPENTS IN GENERAL.}

SkINvivg. - In skinning serpents there is some nicety re quired, to cut them so as not to disfigure the scales; the opening should be made in the side, commencing at the termination of the scales; and they should on no account be divided, as upon their number the species is mostly determined.

It is a very frequent practice to send home serpents without the head, which renders the'm quite unfit for any scientific purpose. This proceeds from the fear of receiving poison from the fangs. But there is not the slightest danger of being 
affected, as these can easily be cut out by means of pincers. The head should be cleaned and the brain removed, in the same manner as recommended for birds and quadrupeds, the skull anointed and then returned into the skin.

When the skin is removed, it may be rolled up and packed in small space. The simplest way to preserve small species is to put them in spirits, which must not be too strong, as it will destroy the colours. See Receipts.

Mr Burchell, in his four years' journey through Africa, glued the skins of the smaller serpents perfectly flat on paper, which preserved the size of the animal, and the skin retained all the beauty of life.

StuffisG.-The skin, if not recent, must be first. sofiened in the manner recommended for birds, page 44. A piece of wire is taken the length of the animal, which must be wrapped round with tow till it is of a proper thickness, and above the whole, a spiral band of sliver should be carefully wrapped. It is then placed inside of the skin, and sewed up. The eyes are placed in, as directed for quadrupeds and birds. When dry, give the serpent a coat of varnish, and then twist it into any nttitude wished. A favourite and striking one is to have it wound round some animal, and in the act of killing it.

\section{FROGS AND TOADS.}

Skinnivg.- The mouth is opened, and the first rertebra of the neck is cut. The whole inside of the mouth is cut ont with scissors. The two jaws are next raised up, and the skin is pushed back with the fingers of the right hand; while the body is drawn back in a contrary direction with the other hand, and the whole body is then drawn out at the mouth. The legs are then returned to their proper place.

STUFfing.-The simplest method of stuffing these animals, is with sand. A small funnel is placed into the mouth, and pour in well dried sand. When full, a small piece of cutton is pushed into the throat, with some of the cement, to keep the sand from escaping on moving the animal.

The Frog is then placed on a board, and in an attitude. When quite dry, give it a coat of varnish. When this has perfectly dried, very small perforations are made under the beliy 
with the point of a needle, and the sand allowed to escape. leaving the body of its natural form.

These animals are liable to change of colour from drying; and should, therefore, be painted with the varnish to their natural hues. There is less difficulty with Toads in this respect, as they are usually of a brown colour, and not liable to much change.

They may be perfectly preserved in spirits.

\section{CLASS IV.-FISHES.}

This class of animals, in their native element, have many attractions: some for the singularity of their forms, and others for the resplendent and beautifully contrasted arrangement of their colours; while many exhibit iridescent tints which vie with the splendour of the Peacock, or Humming-bird, reflecting vivid, golden, metallic hues of all shades. But these are too evanescent for the powers of the Taxidermist; for no sooner are they removed from the water, than their transient and fading beauty vanishes for ever.

'The best method of securing the scales and colours of Fish, is, as soon as they are caught, to apply cambric or tissue paper to them, which will soon dry and adhere firmly; the body may be then taken out and the skin dried. When the skin is to be stuffed, roll it in a moist cloth, which will not only render it pliable, but also softun the tissue yaper, so as it can be: removed, when the colours will be found to be much brighter than by any other method with which we are yet acquainted.

\section{LAMPREYS, EELS, AND OTHER FISH OF SIMLAR FORM.}

These species may be skinned in the same manner as Frogs and Toads, by drawing the body through the mouth.

\section{OF SKINNING FISH IN GENERAL.}

The fish should be procured as fresh as posible, more particularly if it is one of those on which the scale's are loosely attached. Lay it on one side and cut out the gills with a pair F 2 
of scissors, then introduce a little tow or a piece of sponge irito the place to prevent the blood from flowing during the process of skinning; carefully wije the sides of the fish with a damp sponge; let the fins be raised and gently extended, and two pieces of paper, something the shape of each, be placed under them, only extending a little beyond them. See plate II. fig. 1. Coat the paper with a weak solution of Gum Arabic, and put a piece of similar size on the top of the fin, by pressing these gently they will adhere and dry in a few minutes; these will keep the fins extended, and preserve them during the operation of stuffing. When these are dry, take a piece of tissue paper or thin silk, and press it gently on one side of the fish. The natural glutinous matter which corers the scales will be sufficient to make it adhere firmly, it will soon dry and form a strong protection to the scales during the skinning; without this precaution the skin could not be removed from Nullet, Sea Beaver, \&c., without the scales being much disfigured, and losing many of them. Indeed, in such fishes, it is not amiss to put on an additional coating of paper with gum-water. This will not only secure the scales, but will also assist in keeping the proper form of the fish, by preventing distention.

When these papers are thoroughly dry, turn the fish on a soft cloth, with the uncorered side upwards, and open it with sharp scissors from the bottom of the tail-fin to nearly the point of the snout, keeping as correctly on the lateral line as possible, which can be seen in most fishes. The cheek should be afterwards eut open, so that the flesh may be removed from it, cut also the flesh from the opposite cheek, and supply its place by cotton. The skin must now be detached from the flesh, which will require some care at first. It must be commenced at the head, and separating it downwards with the assistance of a knife, and the fin-bones must be cut through with scissors. The spine must now be cut through close to the head, and also at the tail, and the body removed.

All the animal matter having been completely removed from the skin, the inside must be wiped dry, and the preservative applied in the same manner as directed for birds and quadrupeds. Great care is necessary to prevent it from being too much distended. 
In Sharis and Large Fishes, an incision is made below the head, and extended to the fin of the tail; the skin is then separated on each side with a scalpel, cutting back as far as possible, so that the vertebra may be cut close to the head. The tail is then skinned. The heat is pushed inwards, and the skin passed over it above, and all the cartilage cut carefully away. Care must be taken not to enlarge the branchial openings too much, which would render it necessary to sew them up again, and it is not easy to hide a seam in a fish's skin.

Diavon, Terradon, and Baristes, and their congeners, are opened by the belly. The ostracion is enveloped in a skin, which consists of a single piece, the tail of which only is free and fiexible. The opening in the belly must not be large; the tail must be opened, the flesh cut away, and stuffed with cotton.

\section{STUFFING.}

The skins being properly anointed, are filled with tow or cotton. This must be so managed that there will be no prominences on the outside of the skin, which, in fishes, is smooth and even for the most part. When properly filled, they must be sewed up, and set aside to dry in the air, but not exposed to the rays of the sun. In a few days, the papers with which the fins were extended are taken off, by damping them with a sponge. The glass eyes are now introduced, after filling the orbits with cotton and a little cement to secure them in their places. The skins may then be varnished, and laid asile to dry. Mr Bullock, of the London Museum, acquired con -irlerable skill in setting up fish. He always used turpentine varnish. Some good specimens of his molinting are to be seen in the Edinburgh College Museum. They are highly creditab:e productions, and have as much the appearance of the living subjects as any we have seen.

Sharks. - In stuffing these large fishes, it is necessary to use a stick for a centre support. 'This must also enter the heiad, throngh the opening of the throat. If it is intended that the specimen shall be suspended from the ceiling, wire-hooks must be fastened into the wood. From these must be placed upright wires, so that they penetrate the skin, and pass through the 
back. Let the whole internal surface of the skin be well rubbed with the preservative. The body is then stufed to its full size, and afterwards sewed up. The stuffing of the head must be completed through the orbits of the eyes, and also by the mouth. This finished, the glass eyes are inserted, as in other animals, and fixed by means of cement.

Many species of fish have semi-transparent cartilages connected with the eyes. These must be imitated with gumarabic and powdered starch, as well as the cornea of the eyes.

The skins of all fish, which are similar to that of Sharks, must be well supplied with spirits of turpentine, after they are mounted, more particularly the head and fins; but as they are not glossy, they do not require to be varnished.

When the fins are strong, it is necessary to ktep them extended by means of a wire introduced through them.

In the Diadons, the chief thing to be attended to, beyond what we have above stated, is, to take care that the spines, with which their skins are beset, are not broken or depressed in any way.

The Fishing Frog, (Lophius Piscatorius), is very easily preserved, as the colours are not so liable to change as in many other species.

Salmon, Trout, Tench, Carp, Pike, \&c. are very easily preserved, as the seales are firmly attached to the skin; and although they become somewhat dim from drying, their colours and brilliancy are considerably restored by means of varnish, if applied before they are thoroughly dried.

After a lapse of time, the varnish will rise into little scales; to remove these, nitric acid, diluted in water, must be applied to the whole external surface, which has the effect of completely taking off the varnish, or at least of raising it from the skin, which, when allowed to dry, can be wholly removed by rubbing it with a small brush. It may then be varnished again: when dry, it will ever afterwards continue quite solid.

The late Mr Stuckbury had a method of preparing the fresh water fishes of Eritain, which was much admired at the time. He skinned them under water, by which means he retained the scales in great perfection. But this method is too troublesome to be generally adopted.

What is above recommented will apply to ahmost all tislies: 
but where there is any difficulty, it must be left to the ingenuity of the operator.

Those travellers who do not wish to take the trouble of skinning fishes themselves, should preserve them in barrels of spirits. Each should be wrapped up in a separate piece of cloth, to prevent their scales being rubbed off by friction.

When travellers intend to preserve fish in spirits, they ought to provide themselves with casks of from four to ten gallons, well bound with iron hoops. An opening is eut near the bunghole, of the dimensions of six inches by four, of this shape $v$. The piece of wood cut out must be so berelled, outwardly, that it cannot fall into the cask, and must be used as a stopper, when the barrel has been filled with specimens. The fish put in should each be numbered with a small leaden ticket, or piece of wood, with the number turned or cut out, and corresponding notes taken of its locality, whether male or female, and of its name, if known, or the provincial name of the country, with any other circumstance connected with its history which can be procured. When the barrel is filled, the stopper must be put in, and hermetically sealed, to prevent the evaporation of the liquor.

If a female is procured, much swollen with spawn, an opening must be made at the anus, and the spawn extracted by it. The liquor must not be too strong, otherwise it will injure the colours of the fish. See the strength mentioned in the receipts.

\section{DIVISION II.-INVERTEBRATE ANIMALS.}

\section{CLASS I.-MOLLUSCA.}

This class contains all the animals which are soft, and destitute of a spine; namely, Cuttle Fisis, Lnivalve and Bivalve Shells, Turbinated Animals, and tỉe Cirrhipeda.

Cutrle Fisn, and all oiher Alulluscons animals, can only be preserved in suirits. The same observation applies to the aninals which inhabit that numerous tribe called Testaceous Shells. They must be detacherl from the shells, and put into spirits, while the sluells themselves mast be preserved, inicpendent of the animal. 
Shells naturally arrange themselves under three distinct hearls; Marine, Land, and Fluviatile, or Fresh Water.

Marine Shells are only to be expected perfect, when pro cured in a living state. The way to extract the animal, is to four some warm water on it; but, if made too hot, it is liable to crack the shells. When the animals are dead, they can easily be pulled out with any hooked instrument, or fork, or, if the animal is small, by a common pin. This applies to all Marine Shells, whether Univalve, Bivalve, or Tubular. It is of great consequence to preserve the ligament of Bivalve Shells entire, so that the valves may not be separated. The animals of Land and Fresh Water Shells are killed by the same means, only that the water requires to be very hot.

Unless the sliells are covered with any extraneous matter, it is not necessary to clean them. Marine Shells are, however, very liable to be incrusted with other marine bodies, particularly with Serpula and Balani, \&c. These must be started off by means of a sharp instrument: an engraving tool is well adapted for this purpose. This must be done with great caution, in species which have spines and other excrescences, as they are very liable to be broken. Should auy of the calcareous matter still adhere, this must be removed, by applying to it a very weah mixture of muriatic acid and water, applied with the point of a quill, and then plunged into water, and allowed to remain till the acid is quite extracted. But on no account whatever, attempt to eradicate these parasitic bodies by means of acid, or acid and water alone, as the chances are that the shell will be completely destroyed by their application. We have seen many fine and valuable shells destroyed by an injudicious application of acids-they should never be used when it can possibly be avoided. We have, on the other hand, seen shells which were so completely enveloped in calcareous crust, that it was impossible to trace their exterual surface, most thoroughly cleared of all this, without being touched at all by acids, the whole being removed by a small knife or other sharp instrument; and these, in many cases, having long and tender spines externally.

Nothing can be more monstrous than the application of pumice-stone, which some recommend, for polishing shells; as is also the use of tripoli, rotten-stone, and imry. Neither clo we 
approve the applieation of varnishes, as such shells neve? have their natural lustre.

If a shell has been found dead upon the beach, it is probable that it will have undergone a certain degree of decomposition, that is, it will have parted with part of its animal matter, and consequently the colours will have faded, and the surface present a chalky appearance. To remove this, take a small proportion of Florence oil, and apply it to the surface, when the colours which were invisible will appear. When completely saturated with oil, let the shell be rubbed dry, and placed in a cabinet. Oil may also be applied, after acid has been used; and it will be found extremely useful, when applied to dry the epidermis, which it will prevent from cracking; or quitting the shell entirely, which it frequently does.

Whether Marine Shells are procured in a living or dead state, a very necessary precaution is to immerse then in pure tepid water, after the animal has been extracted, and allow them to continue in it for an hour or two, so as completely to extract any salt or acid which may be in them.

Fresh-water Shells are liable to a calcareous or earthy incrustation, which must be remored by immorsing them in warm water, and afterwards scraping and brushing them with a nail or tooih-brush. Much nicety is necessary in cleaning these, as their great thinness renders them in general liable to be broken. A little Florence oil will improve the appearance of the epidermis, and render it less liable to crack.

Land Shells seldom require any cleaning, except washing in water, as they are not liable to incrustations of any kind.

When shells are perforated by marine animals, or otherwise broken; if the specimen is rare, it is desirable to remedy these defects, as far as possible. They may be therefore filled u!. or pieces added to them with the cement, which may be coloured, when dry, to imitate its original state.

\section{OF POLISHING SHELLS.}

Many species of Marine and Fresh-water Shells are composed of mother-of-pearl, generally covered with a strong epidermis. When it is wished to exhibit the external structure of the shells, the epidermis is removed, and the outer testaceous 
coatings polished down, till the pearlaceous structure becomes visible. It has been a common practice to remove the strong epidermis of shells by means of strong acids, but this is a hazardous and tedious mode of operating. The best method is to put the shells into a pan of cold water, with a quantity of quicklime, and boil it from two to four hours, according to the thickness of the epidermis. The shells afterwards must be gradually cooled, and some strong acid applied to the epidermis, when it will easily peel off: Two hours are sufficient for the common muscle being boiled. The shells are afterwards polished with rotten-stone and oil, put on a piece of chamois leather.

The epidermis of the Uno Margaritifera is so thick, that it requires from four to five hours boiling. After the epidermis has been removed, there is beneath it a thick layer of dull calcareous matter, which must be started off with a knife or other sharp instrument; this requires great labour, but when accomplished a fine mother-of-pearl is exhibited, which adds an agreeable variety as a specimen.

Various Turbos and Trochus's are also deprived of their epitlermis, and polished with files, sand-paper, pumice-stone, \&c., till the pearly appearance is obtained; but all these modes are invented for disfiguring rather than improving the shells in the eye of the naturalist, and should never be resorted to except where the species is very common, in which case it is well enough to do so with one or two specimens to show the simacture of the shells.

After the operation of polishing and washing with acids, a little Florence oil should be rubbed over to bring out the colours and destroy the influence of the acid.

\section{CLASS VI.-CRUSTACEA.}

In this Class are incluted Crabs, Lobsters, and their congeners. These animals are all protected by a coriaceous corering or shell, which is easily preserved, alihough there is considerable difficulty in preserving the colours of some species.

The flesh must be extracted from the large claws of Lob- 
sters and Crabs by breaking the smallest possible piece from their points and introducing a small crooked wire; in the smaller claws the flesh must be allowed to dry, and to facilitate this, extremely small perforations should be made in opposite sides of the shell by means of a sharp triangular awl, so as to allow the air to pass through it.

In Lobsters the branchie and all the intestines must be cut away, the latter is effected by separating the body from the lower parts, and then extracting the internal parts with any sharp instrument; it should then be dried and cemented together, after being well anointed with the preservative. In Crabs, the body, with all the limbs attached, is pulled separate from the back shell, and the whole fleshy matter carefully picked out, and preserving powder and the solution of corrosive sublimate applied to the different internal parts. In drsing Lobsters, Crabs, \&c., they should be exposed to a free current of air, but not to the sun's rays, as it reddens the shells of crustaceous animals.

It need hardly be mentioned, that before applying the preservatives, the shells should be well washed with cold water.

The Hermit. Crab (Pagurus Bernhardus), always takes possession of the shell of some turbinated Uniralre as its domicile. These are easily preserved by pulling out the animal afier it is dead. An incision is made in the soft tail of the animal, and the contents allowed to run off; it is then filled with cotton and imbued with the preservative, some cement is then put on the tail, and the animal returned to its shell ; which completes the operation of preserving.

In sending home crustaceous animals, the larger specieshould be emptied of their flushy matter, which, however, is not necessary with the smaller species; they should be packed in middling sized cases, and each wrapped in separate papers, with a thick bed of cotton or flax between each. In Lobsters, and the species which are allied to them, great care must be exercised in preserving the tentacula or feelcr's which emanate from their heads, as these become very brittle after they are dried. In proceeding to set up specimens which have been sent home, they should be immersed in cold water for sume time to give pliability to the tentacula and other parts, 
without which it will be impossible to set them up in any way without their breaking.

Mir Bullock recommended, that Crabs and all other Crustaceous animals, should be immersed in corrosive sublimate and water for an hour previous to their being put into attitudes.

When the joints become loose they are in general attached by glue, but the cement is much better.

N.B.-On no account whatever use warm water in cleaning Crustaceous animals as it is certain to change their colours.

\section{H A P. I V.}

OF PRESERVING SPIDERS, GALLY-IWORMIS, AND INSECTS,

\section{CLASS VII.-ARACHNIDES.}

This Class includes all animals of the Spider kind. These were formerly aranged amongst insects, but they have been formed into a separate class by Lamarck.

The general directions which we shall give respecting insects, hold good as to Spiders, only we must mention there is considerable difficulty in preserving the bodies of Spiders, which generally, in a very short time, shrink into a shapeless mass. To prevent this, the body should be prickea with the triangular awl, plate VI. fig. 8, and the contents pressed out; it should then be stuffed with very fine carded cotton or down, which can be pushed in by a heckle tooth, or one of the prickers, Nos. 9. and 10. of plate VI, blunted a little at the point. When properly distended, the small aperture should be filled up with a little cement, or a solution of gum-arabic. The legs of the larger species, such as the Bird-cateling Mygale (Mygale avicularia), and the Scorpions, are also liable to shrink, and should be stuffed in the same manner as that of the body.

In those species of Spiders which we have thus prepared, 
and whose colours are rich and likely to be affected by the action of the atmosphere, we must endeavour to arrest its progress by immediately imbuing the animal after it is set up with the solution of corrosive sublimate, and in an hour aites with a thin coating of a rery weak white-spirit varnish ; for this purpose, take a tea-spoonful of the ordinary white-spirit or elastic varnish, and add to it two tea-spoonfuls of spirit of wine, ap1) th this with a fine camel hair brush, which will quickly dry, and have a strong tendency to preserve the colour. The rarnish being thus reduced in strength, will not leave any gloss on the insect, nor will it be at all perceptible.

Mir Samouelle, auther of "The Entomologist's Useful Compenditum," in speaking of preserving spiders, says, "The best preserved specimens that I have seen are those where the contents of the abdomen have been taken out and filled with fine sand. I have preserved several in this way, and find it answer the purpose."

Ir Donovan, author of "The History of British Insects," and many other splendid and ucitul books on insects and natural history, makes the following observations on the preservation of Spiders:-

"To determine whether some species of Epiclers conlil be preserved with their natural colour, I pht several into spirits of wine; those with gibbous bodies soon after discharged a very considerable quantity of viseid matter, and therewith all their beautiful colours; the smallest retaincd their form, and only appeared rather paler in the other colours tian when they were living:

"During the course of last Summer, among other Spiders I met with a rare species, it was of a bright yellow colour, ele. gantly marked with black, red, green, and purple; by some accident it was unfortunately crushed to piece's in the chip-box wherein it was confined, and was therefore thrown aside as useless; a month or more aiter that time I observed that such parts of the skin as had dried against the inside of the box, retained the original brightness of colour in a considerable degree. To further the experiment, I male a similar atienpt, with some caution, on the body of another spiler (Aranca Diadema), and though the colours were not perfect: preserved, they appeared distinct. 
"From other observations, I find, that if you kill the Spider and immediately after extract the entrails, then inflate them by means of a blow-pipe, jou may preserve them tolerably well : you must cleanse them on the inside no more than is sufficient to prevent mouldiness, lest you injure the colours, which certainly in many kinds depend on substance that lies beneath the skin."

Scorpions, and all the Spiller tribe, may be sent home in spirits, which will preserve them perfectly, and when taken out and dried, they will be found to have suffered nothing from their immersion. We have seen some specimens set up after being sent home in spirits, which rivalled any which have been preserved in a recent state. The animals of this class are particularly liable to the attacks of insects, particularly in warm countries, on which account, the mode of transporting and keeping them in spirits, is, perhaps, superior to all others. If, however, they are set up in a warm climate, they should be well soaked with the sulution of corrosive sublimate, made according to the recipe of Mr Waterton's. See chapter on Receipts.

For the setting up of this class, see the directions for preserving insects.

\section{CLASS VIII.-MYRIAPODA.}

This class contains the Julus, or Gally worms, the Scolopendra, and others, which were formerly ranked as insects. The mode, pointed out for the preceding class, and for insects, also applies to this class. They may also be sent home in the same way, or they may be set up as directed for insects.

\section{CLASS IX.-INSEC'TS.}

Every country of the world is replete with this extensive nnd interesting class of beings, whose forms are infinitely ăiversified, and whose species are the most numerous of any ciass in the animal kingdom. 
Before any attempt is made to collect insects, certain apparatus must be provided, not only to enable us to secure them, but also to preserve them after they are caught.

First, then, we must be provided with a quantity of wooden boxes, from 18 to 20 inches long, 15 to 17 inches wide, and two inches deep. These should have well-fitted lids, with hinges, and fastened by a wire catch, or small bolt. The bottom stould have a layer of cork, abont the sixth of an inch in thickness, which should be fixed down with very strong paste, made according to our recipe; and also some wire nails, to prevent it from springing. Over the cork should be pacted white paper. The box should be anointed inside with oil of petroleum. If that cannot be procured, make an infusion of strong aromatic plants, such as cinnamon, aloes, thrme, laurel, sage, rosemary, or cloves, and wash the inside with it. A small packet of camphor should be wrapped in a prece of rag, and deposited in a corner of the box.

We must also be provided with a quantity of Insect pins, of different sizes, corresponding with the size of the insect. The pins used for setting should be longer than those which are taken to the field.

Bottles, with mouths from an inch and a quarter to two inches in diameter, must also be procured, and these must be three-fourths full of spirits, such as weak brandy, rum, gin, or whisky.

Hunting-Box. - We must besides have what is termed a hunting-box, for carrying in our pocket, when seeking after insects. This should be made of strong pasteboard, or chip, for ightness, or, if this is no consideration, of tin. It must be of an oblong-oval shape, rounded at the ends, for the convenience of the pocket. It should be from eight to ten inches long; four to five inches wide, and two-and-a-lialf to three inches deep. It must have a layer of cork both in the bottom and top of the lid, inside, for attaching insects to, when caught during the day. The larger insects are placel at the bottom, and the smaller ones on the lid.

The Entomorogical Net.-We next procure a net, as figured at plate IV. fig. 7., construeted similar to a bat-fowling net. This is either made of fine gauze or coarse muslin; it may either be green or white-the latter is the hest for observ- 
ing small insects which may be caught; the green, howver, is better adapted for catching Moths. The net-rods sinonld be made of hickory, beech, hazel, or liolly ; they ought to be five feet in length, quite round, smooth, and tapering to an obtuse point, as at fig. 8. plate IV.; the oblique cross-piece at the point, fig. $a$., should be of cane, and fitted into the angular ferrule; the rod, marked $b$., must be diviled into three or four pieces, so that it may be taken asurder and carried in the pocket; the upper part of each joint must have a ferrule affixed to it, for the purpose of articulating the other picees, $d$. Each joint should liave a notch or check, as marked at $c$, to prevent the rod from twisting.

The net itself, fig. 7., must lave a welting all round it, doubled so as to form a groove for the reception of the rods. In the centre of the upper part or point, at $f$., it must have a snall piece of chimois leather, so as to form a kind of hinge; this must be bound round the welting, and divided in the miclule, so as to prerent tile cross pieces from slipping over each other; $y$. shows aboit four inches of the gauze tumed up, so as to form a bay ; $h$. $h$. are strings for the purpose of passing through the staple $e$, to which the net is firmly drawn on each side. When the net is used, a landle is to be held in each hand.

If it is intencled to take insects on the wing, by means of this net, for which it is admirably adapted, it may be folded together in an instant. If the gauze is fine enough, and preserved whole, eren the smallest insect cannot escape. It may be also applied in catching Coleopterous Insects, which are never on the wing, as well as Caterpillars. When used for this purpese, the Entomologist must hold it expanted under trees, while another must beat the branches with a stick. Great numbers of both insects and larva will fall in the ganze, and by this means many hundreds may be captured in a day.

Another method is to spread a large table-cloth under trees and bushes, and then beat them with a stick. An umbrella reversed has frequently been used for the same purpose. Bosc, the celebrated naturalist, used this last method,--he held the umbrella in the left hand, while he beat the bushes with the other.

THe Hoop or Aquatic NFr, nlate IV. fig. 9. This uset is 
used for capturing Aquatic Insects, which are either lurking at the bottom, swimming through the liquid element, or adhering to plants. It may also be successfully used in sweeping amongst grass and low herbage, for Coleopterous Insects, and others which are generally to be found in such situations. The socket, for the handie, may be made of such dimensions, as will answer the second joint of the Entomological net-rod, which will save carrying another handle; or a walking-stick may be made to fit it.

A Phial, plate IV. fig. 11. This may either be male of tin or crystal, and used for collecting Coleopterous and other Creeping Insects. The mouth should be nearly an inch wide, and a cork exactly fitted to it, in the centre of which must be inserted a small quill, to afford air, and inserted about an inch heyond the cork, to prevent the insects from escaping. If the bottle is made of tin, and of a larger size, a tin tube must be introduced into its side, and terminating externally at the surface.

A Digger, plate IV. fig: 13. This instrument is either made of iron or steel, and is about six or seren inches in length, fixed into a turned wooden liandle. It is used for collecting the pupe of Lepidopterous Insects, at the roo:s and in the clefts of the bark of trees; and also for pulling off the bark, particularly from decajed trees, under which many curions and rare insecis are frequently found. It is most useful with an arrowheaded point.

Setring Nefdlfs, plate IV. fig. 12. Fitted into a small wooden handle, the needle itself should be about three inches long. and about the thickness of a small darning-needle slightly bent from about the middle. Fig. 16. is a straight nerdle, which is used for extending the parts of insects; at one end of the handle is the needle, and at the other a camelhair pencil, which is used for removing any dirt or dust which may be on the insects. The pencil may be occasionally drawn throngh the lips, brought to a fine pont, and used for disposing the antenne and palpi of insects of the minnte kimls.

Brass Pliers, plate IV. fig. 11. These are used for picking up small insects fom the ronts of graks, \&c. They may also be used for laring hold of small insects, while they are set fiee and not set up. 
Fan Forceps, plate V. fig. 12. and 13. This very useful instrument to the Entomologist, must be made of steel or iron, and about eight or ten inches in length; its general construction is like that of a pair of scissors, and it is held and used in the same manner. Towards the points are formed a pair of fans, which may either be square, oval, hexagonal, or octaggonal in the edges, and the centres covered wilh fine gauze. The general size of the fans is from four to six inches. These are used for capturing Bees, Wasps, and Musce. Thes are also used for catching Butterflies, Moths, and Sphinges. I. an insect is on a leaf, both leaf and insect may be inclosed within the fans; or if they are on a wall or the trunk of a tree, they may be very easily secured by them.

If a Butterfly, Sphinx, or Moth, are captured by the forceps, while yet between the fans, they should be pressed pretty smoothly, with the thumb-nail, on the thorax or boty, taking care, however, not to crush it. It may then be taken into the hand, and a pin passed through the thorax, and then stuck into the bottom of your hunting-box.

Qinl.s.-These are of great use in carrying minute insects. They should be neatly stopped with cork and cement, at one end; the other end should be prorided with a small moveable cork, for a stopper. Each end should be wrapped carefully sound with a silk thread waxed, to prevent them from splitting.

Pocket Larva-Box.--For collecting Caterpillars, this box is rery essential : it consists merely of a chip-box, with a hole pierced in the centre of the ton and bottom, and covered with gauze, for the admission of air. It will be necessary to put into the box some of the leaves on which the larre feed, as they are very voracious, and camot long exist without food.

Pill-Boxrs.-No Entomologist should be without five or six dozen of these useful articles. They are of great value, in collecting the smaller species of Lepilopterous Insects, such as the Tinea, \&c., and only one specimen sirould be put in each box, as, if more than one, they are apt to injure each otleer's wings, by beating against each other.

Setting-Boards. - These must be made of deal board, from a foot to fifteen inches long, and eight or ten inches broad, with a piece of wood run across the ends, to prevent them from waping. They are covered with cork, which must be periecty 
smooth on the surface, with white paper pasted over it. Several boards will be required, by persons who are making collections, as some of the insects take a considerable time to dry, so that they may be fit for introducing into a cabinet.

The boards should be kept in a frame made for the purpose. It should consist of a top, bottom, and two sides; the back and front should have the liames of doors, attached by small hinges, and their centres corered with fine gatize, for the free passage of air; the sides should have small pieces of wood projecting from them, for the boards to rest on ; which should be at such a distance from each other, that the pins may not be displaced, in pusining the boards in, or drawing them ont. The frame should be placed in a dry airy situation.

BrACEs.-These are merely small pieces of card, cut in the form exhibited on plate IV., attached to the Butterfly, and other insects; and also at No. 17. They are pimned down on the insects, to keep their wings, \&c., in a proper state, till they acquire a set.

\section{SETTING AND PRESERVING INSECTS.}

Of the Orders Coleoprera, Orthoptera, and Hmirters. These are very easily preserved.

They are killed by immersing in scalding water, and then laid upon blossom or blotting yaper, for the purpose of alssibl)ing as much of the moisture as possible; or they may be placed in a tin box, with a little camphor in it, near the fire, which soon kills them. This is besides of considerable efiect in their preservation.

Insects of the genera Gryllus (Cricket), Locusta (Locusts), \&c., have tender bodies, and are sure to shrivel in drying. The intestines should therefore be extracted, while they are jet moist, and the skin filled with cotton, as directed with some of the spiders, at page 72 .

When Coleopterous insects are set with the wings displayed, the elytra siould be separated, and the pin passed through their bolly, near the midlle of the thomx, as in plate IV., fig. 3 , a. The wings are exhibited as in the act of tlying, and are retained in this situation until they are quite dry, by the cost-hraces, $b$ and $c$. The insects of this orler should always 
have the pin passea through the right elytra, on the right side, as shown at plate IV., fig. $4, a$ : that is, it should pass underneath, between the first pair of feet and the intermediate ones.

The legs, palpi, and antemne, should be displayed in a natliral order on the sctting-board, and retained in the position by means of pins and braces, as shown in plate $I V$., figs. 3 and 4. These must be kept in that state, either longer or shorter, accoriing to the insect and state of the weather, as if placed in a cabinet before they are quite dry, they are sure to get mouldy, and will ultimately rot.

Minute insects should be attached to cards with gum, as shown, plate IV., figs. 5 and 6 , with the legs and other orgaus displayed. Entomologists generally adont triangular cords, as at fig. 5, as less liable to hide the parts of the insects.

Order Lepidoptera.-Mr Haworth, in his " Lepidopterc Britannica," in mentioning the tenacity of life in the Bombyx Cossus, or Goat Moth, states, that " the usual way of compressing the thorax is not sufficient to kill this insect. They will live several days after the most severe pressure has been given there, to the great uneasiness of any humane Entomologist. The methods of suffocation by tobacco or sulphur, are equally inefficacious, unless continued for a greater number of hours than is proper for the preservation of the specimens. Another method now in practice is beiter, and however fraught wils cruelty it may a!pear to the inexperienced collector, is the greatest piece of comparative mercy that can, in this case, be administered. When the larger Moths must be killed, destroy them at once by the insertion of a strong, red-hot needle into their thickest parts, beginning at the front of the thorax. If this be properly done, instead of lingering through sfveral days, they are dead in a moment. It appears to me, however, that insects being animals of cold and sluggish juices, are not so susceptible of the sensat ors we call pain, as those which enjoy a warmer temperature of body, and a swifter circulation of the fluids. To the philosophic mind, it is self-evident that they have not such acute organs of feeling pain, as other animals of a similar size, whose juices are endowed with a quicker motion, and possess a constant, regular, and genial warmth, such as 
young mice, or the naked yomg of birts. If any of these have the misfortme to lose their heads or limbs tirom force, speedy death is the certain consequence; but insects, unt? similar circumstances, it is well known, are capable of surviring a considerable time."

Buttertlies are soon killed by passing a pin through the thorax; but probably the safest way is to adopt Mr Haworth's flan, of making their instant death certain. The pin passed through the thorax of small Moths, generally proves almost instantly fatal to them.

The best mamer of preserving the minnte species of Moths, is by pili-boxes, as alove stated, each moth being kent in a separate box. We have found the following the best mode of destroying them :-

A picce of flat hard-wood is taken, and a circular groove cut in it, sufficiently deep to admit the month of a tumblex being placed within it. In the centre of the woot, pierce a hole about a third of an inch in diameter in its centre : place the pill box under this tumbler, with the lid off, and the insect will soon creep out: but whether it does so or not, a match well primed with sulphur is lighted and placed into the hole under the centre of the tumbler, which will sufocate the insect in a few seconds. I have also found this an efrectual method of killing the larger species of Butterites, and Moths. In piercing them, the pin should be quite perpendicular, that no part of their minute frame should be lidden by its oblique position.

The larger insects of this order are set by luaces clictly. A single one should in the first place be introduced under the wing, near the thorax, as shown in plate IV. fig. I, $c u$, and a longer brace extending over the wings, as at $b \quad b$. These should not bear upon the wings, but be reatly to rest gently on them, when required. The wings are now elevated to their proper position by the setting needle $c$, and other braces are used as necessity dictates, in the manner represenfed at $d, e, f, g$, and $h$. The feet and antenne are extemled and kipt in their places by means of pins; in which ofremation small braces are also occasionally used.

The French Entomologists set Bntternites, Mo:lis, and

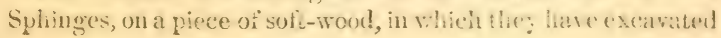


a groove for the reception of the body, as deep as the insertion of the wings. They are otherwise preserved as above directed.

In the larger Butterflies, Moths, and Sphinges, the abdo men should be perforated, its contents extracted, and then stuffed with fine cotton, after having been washed interually with the solution of corrosive sublimate. Indeed, the cotton should also be rubbed with the arsenical soap before being introduced, as these insects are particularly liable to the attack of smaller insects, such as the Mite.

Several of the Moth tribe are extremely liable to change their colour some time after they have been placed in a cabinet. This change is frequently occasioned by an oily matter which is common to many of them. This first makes its appearance in small slots on the body, but soon spreads itself over the abdomen, thorax, and wings; and ends in a total obliteration of all the beautiful markings. A method which has been sometimes successfully adopted is to sprinkle all the wings with powdered chalk, and holding a heated iron over it; the chalk absorbs the grease, and may then be blown off by means of a pair of small bellows. Another way of applying the chalk, and perhaps the better of the two, is to throw some powdered chalk on the face of a heated iron, and then put it into a piece of linen cloth, and apply it to the body of the insect; the heat of the iron will soften the grease, and the chalk will absorb it.

Another method is to hold a heated iron over the insects for a few minutes, and then to wash the spotted or greasy places with ox gall and water, applied with a camel-hair pencil, and afterwards wash it with pure water, and dry it by an application of bloating paper, and when perfectly dry imbue it with the solution of corrosive sublimate. But grease seldom appears where the contents of the abdomen have been removed.

Orders Neuroptera, Hrwexoptera, and Diptera.-The Dragon-Flies (Libellulce) are frequently very difficult to kill, being powerful and nerrous animals. When canglit they should be transfixed through the sides, and it sometimes becomes necessary to put braces on their wing to prevent them from fluttering while in the hunting box. The only certain method of killing them speedily is by the method recommend- 
ed by Mr Haworth for the larger moths at $\mathrm{p}$. 80. They may also be killed sometimes by placing them under a tumbler and sutrocating them, as recommended at p. 80. Some Entomologists put them in scalding water for an instant.

The contents of the abdomen should always be removed from Dragon Flies, otherwise it will become black and shining through the skin, and destroy the beautiful bands with which they are ornamented. They can be stuffed with cotton on a small roll of paper introluced. If these precautions are attended to, the insect will preserve the perfect beauty of its living state.

The other species of these Orders soon die afier being trans fixed. They may be set by braces and pins, as represented in figures 3 . and 4 . of plate $I V$.

Some of the Dipterous insects are very perishable in point of colour after death, paricularly in the abdomen, the skin of which is very thin. The only way of remedying this is to pierce the ablomen, and afier taking out the contents the cavity should be filled with a powdered paint the same colour as the living subjects, which will shine through and give it all the appearance of nature.

\section{METHOD OF RELAXING DRIED INSECTS.}

Insects frequently get stiffened before the Entomologist has leisure to get them set; and it usually happens that those sent home from foreign countries have been ill set, and require to be placed in more appropriate attitules after they have fallen into the hands of the scientific collector. They may be relaxed and made as flexible as recently killed specimens by the following simple process, from which they can receive no injury: pin them on a piece of cork and place the cork in a large basin or pan of tepid water, and cover the top tight with a dam! cloth, taking care that it. is sufficiently high not to injure the insects. In most cases a few liours is sufficient to restore them to their original flexibility, so that they may be easily put in their proper positions. In some insiances, three or four days are necessary to relax them thoroughly, so as to set the wings without the risk of breaking them; no force whatever must be used with any of the mombers. When set up afier being 
relaxed, they must be treated in exactly the same manner as recent specimens.

IVe must again caution the Entomologist to be careful that he applies the solution of corrosive sublimate to all his species, otherwise there is little chance of their continuing long without being attacked by the Mite ; they ought to be frequently imbued.

Mr Waterton, who has studied deeply the subject of preserving animal substances, and applied them not only in our own country, but also under the influence of a tropical climate, makes the following observations on the preservation of Insects : - " I only know of two methods," says he, "to guard preserved insects from the depredations of living ones. The first is, by poisoning the atmosphere-the second is, by poisoning the prepared specimens themselves, so effectually, that they are no longer foud for the depredators. But there are some objections to both these moles; a poisoned atmosphere will evaporate in time if not atiendel to, or if neglected to be renewed ; and there is great difficulty in poisoning some specimens on account of their delicacy and minuteness. "If you keep spirits of turpentine in the boxes which contain your preserved specimens, I am of opinion that those specimens will be safe as long as the odour of the turpentine remains in the box, for it is said to be the most pernicious of all scents to insects. But it requires attention to keep up an atmosphere of spirit of turpentine, if it be allowed to evaporate entirely, then there is a clear and undisputed path open to the inroads of the enemy; he will take adrantage of your absence or neglect, and when you return to view your treasure you will find it in ruins. Spirits of turpentine poured into a common glass inkstand, in which there is a piece of sponge, and placed in a comer of your box, will create a poisoned atmosphere and kill every insect there. The poisoning of your specimens by means of corrosiv' sublimate in alcohol, is a most effectual method. As soon as the operation is properly performed, the depredating insect perceires that the prepared specimen is no longer food for it, and will for ever cease to attack it ; but then evers part suust have received the poison, otherwise those parts where the poison has not reached will still be exposed to the enemy, and he will pass unhurt over the poisoned parts till he arrives at 
that part of your specimen which is still wholesome food for him. Now, the difficulty lies in applying the solution to very minute specimens without injuring their appearance; and al! that can be said is, to recommend unwearied exertion, which is sure to be attended with great skill, and great skill will insure surprising success. I myself have attended to the preservation of insects with the assiduity which Horace recommends to poets:-“ Nocturna versate manu, versate diurna," 'Tine result has been astonishing success, and a perfect conviction that there is no absolute and lasting safety for prepared specimens in Zoology from the depredations of insects, except by poisoning every pari of them with a solution of corrosive sublimate in alcohol.

Mr Waterton is of opinion, that tight boxes, with aromatic atmospheres, are not to be depended upon, in the preservation of insects. He says: "The tight boxes, and aromatic atmospheres, will certainly do a great deal. but they are liable to fail, for this obvious reason, viz. that they do not renter for ever absolutely baneful and abhorrent to the depredator, that which in itself is nutritious and grateful to him. In an evil hour, through neglect in keeping up a poisoned atmosihere, the specimens collected by industry, and prepured by art, and which ought to live, as it were, for the admiration of future ages, may fall a prey to an intruling and almost invisible enemy; so that unless the solution of corrosive sublimate in alcohol is applied, you are never perfectly sate from surprise. I have tried a decoction of aloes, wormwood, and walnut leaves, thinking they would be of service, on account of their bitierness: the trial completely failed. Wherefore I venture to recommend not to put much trust in simples.

\footnotetext{
"Contra vim mortis, non est medicamen in hortis."

"Against the deadly moth, "an I,

From herbs, no remedy supply."
}

Many Entomologists are satisfied with possessing the insect in its perfect, or imago condition. But it is excecedingly interesting to be able to trace these through their different states of existence, from the egg to the perfect insect. Besides, we are ceritin to proluce the insects in the highest state of 
preservation, when we breed them ourselves; and it is besides very interesting to have the eggs or the different species, as well as the caterpillar and pupa.

\section{THE EGGS OF INSECTS.}

The eggs of insects preserve their form and colour, in a cabinet, in general without much trouble. Swammerdam had a method of preserving them, when they appeared to be giving way. He made a perforation within them, with a fine needle, pressed out their contents, afterwarls intlated them with a glass blow-pipe, and filled them with a mixture of resin and oil of spike.

THE LARV RE, OR CATERPILLARS.

The easiest way of destroying the Caterpillar is by immersion in spirits of wine. They may be retained for a long time in this spirit, without destroying their colour.

$M r$ William Weatherhead had an ingenious mode of preserving Larve. He killed the Caterpillar, as above directed, and having mate a small puncture in the tail, gently pressed out the contents of the abdomen, and then filled the skin with fune dry sand, and brought the animal to its natural circumference. It is then exposed to the air to dry., and it will have become quite hard in the course of a few hours, after which the sand may be shaken out at the small aperture, and the eaterpillar then gummed to a piece of card.

Another method is, after the entrails are squeezed out, to insert into, the aperture a glass tube, which has been drawn to a very fine point. The operator must blow through this pipe, while he keeps turning the skin slowly round, over a charconl fire; the skin soon becomes hardened, and, after being anointed with oil of spike and resin, it may be placed in a cabinet, when dry. A small straw, or pipe of grass, may be substituted for the glass-pipe.

Some persons inject them with coloured wax, after they are dried. 
When tite insects have escaped from their Pupa skin, the skin usually retains the shape and general appearance it did while it contained the insect. It is therefore ready for a cabinet, without any preparation whaterer. But if the animal has not quitted its envelope, it will be necessary, either to drop the Pupat into warm water, or to heat it in a tin case before the frre; the former mole however is the best, and least liable to change the colours of the Pupa.

\section{METHOD OF BREEDING INSECTS.}

BreEnivg Cages. - These must be made of wainscot, or other hard wood, as deal is apt to kill the caterpillars, from its strong smell of turpentine. The best form for these, is represented plate IV. fig. 10. The sides and firont are covered with gauze; $a$. is a small square box, for the reception of a phial of water, for placing the stalks of planis in, on which it is intended the caterpillars are to feed. The most convenient size for a breeding cage is, eight inches in breadth, four deep, and one foot in height. It is not proper to place within a cage more than one species of caterpillar, as many of them prey upon each other. Indeed animals of the same species will derour each other, if left without food. The Caterpillars of insects, for the most part, will only eat one particular kind of food, so that it is better to have no more than one sori in a cage.

There mist be at the bottom of the cage earth to the depth of two inches: this shonld be mixed with some fine sand and regetable earih, if possible, to prevent it fiom drying. The cages should be kept in a cool cellar or damp place, because many insects change into the P'upa condition unler the earth; so that it would requirs to be somewhat moist, to prevent the destruction of the animal. The shell or cas' of the Pupa also becomes hard, if the earth is not kejt molet; and, in that event, the animal will not have sufficient streigth to break its case, at the time it ought to energe from its confuement and 
must consequently die, which but too frequently happens from mismanagement.

Some seasons are more favourable than others for the production of Caterpillars, and to keep each kind by themselves would require an immense number of cages, as well as occupy much time in changing the food, and paying due attention to them. To obviate this, some persons have large breeding cages, with a variety of food in them, which must be cleaned out every two days, and fresh leaves given to the cat $\boldsymbol{s}_{\text {rpillars }}$ as, on due attention to feeding, the beanty and vigour of the coming insects will much depend.

The Larve of insects, which feed beneath the surface of the earth, may be bred in the following manner: Let any box, that is about three or four feet square, and two or three feet deep, be lined internally with tin, and a number of very minute holes be hored through the sides and boitom. Put into this box a quantity of earth, replete with such vegetables as the Caterpillars subsist on, and sink it into a bed of earth, so that the suriace may be exposed to the different changes of the weather. The lid should be covered with brass or iron net-work, to prevent their escape, and for the free admission of air.

Cabinet.-Sich is the advanced state of Entomological science, that a collection of British Insects requires a cabinet of from 50 to 100 drawers, which are generally about fourteen or fiteen inches in length, and eighteen in breadth, and about iwo inclies deep. The bottoms should be lined with cork, of about the sixth of an inch in thickness. It must be chosen as free from cracks and knots as possible. Each drawer must have a lid of glass, with an edge of wood very nicely fitted, so as to prevent, as much as possible, the admission of air or dust. Tinis lid must rest on a rabbit.

The young Entomologist should obtain a cabinet of about thirty drawers, arranged in two tiers, and covered in with folding doors. There is a great convenience in this size, as the cabinet is rendered more portable, and at the same time admits of having another of the same size, being placed above the top of it, as the collection increases, without injuring the uniformity, and thus the drawers may be augmented to any cxtent. It is immaterial whether the cabinet is mate of ma 
hogany or wainscot; sometimes they are consiructed of cedarwood, but seldon of deal, or any other soft wood. Small cells must be made in the inside of the fronts, for camphor.

Conkrvg of Drawers. The simplest way to get the cork is to prirchase it of a cork-cutter, ready prepared, but it will be much cheaper for the Entomologist to prejare it himself. In this case, it shculd be cut into stripes, of about three inclies wirle, with a cork-cutter's knife, to smooth the surface and to divide it. The stripes should be fxed in a vice, and cut to the thickness required with a fine saw; but grease must not be used in the operation, as it will not enly prevent the cork from arlhering to the bottom of the drawer, but will also grease the paper which should be pasted on its surface. The black surface of the cork should be rasped down to a smooth surface. Alicr laving reduced the slips to about three quarters of an inch in thickness, the darkest, or worst, side of each slip should be glued down io a sheet of brown, or cartridge, paper; this s!ould be laid on a deal board, about tinese feet in length, and the widtin required for a drawer or box; a few fine nails, or bruls, must be driven thro:toh each piece of cork, to keep it firm and in its place, until the glue be tried: by this means, sheets of cork may be formed the size of the drawer. All the irregularities are filed or rasped down quite to a level surface, and tinen polished smooth with pumice-stone. The sheet, thus formed and finished, is glued into the llawers. To prevent its warping, some weights must be equally distributed over the cork, that it may adhere firmily to the bottom of the drawer. When quite dry, the weights are removed, and the cork covered with fine white paper, but not very thick. The paper is allowed to be quite damp with the paste before it is placed on the cork, and, when diry, it will become perfectly tight.

Insect cabinets should be kept in a rery dry situation, otherwise the antemne, legs, \&c., will become quite mouldy. Tire same evil will ensue if the insect is not perfectly dry, betore it is placed in the cabinet. Should an insect be covered with mould, it can be washed or with a camel's hair pencil, dipped in camplorated spirits of wine; in which ease, the insect must be dried in a warm or airy situation, before being placed in the cabinet. 
There should always be plenty of camphor kept in the drawers, otherwise there is great danger to be apprehended from mites: where these exist, they are easily discovered by the dust which is under the insects by which they are infested. In which case, they must be immediately taken out, and rubbed clean with a fine camel's hair pencil, and well imbued with the solution of corrosive sublimate, and then placed near a fire, taking care, however, that too great a heat is not applied, as it will utterly destroy the specimen. The Butterfy, Sphinx, and Moth tribes are extremely liable to the attack of mites, and should therefore be fiequently examined.

STone Boxes. - The neatest manner of constructing these, is to have them about a foot square, the top and bottom about two inches deep, on the same principle as back gammon boards, the inside being lined with cork.

\section{CLASS X.-ECHINODERMATA.}

All the soft animals of this class ought to be preserved in bottles of spirits. Those with a coriaceous or crustaceous covering may be dried.

\section{Asterias.-STAR-FISH.}

Those Star-fish, which have fragile crustaceous tentacula, are difficult to preserve. They must first be immersed in fresh water for four or five hours, and then extended on a plank of soft wood; the rays must be properly arranged, and pins used to keep them so, till they are quite dry. These are stuck into the plank, alongside the rays, and not into the rays themselves. They must not, hovever, be placed near a fire, or in the rays of the sun, as, in either case, they wili have a tendency to change their colours. It is almost invariably found, that all colours in the crustaceous coverings of animals become reddish by exposure to the heat of the sun or of a fire.

The larger kinds should have the flesh cut out of the inside of the rays, and a little of the dry preservative applied to tham. The species called Medusis's Heads undergo the 
same preparation as other Star-fish, only that much cantion is required.

When these are packed, they will require great altention. The larger kinds should be wapped in fine and soft paper and the smaller ones packed between layers of cotton.

\section{Echini and Sputangus,-SEA-URCHINs.}

There is a great dificulty in preserring these animals, in consequence of the spines with which they are invested, principally from the care required in retaining the natural positions, the spines of which are, in many species, pointed in all directions. This is particularly the case with those of the genus Cidarites. These animals inhabit the Mediterranean and Indian seas, and are distinguished by the shells having large tubercles, pierced with holes, for a muscular cord which moves the spines. These spines are extremely large, solid, and heavy, and are very liable to fall off, even from their own weight while drying.

The anal opening should be a little enlarged, a small spatula introduced, and the whole intestines removed; it should then be immersed in firesh water for a quarter of an hour, taking care to preserve the spines. When taken out, fill the shell with cotton; the shell should then be placed on a plank to dry, and between each spine a pad of cotton, to prevent the weight of the shell resting on the spines, and also to keep those on the upper surface in their proper place, and so that they may all radiate from the body of the shell.

In sending them home, each should be separately packed retaining the cotton between the spines, placing them in a box, so that they cannot rub against each other, and with a thick padding of cotton between each. Small species should be placed in little boxes, and packed as above directed.

Nothing is more difficult than to preserve entire the spines of these large shells, and it is seldom that the larger species can be kept complete. But these can be again fixed, if they have fallen off. The whole spines of the Echini and Spatangi are seated on small tubercles. A little hole must be drilled in the end of each spine, at its base, with a triangular awl, or a saddler's awl, to the depth of about a quarter of an inch; 
a acedle, or very fine wire is introluced into the perforation, after it has been filled with cement. The shell of the Fichins must now be filled with melted bees'-wax : care is taken to stop up all the openings, while in the act of pouring in the melted wax. When the wax has cooled, a hole is bored in each tubercle, for the reception of the neclle, which must first be warmed at a lighted candle, and, the wax cooling, holds the needle firmly in its place.

A better plan, however, than the above is, to use very fine wire, which ought to be bent as nearly at righit angies as pos sible, before being introiluced; and, having filled up all the vacancies of one sille in this way (always leaving as much ontside as will fit into the perforation made in the base of the spine); poir in some cement, male as thin as it will flow easily, and then set it aside to dry. Repeat the same operation with the other side; and, when dry, the spines may be placed on the projecting wires with cement, as above directed. The wire which is left outside should be roughened with a file here and there, previous to its being inserted, so that it may the better retain its hold in the cement.

\section{CLASS XI.-ENTOZOA; AND CI.ASS XII.- ACALEPHA:}

The animals of these classes are best preserved in spirits, and indeed there is no other manner of setting then up. We have made attempts to preserve worms, by removing the intestinal canal and oriducts, and injecting the skin with wax, but we never succeeded in rendering them natural in point of shape. We have also tried the same method with different species of Actinea, or Sea Suckers, but the same unsuccessful results have attended them.

\section{CLASS XIII.-POLYPI.}

Zoophites, or Corals, generally live in families or congregated masses. Their axis is of a horny consistence, generally hard, and disposed in layers; their surface is usually fur- 
nished with small spmes corered by a gelatinous substance. The axis of the Gorgonia is also of a horny consistence, and the fleshy matter by which it is covered contains detached particles, that are very friable in nearly the whole species. These are first piaced, for an hour or two, in fresh water, and then dried, while the branches are held open. The same method is adopted with the Pennatulæ, or Sea Pens.

There is no difficulty in preserving the calcareous covering of the various Madrepores, \&c.; all that is necessary is to immerse them in fresh water for some hours, so as to extract the salt, and then dry them thoroughly.

In packing the surall kinds, they may simply be placed in cotton; but the ponderous and heary ones should be fixed to the bottom of the case which is to contain them. This is done by passing corls between the branches at the base, and bringing these through holes bored in the bottom of the box, and fixed outside with nails. The feet of the Malrepores have sometimes large openings, in which case, advantage is taken of them, to introduce pieces of wood into these natural apertures, and then nailing them to the bottom of the case.

We have known many fine specimens of all kinds brought home, by gluing them to the sides and bottoms of packinghoxes; and, when removed, the packing-bcx is taken to pieces, and floated in water to moisten the glue, and the specimens can easily be taken off.

Sponges require merely to be soaked in fresil water, and dried. No care is necessary in packing them.

\section{CLASS XIV-INFUSORIA.}

The animals of this Class are only tound in infusions, or in water, and are so minute, that they are of no use in a preserved state. 


\section{CHA P. V.}

\section{OF PREPARING SKELETONS.}

\section{CLEANING AND PIEPARING BONES IN GENERAL.}

As much of the fleshy parts should be removed from bones intended for preparation as possible with the scalpel, but it is not required that they should be separated from each other, more than is necessary for placing them in a vessel for the purpose of maceration. The bones are to be entirely covered with water, which should be changed every day for about a week, or as long as it becomes discoloured with blood; after which, allow them to remain in water without changing till putrefaction has thoroughly destroyed all the remaining flesh : this will require from three to six months, according to the season of the year or temperature of the atmosphere. We here speak of great Britain, but in wamer climates, putrefaction will take place more rapidly. In tropical climates, fourteen days will be sufficient to disengage the flesh completely from the bones.

The large cylindrical bones of the thighs and arms should have holes bored in their extremities of the size of a goose quill, to give the water access to their cavities, and a free exit to the medullary substance.

As the water will gradually diminish in quantity from evaporation, more should be added from time to time, so that none of the bones, or any part of them, may remain uncovered, as by exposure to the atmosphere they would become of a dirty colour, and have a disagreeable appearance. To be free from such stains, is considered a great beauty in skeletons.

In towns, the macerating ressels should always be closely ') vered, as from neglecting this, the water is apt to get mixed with particles of soot, and other impurities, which have a strong tendency to blacken the bones. When the putrefaction has destroyed the ligaments, the bones are then fit for cleaning, 
which is done oy scraping of the flesh, ligaments, and periosteum. When this is effected, the bones should be again laid in clean water for a few days and woll washed ; they oughit then to be placed in lime water, or a solution of pearl ash,* for a week, when they may be taken out to dry, after having soaked then five or six liours in pure water, to remove the solution of pearl-ash, which would act upon their surface when exposed to the atmosphere.

In drying bones they should not be exposed to the rays of the sun, or to a fire, as too great a degree of heat brings the remaining medullary oil into the compact substance of the bones, anil gives them a disagreenble oily transparency. This is the great objection to the process of boiling bones, for the purpose of making skeletons, as the heat applied in that way has the same effect, unless they are boiled in a solution of pearl-ash, which some are of opinion is one of the most effictual methols of whitening them by is effectually destroying the oil. But there can be but little doubt hat bleaching is, of all methods, tire most effectual where it can be done to its greatest advantage, namely, in a pure air, and more especially on a sea shore.

It is much more difficult to clean the bones of animals that have died in good condition than those that are lean and reluced by disease.

\section{OF NATURAL SRELETONS.}

Natural skeletons are made without separating the bones from each other, in which case all the animal ligaments are allowed to remain entire. 'This plan is generally adopted, with young and small animals, because the ligmonis when diry, being divested of their natural flexibility, oecasion an inconvenience, as the different extents and varieties of moiton cannot be shown in the difierent articulations.

In makig these, we are first to remove from the bones tile skin, muscles, tentuns, and viscera, and, in short, every thing except the connecting ligaments and carilages, which ought to be curefully preserved. This is done without any reguliar or- 
ler of dissection; neither in this part of the process need any attention be paid to making the bones clean. The brain may be removed through an opening in the large fontanel, if the subject is very young, if not, a perforation may be made with the trephine for that purpose. Sone separate the head from the spine, so that the brain may be the more easily removed by the occipital hole. The skeleton is put in water and allowed to remain for several days, it is then taken out and more thoroughly cleaned by a knife, forceps, and scissors, and replaced in fresh water. This is repeated from day to day, constantly changing the water, the olject being to preserve the ligaments fresh and transparent. It is of great consequence to work hard by daily scraping and scrubbing until the hones are deprived of their blood and oleaginous matter and become white and clean, then remove them into clean line water, or solution of pearl-ash, for two or three days to take off any greasiness, and give a more beautiful white. When they have lain long enough, wash them with clean water; they are then placed in a position, by the assistance of a frame or piece of wood and wire, exposing them to a current of air. When perfectly dry, they may receive a coating of copal or mastic varnish.

It must be kept in view, that if the preparation is allowed to remain too long in the state of maceration, the ligaments themselves will be sestroyed by purefaction, and the intention of procuring a natural skeleton defeated.

An excellent and simple way of procuring natural skeletons of Mice, small birds, and fish, is to put them into a box of the proper size, in which holes are bored on all sides, and then buried in an Ant hill. The Ants will enter numerously at these holes and eat away all the fleshy parts, leaving only the bones and connecting ligaments; they may be afierwards macerated in clean water for a day or two to extract the bloody colour, and to cleanse them from any dirt they may have acquired, then whitened by lime and alum water, and dried in frames or otherwise, as may be most convenient. In country situations Wasps may be employed in this service; these are most voracious animals, and if a skeleton is placed near one of their nests, or in an empty sugar cask, where they resort in plenty, they will perform the dissection with much greatire expedition, and equally well as the Ants. Wasps have been 
snown to clean the skeleton of a mouse or small bird in thiree or four hours, while Ants would require a week to effect it.

When the animal is of a large size, the ligaments are sometimes unable to sustain the weight of the bones, in which case, an iron wire, of sufficient thickness, is passed through the centre of the back-bone, which must pass out anteriorly, so as to fix the head to the cervical vertebre. It is made in the form of two forks, the one for the support of the anterior, and the other for the exterior part; for this purpose two pieces of iron-wire are taken the length of the skeleton; they are twisted together, leaving a fork at each extremity, and are then both fixed to the board on which the skeleton is to be placed. One of these should enter the ribs and encompass the back bone, between the scapular bones on each shoulder, the other two should pass between the bones of the pelvis.

It not unusually happens that pieces of the skeleton detach one from anoiher, in which case, two holes are bored in the ends of the bones, which are separated, and are re-united by means of small brass wires.

\section{OF ARTIFICIAL SKELETONS.}

Skeletons of man and animals of a middling and large size, cannot be made in the manner described for natural skeletons. In this case, the bones, covered by the flesh, are immersed in water, and allowed to remain without changing it, until the soft parts begin to get putrid, when the animal matter is easily removed; and by repeating the maceration two or three times, it may all be completely abstracted. The duration necessary for the first maceration will depend upon the state of the atmosphere, being always much shorter in summer than in winter.

After the fleshy matter has been completely freed from the bones, they should be exposed on the roof of a house, or other convenient situation, until they are rendered quite white, and free from grease.

The fat in bones bears a close resemblance to the fixed oils. In the bones of whales it exists fluid like oil. In the long bones of oxen, lioises, and other large quadrupeds, it is semifuid, constituting the marrow. When, therefore, this is pre. 
sent in considerable quantity, the process may be much accelerated by drilling holes with a gimlet or other instrument, in the opposite ends of the bones, and injecting by means of a syringe, a tepid solution of pearl-ash, the pot-ash combining with the oleaginous matter, forming a kind of soap, which being soluble in water, is easily removed. Chloride of lime is also employed for the same purpose.

The relative proportion of earthy and animal matter varies according to the nature of the bone, and the purposes it is intended to serve. The bones of quadrupeds and birds contain a much greater proportion of earthy matter than those of reptiles and fishes, and hence are more easily cleaned. Here it may be remarked, that the colour of bones varies in different animals. In some common fowl it approaches to a dark yellowish brown. Food exercises considerable influence on the colour, as is demonstrated in animals which feed on madder.

When the bones are perfect and dry, they are connected by means of wire and screws, \&c. This is the most dificult part of tise opreration, as it requires considerable skill to reassemble the bones, so that they may be placed in their natural order and position. The operation is begun at one of the extremities, by making lioles in the apophysis, or round ball of the bone, plate I., fig. $1, a \& i$. This is effected by means of a wimble or a lathe, or with a gimlet, although this instrument has hardly sufficient power for periorating so lard a substance as bone. The bones are then attached to each other in their natural order, with nealed iron-wire, ${ }^{*}$ or brass-wire, by means of the perforations which have been made. The ends of the wire should be twisted, and not too firmly, but sufficient to allow a little play between the articulation; this mode to be pursued till the whole wires are put together. They are then ready for placing on a board, and are kept erect by means of one or two perpendicular bars of iron, commensurate to the weight of the skeleton. In the larger species of birds, one support is necessary; it is passed through the breast-bone, and attached under the spine, as represented in the skeleton of the Goshawk (Falco palumbarius), plate I., fig. 1. The po

\footnotetext{
* See Receipts.
} 
sition of this support must be varied according to the attitude in which the skeleton is to be placed.

In skeletons of the Horse, tlie $\mathrm{Ox}$, the Hippopotamus, the Rhinoceros, the Camel, and the Elephant, the links of wire which we have above described, are insufficient to unite their bones; for these, two iron pegs are used with a head at one end, and a screw at the other. Each screw is provided with a nut, and each pair of screws must have a narrow plate of iron bored at each end to pass the screw through. Supposing the bones of the leg and thigh, of a large quadruped, are to be united, a hole is bored through the apophysis, about two inches from the extremity, and the same having been done with both leg and thigh-bones, they are bronght together, and one of the screws passed into one of the holes of the plates which we have mentioned, and then through the perforations in the bene, and lastly into the other plate; they are tightened together by means of the nut. The screws should be nearly an inch longer than the thickness of the bones. The two ends of the bones are thus united and supported by the two plates which are kept together by the screws. Provision must be made for the play of the bones, by leaving a sufficient distance in boring the holes, through which the pegs are passed. This we have represented in plate II., fig. $3 ; a$ is the iron-plate, $b$ the nut, by which the screws of the iron-peg are tightened; $c$ the head of the other iron-peg, the nut and screw of which are placed on the opposite side.

The Horse and other lirge animals require a double har io support them, as represented in plate I., fig. $2, a, a$. A bur is also passed through the vertebre of the neck, spine, and tail, and the ribs are attached by means of wires, or flat pieces of plate iron, as seen at $b$.

In these larger animals, the heads are for the most part sawn through, for the purpose of studying the structure of the internal cavity and partitions. These are kept together by means of a hinge, so that they can be opened anul shut at pleasure. 


\section{H A P. VI.}

OF THE CHASE, AND MANXER OF COLLECTING ANIMAIS.

Quadrupeds and Birds.-It is hardly necessary to recomnend a double-barrelled gun. One of the barrels should be loaded with small shot, or dross of lead for small birds, and the other with large shot. These should have much less pow der than an ordinary charge, so as not to tear and injure the animals. Paper, cotton, or flax, and powdered dry earthen ashes should form part of the naturalist's stores.

When a bird is killed, a small quantity of dry dust is put on the wound. For this purpose, the feathers must be raised with a pin, or a gun-picker, close to the wound. The bill of the bird should have a small quantity of cotton or flax introduced into it to prevent the blood from flowing, and spoiling the plumage. The feathers must be all adjusted, and the bird then placed on the ground to allow the blood to coagulate. Every specimen should be placed in a piece of paper of the form of a hollow cone, like the thumb bags used by grocers. The head should be introduced into this, the paper should then be closed around the bird, and packed in a box filled with moss, dried grass, or leaves.

Birds taken alive in rets and traps are to be preferred to others for stuffing, and also those caught by birdlime, which must be removed by spirits of wine.

Birds should always be skinned the same day they are killed, or next day at farthest, particulariy in summer, as there is a danger of putrefaction ensuing, by which the feathers will fall off. However, in winter there is no danger for some days; but in tropical climates they must be prepared soon after they are killed. The same observations apply generally to quarrupeds.

Bats and Owls are caught during the day, in the hollows of iged trees, in the crevices of walls, and ruins of buildings. 
These are animals winich, it may be presumed, are still little known in consequence of their nocturnal habits.

Those who prepare for the chase, with the intention of preserving animals, should take care to provide tinemselves with implements necessary for fulfilling the oljects adrantageously. The articles most needful are one or two pairs of large pincers, scissors, forceps, scaljels, knives, needles, thread, and a small haichet, as well as one or more camnisters of preserving powder, some pots of arsenical soap, or arsenical composition, and some bottles of spirit of turpentine. If in America, cotton may be employed in stuffing the skins, and therefore a considerable quantity should always be taken along with the naturalist. In parts of Asia and Africa where this camnot be procured, tow must be employed, or old ropes teazed down; and where even these caniot be found, dried grass and moss may be used. MI. Le Vaillant used a species of dog-grass while in Africa, which is very abundant in that country; and it answered the purpose remarkably well.

It being supposed that a traveller has an ample caravan, provided with all the necessaries which we have pointed out, and having killed a quadruped, he will skin it immediately, according to the method which we have pointed out at page 6th. He will then sew up the skin after receiving a parial stuffing, and having been anointed with the arsenical sonp, or composition. All the extremities must then be imbued with spirit of turpentine, and the skin should be placed in some comvenient place to dry, so that it may have the advantage of complete exposure to the air. The turpentine must be again applied at the end of three or four days, more especially around the mouth of the quadruped.

It will be of the utmost advantage to remain a week or ten days at one place; by which means the raturalist will have had time to render himself somewhat acquainted with the animals which localize in that neighbourhood. And as some species frequently confine themselves to a very limited spot, by leaving the place ton hurriedly he is apt to overlook them.

Afier the traveller has determined on leaving his cantonment, he must see that all the oljects he has collected are in ? condition to be removed. He must cxamine carefully each spresinen, and see that they have not been atacked by the 
destructive insects, so abundant in warm climates. Should flies have deposited their eggs in the lips of the quadrupeds or birds, these must be destroyed by spirit of turpentine. When a set of animals or birds are thoroughly dry, they should be packed in a box or case, which has been well joined.

A journal ought to be kept detailing all circumstances connected with the animals, the places in which they were killed, and the colour of their eyes, together with any information that can be procured of their habits from the natives. People are too apt to forget pariculars when engaged in such varied pursuits, and the sooner they are committed to paper the better.

When the traveller arrives in Africa, he will meet with animals of the largest size; such as the Elephant, Rhinoceros, Hippopotamus, Giraffe, Quagga, Urus, Bubulus, Condoma, as well as large Antelopes and Deer. He will unquestionably find some difficulty in his endeavours to bring with him the skins of these animals, as in that country it is even troublesime, in many cases to transport the necessaries of life. But the ardour of the zealous naturalist will here be increased by beholding such splendid specimens as he can never meet with elswwhere. All his energies will be strengthened, and every sacrifice made to enable him to transport the fruits of his toils.

We need only to recur to the zeal manifested by Le Vaillant in his travels, and the rapturous delight experienced by him, when he first beheld, and killed the Giraffe. He brought this large skin from Caffraria, where he killed the anmal, a distance of two hundred leagues from the Cape of Good Hope.

Should the traveller, accidentally, or in pursuit of natural oljects, find himself possessed of the carcase of one of these large and fine animals, he would deeply regret not being: able to fetch away the skin from want of a knowledge how to separate it from the body. We shall, therefore, suppose that he has killed an animal the size of a Bull. He must first make an incision under the belly, in the form of a double cross. The central line must reach from the chin to the anus; the two other transverse cuts must reach from one foot to the other. These are always made inside, so that the seams may be less conspicuous when the animal is mounted. When the skin is stuffed, the hoofs are detached by laying 
them on a stone, and striking them with a hatchet or mallet. The nails or hoofs must be left attached to the skin. After this, the skin is removed from the feet, legs, and thighs, and treated in other respects as pointed ont in skinning the Elephant, at page 21. The bones of the head must be preserveo if possible, leaving it attached at the muzzle only. All the muscles must be removed from the head, and the bones rendered as clean as possible.

As it is probable that an animal of this magnitude has been killed at a great distance from any habitation, there will not be an oppurtunity of macerating the hicle in alum and water, as pointed out for the Elephant. The skin will also be too thick for the arsenical soap to penetrate with effect. Under these circumstances, the next best thing to preserve it, is to take the ashes of a wood fire, and rul it well inside. The skin should then be stretched along the boughs of a tree, and allowed to dry. The skull, afier it has also been dried, must be returned into the skin, and the lips, ears, and feet, imbued plentifully with turpentine, which operation must be several times repeated at intervals. Nothing is more effectual in preventing the attacks of insects than this spirit, and no larva will exist in places which it has touched.

The skin will be sufficiently dried within two or three days, so that the hair may be turned inwards. If some common salt can be procured, a solution of it should be male, and the hair rubbed with it. Both sides of the skin must be rubbed with this two or three times, at intervals of a chit.

When suffic:ently diry, the skin may be rolled up and packed. The hair ought to be inwards, with a layer of dried grass intervening, to prevent friction during conveyance. The operation of rolling up the skin must be begun at the head.

If the journe'y is long, the skin should be unrolled, and placed in the sun for a few hours, and the places liable to the attack of moths should be again rubloed with turpentine.

When a skin thus prepared has reached the place where it is to be put up, ic must undergo a preparation previous to its being mounted. In the first place, it must be extended along the ground with the hair undermost, so that it may acquire fresh pliability, and those paris which remain stiff must be moistened with tepid water. The skin must then be placed 
in a large vessel of water saturated with alum, there to remain eight or ten days; after which, it must be extended on half rounded pieces of wood, and thinned with a sharp knife, which is facilitated by the projections of the rood, enabling the operator the more easily to cut it, while it is gradually shified, till the whole has been pretty equally thimed. When this operation is completer, it is allowed to soak in water with an equal quantity of that saturated with the alum. Twentyfour hours will be sufficient. It must then be placed on the artificial bo:ly, as directed for the Elephant, at page 21 .

In hunting for snakes, great caution must be excrcised, as it is well known that the bite of some of these proves fatal within a quarter of an hour, particularly that of the Rattlesnake and some others. Indeed, it would be more prudent to allow the natives to hunt for these poisonous reptiles, as they are better acquainted with their haunts, and the means of defence to be employed in this dangerous pursuit. They are also better aequainted with those which are poisonous. We mas, liowever, remark, that the poisonous Snakes have, in general, much larger heats than those which are harmless, and their necks are also narrow.

\section{SHELLS.}

Shells, on account of the elegance and variety of their forms, and beauty of their colours, are objects much sought after, not only by naturalists, but also by most persons who are unacquainted with seience. There is no species, particulatly in remote climes, which does not deserve to be brought home: the things nost common in those countries being frequently the most rare in ours. Shells are found on every part of the surface of the globe. Some are inhabitants of the land, while others only frequent rivers, lakes, ponds, and ditches; and another and more numerous class live in the ocean. Landshells are spread over the whole surface of the earth, and althongh more accessible, are perhaps less known than those which inhabit the ' mighty deep.'

LAND-SHELLS, for the most part, are to be found creeping bbroad, either in the evening, or after a gentle shower of rain. Duning the heat of the day thes retire to shaded retreats, un- 
der thick bushes, the crevices of rocks, the hollows of decayed trees, or under their bark; beneath stones, amongst moss, or in holes in the ground. A little experience will teach the naturalist readily to find their retreats.

Fresh Water Shells must be sought for, if in deep lakes, with a dredge, or if in shallow places, with a tin spoon fixed on the end of a stick. This is made of a circular piece of tin four inches and a half in diameter, beat concave, and then perforated with numerous small holes, not exceeding the sixtecnth part of an inch in diameter; around this must be soldered a perpendicular rim, three quarters of an inch broad, and also perforated with holes. To this must be attached a hollow tubular handle, three inches long, for the insertion of a walking stick. It must have a few holes towards its outer end for passing a string through, to tie it firmly, and prevent it being lost. (See plate V., fig. 6.) With this spoon the collector must rake along the mud at the bottom of ditches or ponds, and after bringing a quantity to the surface, he must wash the mud entirely away, by shaking the spoon on the top of the water, and it will all pass through the lioles and leave the shells. The sharp edge of the spoon is also useful in detaching aquatic shells from the under surface of the leaves of water-plants.

The large Swan-Muscle (Anadonta Cygnea), and other Anadons, generally lie deep in the mud, so that they cannot be procured by dredging. I found it necessary to invent a net to fish for these. This consisted of an iron triangle of twelve inches, with a hollow handle fixed on its base, and in this is inserted a pole of sufficient length to reach the bottom. It is firmly screwed to the handle. A net is attached to the triangle either of twine or hair-cloth. The point of the triangle should be sharp, so that it may the more easily penetrate the mud, and it is drawn through it in situations where shells are supposed to exist. (See plate V., fig. 5.)

Marine Shells. - These are to be found in all seas; some of them inhabit rocks on the shore within high water mark: others reside in deep water, and can only be taken by dredging, or by the use of a kind of net called in France the Gangui, and an instrument called the Rake has also been successtully used. 


\section{OF THE GANGUI.}

This is the most simple apparatus for fishing shells. It is a large net in the shape of a bag. The mouth of this bag is kept open while at the bottom of the sea, by means of a stick placed transwersely, lieeping the margins apart from one side to the other. This stick is equal to the diameter of the aperture of the bag, and as it is placed horizontally, it divides that aperture into two halves, the one inferior, and the other superior. The whole circunference of the lower part is furnished with small pieces of lead, whose weight draws it down. The circumference of the upper part is provided, on the contrary, with small pieces of cork, which raise it up; thus the bag remains always open at the bottom of the sea. This bag is dragged by means of a rope, which attaches it to a boat, the motions of which it follows. The lead with which the lower part of the aperture is loaded, causes it to drag strongly along the bottom of the sea, the shells and marine plants of which are pulled off, and enter the bag as it is moved forward.

\section{OF THE RAKE.}

In many cases, the gangui has not suficient power to detach those shells which adhere strongly to the rocks, at the bottom of the ocean; in which case, the rake will be found an efficient instrument.

The rake is composed of a cross piece of iron, armed with teeth. and attached to a long handle, of a similar form to the rake used by gardeners, except that from the two extremities of the cross iron proceed two iron branches, which are attached to the handle, and which form, with the cross piece, a kind of semicircle. This semicircle serves for attaclment and aperture to a net, in shape of a bag. This rake is fixed by the end of a handle to a rope, by means of which, fishers, in a boat, draw it in by the help of a capstan. The teeth of the rake drag along the bottom of the sea, and detach the marine bodies which adhere to it ; these are received into the net, by menus of which they are brought up to the surface. 


\section{OF TIE DREDGE.}

There is no instrument like the dredge, in point of general utility. It is much used for fishing oysters. It acts upon the bottom of the sea almost like the rake, which we have above described : it is only a rake of a different form, better fitted for attaining its end. No naturalist, who lives on the sea-coast, should be without a dredge ; and to those travelling in foreign countries, in search of natural objects, it will be found of the utmost utility. The following is a representation of that instrument.

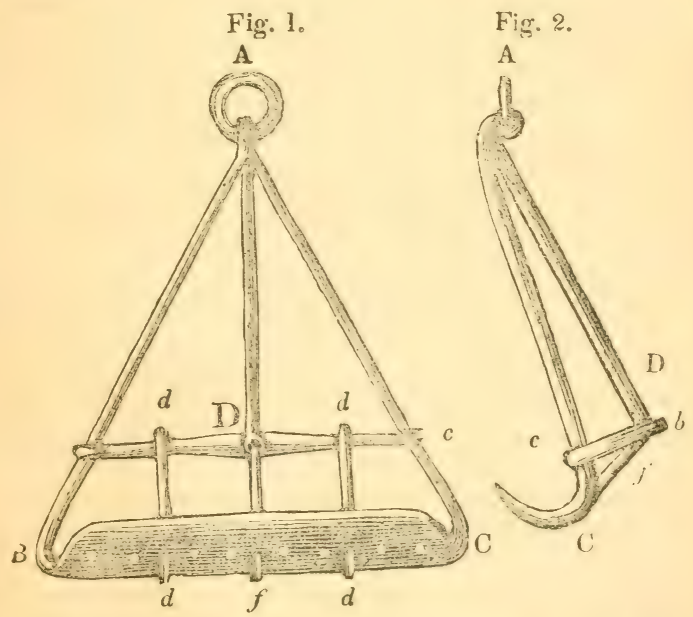

To have a clear idea of the dredge, and the parts which compose it, we must inagine a circular bar of iron, forged in the shipe of an alnost equilateral triangle, $A, B, C$, of the above figure, whose two extremities are joined at $A$. To form the summit or point of the triangle, each of the sides should be above five feet. The two branches, A B, and A C, are rounded and bent, as they approach the base of the triangle. The base, B C, is forged into a plate, six inches in breadth with a sharp 
cutting edge in front, turned upwards, at an angle of alout sixty degrees. The back, or that part opposed to the edge of the plate, is an inch thick. By means of the curvature, $b \mathrm{~B}$, c C, fig. 1. and 2., of the two lateral branches, A B and A C, the edge of the plate, $\mathrm{B} C$, is brought forward, and a little turned to the side of the summit, A, as may be seen in the profile of the dredge, fig. 2. A C. This edge makes, with the plane of the triangle, contained between the straight parts of the two descending branches, A B, A C, an angle of about sixty degrees.

There is a large iron ring attached to the summit $A$; when, by means of a rope passed through this ring, the dredge is dragged along the bottom of the sea, the edge, $\mathrm{B} \mathrm{C}$, which is turned to the lower side, next the bottom, rakes it strongly, and detaches from it all the bodier which adhere to it: but it is not enough that these bodies should be detached from the bottom of the ocean; they must also be retained, and raised by means of a net.

This net, attached to the dredge, and which follows it at the bottom of the sea, in order that it may receive within it the bodies that are detached, has the form of a bag. The lower part of this bag, which is intended to drag along the bottom, should be made of untanned hide, so as to resist the friction. The side next the plate should consist of straps of leather, crossing each other like a net; which are attached to eight holes in the lack of the plate, $\mathrm{BC}$, which may be seen in fig. 1. This plate is pierced with eleven holes, but three of them are intender for the reception of three bars, whose use will afterwards be explained.

The upper part of the net is attrched to a rod, $b c$, fig. 1. and 2., which crosses the triangle, A B C, parallel to the plate $\mathrm{B} \mathrm{C}$, which is distant fiom that plate about two feet : this rod is round, and nearly two inches in diameter; the two extremities terminate in a flattened end, perforated to receive the two ascending branches, A B, A C.

The curvature of this rod removes it from the plane of the triangle, $b \mathrm{~A} c$, in a way contrary to that in which the base of the plate, $\mathrm{B} \mathrm{C}$, is removed from it, by means of the curvature of the two ascending branches, A B, A C, at their inferior extremities; and these remorals in a contrary way, keep the bag 
always open, of which the edges have been attached, as we have said, one end to the back plate, $\mathrm{B} \mathrm{C}$, and the other to the transverse rod or bar, $b c$.

This rod must be firmly fixed in its place; for this purpose, it is a little flattened, and pierced in its midlle, D, with a hole. A bar, A D, figs. 1. and 2., which comes from the summit, A, of the dredge, and which is also flattened and pierced with a hole at its extremity, $\mathrm{D}$, is joined, by means of that extremity, to the midulle of the rod, $b c$, on the concave side, so that the two holes are adapted to each other. The extremity of a small cross bar of iron, $\mathrm{D} f$, is made to pass these, which issues by the oiher side of the rod, $b c$, and the bar, A D. The same cross piece of iron, $\mathrm{D} f$, is attached, in a similar manner, by its other extremity, $f$, which is made to pass, that it may be afterwarks bent, through one of the holes, with which the back of the plate, $\mathrm{B} C$, is pierced.

This plate, as we before mentioned, is pierced with eleven holes, of which eight only are employed in giving passage to the meshes of the net or bag. These holes are arranged two and two together: an idea of their arrangement, and the use of the three others, may be leant by inspecting fig. I. That in the midule serves to attach the cross bar, Dff. The two others serve to attach, in like manner, two similar cross bars, $d d$, $d d$, fig. I., which strengthen the whole machine, and of which the other extremity is attached to the rod, $b c$, by a kind of hook, which embraces that rod.

The bar, A D, and the cross bar, D f, are inclined to one another. By means of this inclination, the bax A D, through which passes the cross bar $\mathrm{D} f$, is strongly fixed to the rod $b c$, from which it can be removed only by being elongated. This bar, A D, is a little less thick than the two ascending branches A B, A C; they are, however, nurly two inches in diameter. The three branches, A B, A C, A D, unite again at the summit of the dredge, where they are whied together so as to make only one, whose extremity is bent to embrace the ring, as seen at $\mathrm{A}$, figs. 1 . and 2 . The common oyster dredge is smaller than that which we have described, and of a lighther make.

We have still to describe the manne in which this instrument is used for the fisting of shells. A corl is passed through 
the ring attached to the point of the dredge, anotler cord is attache 1 to the middle of the rod, $b c$, by a knot which embraces the rod $b c$, the perpendicular branch $A D$, and the small crois-bar if $f$ at the point where they unite. When the boat has reached the place of fising, the diedge is thrown out at the stern in the same manner in which an aschor is thrown out, the last named cord serves to keep the dredge in its place, the plate being turned below till it arrive at the botfom of the sea, and to prevent it from being overturned by the way. When the dredge has reached the bottom, it is hauled along by rowing and sailing. Should the dredge be stopped by any rock or irregularity at the bottom, the rope attached to the ring should be pulled. When the bag is supposed to be full, the dredge is drawn on board by the capsian, and the bag is emptied of its contents.

Different species of sea weed are fiequently covered by minute shells, - weeds should always be carefully examined. Nany of the smaller and microscopic shells are found at high water mark among the fue dross and drifted fragments of shells; this sand should be brought home and examined at leisure. To facilitate the process, a small wire-cloth sieve should be made, of about six or seven inches square, and all the sand sifted through it, and the shells left. see plate V., fig. 7 .

\section{MOLLUSCOUS ANIMALS.}

Many species of worms, and other soft invertebrate animals, arc to be caught also by the dredge. There is no way of preserving these animals except by putting them in spirits. Animals of this kind are still very imperfectly known; notwithsianding the researches of Lamarck, Poli, and other celebrated naturalists. Every opportunity should, therefore, be embraced of bringing them home ; indeed, we are still little acquainted vith those which inhabit our own seas. Colonel Montagu and Dr Grant have, however, thrown much light on this department.

When animals of this kind are procured in foreign parts, a careful noting of the latitude should be taken; and it should be stated, whether they live singly or are congregated, if they 
are phosphorescent, and if they were taken in deep water. And as these animals are very liable to lose their colouns by being put in spirits, a carefil noting of these should be taken whenever they are canght, as the colours are very evanescent: or, what would be still better, a drawing of the animal should be made.

Intestinat Worms. - Whenever wo lave killed eilher a quadruped, bird, or fish, we should cartilly examine the stomach and intestinal canal of the animal, to see if there are any worns; indeed, there are few animals without them; liey must also be preserved in spirts. liesiles the stomach and intestines, worms are also found in the livers and other parts of the body; also in the back of skate and rarons fishes.

\section{INSECTS.}

This class is sulbject to infinite rariety, accorting to climate and soil. 'The Entomologist, or the mere collector, mut not confine limseli to those whose beatiy of coloning renders them attrictive, but collect all that come in the way. Those species which have wings, and fly around plants, we take by means of gatuze nets, as also those which swim in the water. For the construction of these different nets, see plate IV. figs. 7. and 9. - See descriptions, p. 7j, \&c. Those which live on putrid substances, and such as are disigreeable to the touch, are seized with pincers; tisey are first put inte canphorated spirits to render them clean. irees are the habititions of inmumerable insects, many of them skulk unter the old rotten bark, and others attieh themselves to the foilinge. A cloth sliould be spread under the trees, or an mbrellat, and the branches shaken with considerable force, when they will fall down, and may then be caught.

Insects are killed by makiag a crow-rulll into a long point, and dipping it into prissic acid, an incision with it maty be mate immediandy below the laeal of the insect betwixi dhe shoulders, which usually groduces instant death. Jut this acid mist be used with intach caution, heanse its eflects are ahmost as instantanemes and fatal in the human subject as in the lower aninalk. When cork canot be hat for lining the bottome of the boxes, a hajeg vi lees wax may be used in its stewd. 
The pin sliould be deeply sumk in this substance, as it is mere liable to loosen than when in cork.

It is of much imprtance to procure the caterpillar as well as the insect, and, in this case, some of the leaves on which it feels shonld be placed in a box beside it, so that it may reach maturity. A small perioration should be made in the box for the admission of air.

Every kind of insect, except Butterflies, Silhinges, and IIoths, may be preserved in bottles of spirits, which will not injure then; when they are taken out they are immediately placed in the posilion in which it is wished to preserve them, and they are then allowed to dirs. Another mode of preserving Colenpterous Insects, such as Bectles, Ec., is to put them in a dry box amongst fue siml. A row of insects is placed in a layer of sant, and then a new layer of an inch in depth laid on the top, and so on till the box is filled. This mode of packing will not, howerer, do will soft insects, and those having fine wings.

It is extremely desirable that all the different kinds of Spiders should be caught, particularly those said to be venomous; also Termites, or White Ants, the different Scolopendra and Gally Worms, \&c. The nests of Spilers and other insects should also be sent home; in short, every insect which is remarkable, in any way, either for its history or properties.

It is also of much imporiance to bring specimens of the plants on which they feed; these should be dried, and their localities marked, the kind of soil on which they grow, and the situations, whether moist or dry, should be noted.

\section{BRITISII INSECTS.}

Wroods, Hedges, and Lanes.-By far the gaeatest portion of insects are found in these situations. In wools, the Entomologist nust beat the branches of the trees into his folding net, and must select for this purpose the open paths, skirts, \&c. The trunks of trees, gates, and timber which is cut down, should be carefully examined, and a great many Lepidopterous and Coleopterous insects are found in these situations, and in no other. In hedges and lanes, many of the most valuable and beautiful insects are found, as also in nettles and othe: 
thants which grow under thom ; these should be wall beat, but nore expectally when the white thorin blosons in the montlis of May and June. Hedges where the ronds are dusty are very seldom productive.

Hump And Commons. - Many insects are peculiar to these situations from the plants which grow on then:, as well as from the dung of cattle by which many of them are frequented, in the latter of which, many thousands of insects may be found in a single day, in the montls of April and Miay. These are principally of the Order Coleoptera.

SAND PrTs - These are farourable for the propagation of Canris lunarius, Notoxus monoceros, lixus sulcirostris and other rare insects. Minute species are found abumlandy at the roots of grass.

Meadows, Marsines, And Ponds. - In meatows, when the Ranunculi, or butter-cups, are in blossom, many Wuscee and Lipterous insects generally abound. The flag-rushes are the laabitations of Cassida, Dunacina, and others. Drills in marshes siould be exrmined, as miny species of insects are found Dil long grass. The larve of rarious Lepidoptera, and Neuroptera are confined to these situations, more esprecially if hedges nnd trees are near the spot. Fonds are rich in microscopic insects. These are oblained by means of the landing net, which, for this purjose, need not be so long as represented in plate IV., fig. 9, and sliould be made of pretty thick cotton cloth, but suficiently thin to allow the water to escape. The mud which is brought up from the bottom of ponds and ditches slould be examined, and what small insects are found may be put in a small phial filled with water, which will not only clean them, but keep them alive; and in many instances the naturalist will be suprised upon the (xamination of these, the most wonderful productions of nature.

Moss, Decayed Thees, Roots of Grass, \&e.-Many insects will be found in moss and under it; thir roots and wood of decayed trees aford nourishment and a hititation to a number of insects; many of the larva of Lefridopiteru penetrate the trunks of trees in all directions; mosi of the Ceranbjoes feed un wood, as well as some specics of Carabidn, Elateride, \&c. In seeking for these, it is necessary to use the digger,-see К 3 
plate IV., fig. 13. It is sometimes requisite to dig six or seven inches into the wood before they are found.

Banks of Ponds and Roots of Grass. - These are a never failing source of collecting, which may be followed at all seasons of the year, and in general with great success; those banks are to be preferred which have the morning or noonday sun.

Banks of Ruvers, Saxdy Sea Emore, \&c.-These situations aforou a great variety of Coleoptera, Crustacea, \&c. The dead carcases of animals thrown on the shore should be examined, as they are the receptacles and food of Silphiodce, Staphilinide, Lic. May and June are the best seasons for collecting these insects.

Dead Axmals, and Dried Bones, sliould be constantly examined, for these are the natural habitats of several insects. It is not uncommon for country people to hang dead moles on bushes; under these the Entomologist should place his net, and shake the boughs on which they are hung, as many of the Coleoptera generally inhabit these.

Fungi and Flowers. - These are the constant abode of insects, and many curious species will be found on them.

It is a mistaken idea that insects are only to be found in summer, as they are to be met with, either in a living or pupa state, at all seasons. Dried moss, beneath the bark of trees, and unler stones, are extremely likely places to find insects in winter; and even then, the F.ntomologist is more likely to procure some of the rare species, than in summer, as these are ranging in scarch of food, and in situations hidden from view.

At this season, if the weather is mild, the pupa of Lepidopteri will be found at the roots of trees, more especially those of the elm, oak. lime, \&c., or beneath tine underwood, clnse to the trees, and these frequently at the depth of some inches under the ground.

In the months of June, July, and August, the woods are the best piaces to search for insects. Most of the Butterflies are taken in those months, flying about in the day-time only. Moths are either found at break of day, or at twilight in the crening. The following method of taking Moths is pointed 
out by Haworth, in speaking of the Oak Moth (Bombyx Quercuss). "It is a frequent practice with the London Aurelians," says he, "when they breed a female, of this and some other day-flying species, to take her, whilst yet a virgin, into the vicinity of wools, where, if the weather is favourable, she never fails to attract a numerous train of males, whose only business seems to be an incessant, rapid, anl lundulating flight, in search of their unimpregnated females; one of which is no sooner perceived, than they become so much cnamoured of their fair and chaste relation, as absolutely to lose all kind of fear for their own personal safety, which, at other times, is effectually secured by the reiterated evolutions of their strong and rapid wiings. So fearless', indeed, have I beheld them on these occasions, as to climb up and down the sides of a cage which contained the dear object of their eager pursuit, in exactly the same hurrying manner as honey-bees, which have lost themselves, climb up and down the glases of a window."

\section{H A P. VII.}

\section{RECEIPTS}

FOR VARIOUS ARTICLES USED IN THE PRESERVATIUN AND SETTING UP OF ANIMALS.

\section{SOLUTION OF CORROSIVE SUBLIMATE.}

\section{Mr Waterton's Method.}

PuT a good large tea-spoonful of well pounded corrosive sublimate into a wine-bottle full of alcohol (spirits of wine). Let it stand over night, and, the next morning, draw it off into a clean bottle. When the solution is applied to black sub. stances, and little white particles are perceived on them, it will be necessary to make it weaker, by the addition of some alcohol.

A black feather, dipyed in the solution, and then dried, will 
be a very good test of the state of the solution: if it be too strong, it will leave a whiteness ujun the feather.

\section{ARSENICAL SOAP.}

Invented by Búcour, Apothecury, Bretz.

\begin{tabular}{|c|c|c|c|c|}
\hline Arsenic, in powde & & - & & \\
\hline Camphor, - & - & & & \\
\hline White Soap, - & - & - & & \\
\hline Salt of 'Tartar, & - & - & & \\
\hline Powdered Lime, & - & - & 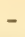 & \\
\hline
\end{tabular}

The soap must be cut in small and very thin sliees, put into a crucible with a small quantity of water, and held over a gentle fire, and frequently stirred with a wooden spatula, or a piece of wood of any kind. When it is properly melted, the powatered lime and salt of tartar must then be added, and thoroughly mixed. It must now be taken off the fire, the arsenic adied gently, and stiried. The camphor must be reduced into a powder, by beating it in a mortar, with the addition of a little spirits of wine. The camphor must then be added, and the composition well mixed with a spatula, while of the fire. It may be again placed on the fire, to assist in making the ingredients incorporate properly, but not much heated, as the camphor will very rapidly escape. It may now be poured into glazed earthen pots, and allowed to cool, after which a piece of paper should be placed over the top, and afterwards some sheep leather; and then set aside for use. The composition is about the thickness of ordinary flour paste.

When it is necessary to use the soap, put as much as will answer the purpose into a preserve pot, and add to it about an equal proportion of water. This is applied to the skin $u^{\circ}$ feathers with a bristle brush.

N. B. it should be kept as close as possible, and used with caution, as it is a deadly poison.

The above is the recipe made use of at the Jarin des Plantes, Paris. 


\section{ARSENICAL COMPOSITION.}

\section{IIr Laurent's Receipt.}

A distinguished French naturalist, Laurent, recommends the following composition, after ten years' experience, for preserving the skins of stuffed animals. He obserres, at the same time, that it penetrates them with greater readiness, and preserves them much better than any preparation which has hitherto been in use.

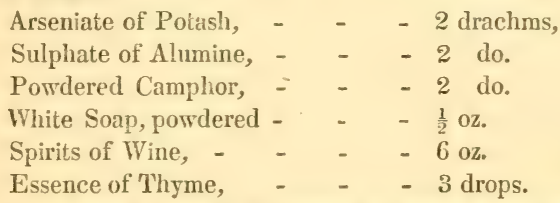

The arseniate of potash, sulphate of alumine, and soap, a:e to be placed in a phial, with a large mouth, and the spirits of wine to be poured on them, at a heat of twenty-five degrees, and they will be perfectly combined in twenty-four hours. The essence of thyme is then added, when the phial must be carefully corked. This composition is to be shaken together, before it is made use of, and it must be spread over the skin of the animal or bird with a brush.

\section{SOLUTION OF PEARL ASHES.}

Two ounces of pearl-ash to one gallon of water.

\section{ANNEALED IRON WIRE.}

Take common iron wire, make it red hot, and suffer it to cool gradually; this renders it soft and pliable, so that it mar be easily bent in any direction.

\section{CEMENT.}

\begin{tabular}{|c|c|c|c|c|c|}
\hline Fine Whitening, & - & - & - & - & \\
\hline Gum Arabic, & - & & - & - & - \\
\hline $\begin{array}{l}\text { Finest Flour, } \\
\text { Ox-Gall, a tea-st }\end{array}$ & - & - & - & - & - \\
\hline
\end{tabular}


The whole to be dissolved, and mixed well with water into a thick paste.

This is well alapted for altuehing different objects, and especially for fixing sikells to pastebourd, \&c.

\section{GUM PASTE.}

White Sugar Candy, - - - $\quad 2 \mathrm{oz}$.

Common Gum Arabic, - _ _ - - 4 do.

Let those be melted in a pot of hot water, and then strained through a linen or horse-hair sieve. When properly dissolved, add to it two table-spoonfuls of starch, or hair-jowder, and mix the whole well together. This paste may be used for many purposes, and it never spoils. It may be dried, and by pouring a little warm water on it, it will soon be ready for use. If is is wished to be all melted, and hurredly, the pot cuntaining it should be placed in warm water, or sand.

\section{FLOUR PASTE.}

Make four paste in the ordinary way, and add to it a small portion of the solution of corrosire sublimate, or powdered corrosive sublimate. This will prevent the attack of mites, to which paste is very liable when dried. This paste may be dried into a cake, and moistened when requirel.

\section{SOLUTION OF GUM ARABIC.}

The solution of gum aralie is made by sinply adding water to it. When used as a vamish, or for attaching objects, it is 4.xtremely apt to get too brittle, in very warm weather, and to rack, or split off in scales; to prevent this, a quarter of an ounce of white or biown sugar candy must be added to two ounces of gum arabic.

\section{PAPER PASTE, GUMMED.}

Take a coffee-pot, filled with waier, and add to it a quantity of paper, which has been slightly sized, like thin used for frinting engravings. Let it boil for three hours, and, when 
the water has evapoiated, boil it again for a sinilar length of time. Take ont the paper, and squeeze it well in a colunder, and then pound it in a mortar, until it is relueed to a very fine paste. It must then be dried. When it is required for use, add to it some of the solution of gum arabie; and keep it in a pot for use.

\section{POLLEN POWDER,}

The paper male as above directed, when well dried, is pounded in a mortar till it becomes a very fine powder; it is then put into a tin peiper-box, and when any of the parts of Parrots' bills, \&.c. are wished to have this powdered appearance, a little of the solition of gum arabic is washed over the part with a camel's hair pencil, and the powder clusted on it, and allowed to dry.

\section{RED VARNISH.}

Take a stick of red sealing wax, beat it down with a hammer, ant then put it into a phial, with an ounce of strong sprit of whie, which will dissolve it within four or five hours. It may be applied to any part with a camel-hair pencil, and it will dry in less than five minutes.

Black, yellow, and green, or indeed any colour of varnish, may be made from sealing-wax of these various colours.

To those unacquainted with the combination of colours, we may mention, that a mixture of blue and yellow protuces green; pink and blue makes purplo; red and jellow, oriage; black, red, and yellow, brown ; black and blue, gray. Tiıese may be varied, in an infinity of shades, by either coluar yredominating, and by the addition of other colours.

Varnishes of gum-conal and gुum-mastic, and white spirit rarnish, are also used for different preparations, but as these can be easily purchased at a cheap, or even a chespre rate than they can be made in small quantities, we think it unnecessary to give receipts for making them.

Wax of different colours for these vamishes, is prepared and sold by Messrs George Waterston and son, No. 14, Somh Hanover Street, Edinburgh. 


\section{LUTING FOR RENDERING BOTTLES AIR-TIGHT.}

Common Resin.

Red Ochre reduced into a fine powder.

Yellow Wax.

Oil of Turpentine.

These must be melted over a fire in the following manner; and the vessel in which it is made should be capable of holding three times the quantity required, to allow ample room for boiling up. An earthenware piplin with a handle is the best thing for the purpose, and a lid must be made of tin to fit it. The luting will be rendered more or less brittle, or elastic, as the red ochre prevails :-

The wax is first melted, and then the resin; the ochre is then added in small quantities, and stirred quickly with a spatula each time. When all the ochre has been added, it must be allowed to bnil six or eight minutes; the turpentine is then added, and briskly stirred with the spatula, and continue to boil it. There is considerable risk of the mixture taking fire, and should it do so, the lid must immediately be put on the vessel to extinguish it.

To ascertain the consistence of the luting, a little must be, from time to time, dropped on a cool plate, or flat piece of iron. If it is too soft, more of the ochre must be added to it ; and if too hard, additional wax and turpentine.

\section{TOW AND FLAX SLIVERS.}

These are fillets of prepared tow and flax, of from one to three inches in breadth. They are extremely uniform in their thickness, beiug made to weight, and can easily be procured from any flax-spinning mill, at a moderate price per pound weight.

\section{METHOD OF MAKING ENAMEL-EYES FOR ANIMALS}

Much of the character and expression of animals depends upon their eyes : it will, therefore, be evident that great attention is necessary in the artificial imitation of these. 
The instruments necessary for making these are an enameller's table, bellows, lamp. round pincers about six inches in length, which are closed by means of a ring, and with which is held the iron-wire forming the support, and the base of chese eyes, which it is impossible to blow. Procure another flat pair of pincers of the same length, which are used for handling the enamel, as also for stirring up the lamp. These instruments can be had ready made in every hardware shop.

The materials from which the eyes themselves are formed is an assortment of cylinders of enamel of all colours, which can be purchased; besiles some fragments or clippings of mirror-glass, which are melted in the lamp into a kind of cylinder like the enamel, so that they may be ready for use when required. During the process of melting these pieces of glass, considerable attention is necessary to free them from spots and globules of air. These cylinders can be procured ready made in the shops; and at various glass-manufactories.

The table is placed in a situation where the light of day cannot reach it, as the double light would distract the vision during the operation.

After the lamp has been lighted, the pipe of the bellows is directed towards the middle of the wick, which is slightly scattered in that part so as to procure a clear light-bluish flame, which is necessary to secure success in the operation, because if it is not clear, the colours of the enamel are liable to change during the operation of making the eyes. The enamel which we wish to melt should be applied to the extremity of the jet of the flame, which it will not burn, and often melts more easily than in the centre.

As small eyes are less difficu!t than large ones, it will be advisable to commence with them until we shall have acquired practice. For small eyes, a small iron-wire is used about an inch and a half long, one end of which is held in the round pincers, and the other is approached to the fire, to which is exposed at the same time the enamel of the colour we wish the eye, whilst the other is turned between the fingers until it begins to melt. The quantity necessary for the size of the eye is then fastened to the end of the iron-wire. This by being turned in the flame forms a small globe, and when it is sufficiently rotinded, a little speck of black enamel is placed in the 
centre, for the purpose of imitating the pupil. It is again exposed to the flame that the pupil may be blended into the mass. When it is properly incrusted, some glass is put upon it, which should extend three quariers across the hemisphere of the eye. This glass is intended to represent the virrous humour of the eye, and from which all its brilliancy proceeds. The eye is still exposed to the flame until the glass las extended over that part of the eye which is intended for the iris; when we effect this, it is allowed to cool slowly. This kind of eye is made by joining several pieces of iron-wire together, which renders it easier to make them all uniform in point of size, because the first being close to our eyes guides us in the formation of the others.

\section{SECOND METHOD OF MAKING EYES.}

Another method of making eyes is the following:- Some pieces of iron-wire, from three to four inches long, are prepared, which have been well burned. Their strength must be proportioned to the size of the eye which is intended to be made. These are curved in the middle over a tube of glass enamel, or any other cylindrical and polished body: the extremities of each wire are united by twisting one over the other, so that they perfectly fit the substance which they embrace. It is this circle formed by the wire which makes the diameter of the eye, and the wire thus prepared is in the form of a rocket. The handle of this rocket is fixed into tise round pincers, and the head of it curved by making it parallel to that of the pincers. This circle is filled with common enamel, of the colour which we wish, extending it from the circumference to the centre, and when it is nearly the thickness of the wire, it is pressed while yet in a state of fusion with the fat pincers, so that it may extend equally over the entire circumference. It is then put into the fire to consolidate it. This having been done, the iris is formed by a drop of enamel of the proper colour. This is heated and pressed as before with the flat pincers, and when it is incorporated with the first enamel, the pupil is represented with a small speck of black enamel, as before mentioned. When this is melted anu incrusted in the iris, both are covered with glass, and heated 
ngain until all the parts are smooth, ant the glass has diffused itself over the whole iris. The ere is now placel on some warm cinders, and left to cool slowly, without which precantion it is liable to break; or it may be put into warm water, and allowed to cool gradually. It is then removed from the wire by loosening the latter. This method is only adapted for' eyes of a middling size.

\section{THIRD METHOD OF MAKING EYES.}

There is still another methol of making exes, which is per. haps better than those we lave alreaty described; and that is, to blow them if we possibly can; which, howerer, camnot be done when they are small. In this operation, a pipe of baked earth is uscd, or a zube of glass six or seven inches in length, at the end of which a little whice enmel is placed. This is placed to the flame, so that it may be blown. This enamel forms a globe, whose dimensions depend upon the quantity of air introduced. When this globe is of the size wished, we place in the midule, and peripendicularly to the point of the lipie, the quantity of enamel necessary to form the enamel. The second enamel is then inconporated with the first, by presenting it to the flame, while attention is paid to turn the pipe gradually round, so that the enamel may diffuse itself erqually, and the iris be exactly circular. If it is required that this ir:s should be of rarious culours, like that of man for example, smail filaments of enamel are distributed in diverging rays of the suitable colour ; the eye is then placed in the flame, until these have incornorated with the iris, after which the pupil is placed as before directed, and the glass anylical as before directed.

During this operation, the glolue is almost certain of sinking down, partly from the air escuping, partly from the heat, and from the pressure which is used in applying the different substances: air must again be supplied from time to time to prevent it from losing its form. This becomes particularly noresiry when glass is applied, and when it is exiended orer the whole surface of the iris.

The eye having got its form and size, the pipe is taken away. To effect this, after the air has been introluced, the entrance 
124 ARTICLES For SKINNING AND MOUNTYNG QUADRUPEDS, \&c.

of the pipe is stopped with the finger, and the back part of the eye exposed to the flame; when the air contained in the globe, and rarified by the pipe, comes through at the place where the flame has most action. This opening is prolonged by turning the point of the flat pincers, or an iron-wire, all round the pipe; one point only is left by which the eye remains fixed. It is then warmed equally all over, after which it is exposed to a gentle heat, and when it again cools, it is separated from the pipe.

These eyes can also be purchased at different shops in London and Paris, at from a penny a pair to twenty-five shillings, according to size.

ARTICLES REQUIRED FOR SKINNING AND MOUNTING QUADRUPEDS, BIRDS, REPTILES, AND FISHES.

1. A box containing scaipels of different shapes (plate VI., fig. $1 \& 2)$; a pair of scissors with pointed blades, fig. 3 ; and two or three pointed forceps of different sizes, fig. $6 \& 7$; the extremities of one of which onght to be indented.

2. Two flat pincers, or pliers, large and small.

3. A round pincer for turning wire, fig. 4 .

4. A cutting pincer for wire, 5 .

5. A hammer.

6. Two files.

7. A triangular.

8. Points for perforating holes, figs. $9 \& 10$.

9. A saddler's awl for drilling holes, also various shoemakers' awls, which will be found useful.

10. Bruslies of different sizes for putting the preservative on the animals' and birds' skins, and for smoothing and dusting the feathers.

11. An assortment of iron-wire of all sizes.

12. Flax and tow, coarse cotton. When these cannot be had, untwisted ropes or cords. A quantity of tow and Hax slivers for twisting round the leg. bones of small quadrupeds and birds.

13. Some small hardwood meslies for assisting in stufing. 


\section{H A P. VIII.}

\section{INSTRUCTIONS TO TRAVELLERS.}

\section{THE ANIMAL KINGDOM.}

Ervee the establishment of the menageries of the Jardin des Plantes at Paris, and the zoological gardens of Loulon, a naw feld of investigation has been thrown open to the scionfife matumalist. In these splentid establishmenis, the animals are, for the most part, placed in situations somewhat congenial to their nature, and in which their native energies may be party awakened.

Until the institution of these esiablishments, it was merely the forms of the animals which could be studied, with a simple knowledge of their organs. But now we are enabled to trace the developement of their sagacity, and instinctive habits. These we acquired, in former times, fiom the accounts of travellers, which, it is to be lamented, were fiequently garnished with imaginary wonders. By this means also we can compare their manner of living, with their internal anatomy after death; and we acquire certain information on the imporiant modes of their copulation, gestation, and birth, and we are enabled to trace the variations which take place in their fronress from infancy to the mature state, and from that to old age, and many other important points.

Much useful information has been acquired since the institution of menageries. This, therefore, ought to be a strong excitement for travellers to embrace every opportunity of sending home living specimeus of all animals not European. Very little is yet known of the liabits of animals which burrow in the ground.

The best means of procuring living animals, is by applying to the natives of the different countries, who are accustomed to their habits, and the situation in which they are likely to be 
found, and to take them in traps and snares. They are also more likely to be able to find their retreats, so that they may take these animals in a young state, and also birds in their nests.

By thus securing animals while young, they are much more likely to reach Europe in a living state. Every exertion should be used to render them familiar, when, being habituated to the appearance of man, they will be more able to resist the effects of a tedious sea voyage than those which have been taken when wild, and are under a continued degree of excitement. Every care slould be taken to soothe and caress them; and there is no animal whose rianners cannot be softened by gentle treatment. During fine weather, they should be allowed to take exercise on the deck, as nothing is so injurious to their health and growth, as being long pent up in a small cage. While thus confined, it will be obvious that they require a much smaller portion of food than when they can have sufficient room to exercise themselves. Many of these animals are lost from orer feeding. Their diet should be given with great regularity, but always in such quantity as they can easily digest.

Next to food, cleanliness is of the utmost importance, and if this requires too much of the attention of those who are bringing them home, it will be easy to procure the assistance of some of the crew. And unless this is strictly attended to, there is little chance of preserving their health.

When animals' skins are imported, it is also necessary to bring the head and feet. Those of the mammalia, which can be put into a barrel or boitle, should be preserved en. tire in spirits.

In the event of not being able to transport the carcase, the next best thing is to bring the skeleton along with the skin. It will not be necessary to mount these. All that is required is to boil the bones, take off the flesh, and dry them. Afterwards, all the bones belonging to the same skeleton should be put in a bag by themselves, taking care to fill up the bag with dried moss, or any other substance which will prevent friction. The more effectually to secure this, the small and tender bones ought to be wrapped in paper. It is of the utmost consequence that not a bone should be lost. 
In shooting birds, it is of much importance not to use the shot too large; indeed, it ought to be proportioned as nearly as possible to the size of the bird to be shot at. When the bird is killed, the blood must be carefully wiped away, and a little cotton must be put into the bill to prevent the blood flowing from it to injure the feathers. The wound should also be stuffed with cotton.

Birds should be skinned as soon as possible, as the feathers are apt to fall off if kept too long. Directions for skinning will be found at page 25. The os coccrgis must be kept attached to the skin. (See plate I., fig. $1, m, n$.) If several individuals of the same species be killed, one should, if possible, be preserved entire in spirits, with the whole muscles of the body. If the bird has a fieshy crest, it ought to be preserved in spirits.

It is of the utmost consequence to procure the male, female, and young, and these at different ages besides, as many species are subject to great variety, in their progress from the young to the adult state. This is more particularly the case with Eagles and Hawks; many of which have been described as different species in their immature state. The eggs and nest should also be procured. (See page 58.)

Repriles. - The chief thing to be attended to in skinning reptiles, is not to injure the scales; and in the Lizard kind, care must be taken not to break the tail. But for all the smaller and middle sized species, the best mode is to preserve them in spirits; and of the larger kinds which are skinned, the skeletons ought to be kept. The flesh should be taken away with knives and scalpels as well as possible, and the bones thoroughly dried, and packed in a box with cotton or grass, and they can be articulated after they are brought home. When the skeletons are too large, they may be sepurated into convenient parts for packing.

Fisues.-Many species are common to all seas, but there are a vast number which are quite local. Unless, therefore, the traveller is certain of the frequency of those he meets with in his own country, he ought to bring them home. River and fresh water fisles generally are subject to great variety, every lake and river having rarieties peculiar to itself, which the experienced fisher, or naturalist, can at once detect. It is, there- 
fore, very interesting to be possessed of these varieties. When the species are too large for preservation in spirits, they ought to be skinned, taking care to preserve the heal and fins entire. The brain ought to be removed by the occipital hole.

For Insects, Shells, \&c., see their respective chapters.

Every animal sent home should be accompanied by a note, slating the country where it was found,-the particular situation where it localises, - its food, - the season it was taken, - the peculiarity of its habits, -its native name,-whether its flesh was used as food,-any popular or superstitious opinions regarding it amongst the natives. A number corresponding to the note should be attached to the animal.

The most certain way to prevent these numbers from being injured, is to have them either painted, or stamped unon wool or metal, and attached with brass wires; or these may be engraved on pewter plates.

In packing oljects of natural history, attention is required to see that they are well preserved from the attacks of insects; the skins must be well rubined inside with the arsenical soap. (See page 116.) Caution must, liowerer, be exercised in the use of it; and in mounting the skins afterwards, it is necessary to aroid touching them with the hands as much as possible, as it often produces disagreeable effects. Those oljects which are prepared with the preservative should be marked, so that the stuffer may avoid touching them too much. Or other preservatives may be used, such as spirits of turpentine, oil of petroleum, and camphor, which are sure to disperse insects if on the skins, and will also prevent them from attacking them, while transporting from one place to another.

Before skins of any kind are packed, they must be well shaken, and then rubbed over inside with oil of petroleum, or spirits of turpentine; these must be applied with a brush. They are then slightly packed with cotton, but just suficient to prevent the inside of the skins from pressing on each other. In case oil of petroleum, or turpentine, cannot be procured, a decoction of bitter and aromatic herbs may be rubbed over the inside of the skins, and the ontsides should be dusted with pounded tobacco, or pepper. The box in which they are packed must be pitched all over to prevent damp and air from reaching the inside. 
For the preservation of animals in ardent spirits, glass-buttles are by far the best, and those of a square shape are to be preferred, on account of their packing better.

Considerable attention is required in placing the anmmls, and also in regulating the proper strength of the spirits.

Rum, brandy, gin, arrack, or whisky, may be used, but the less it is coloured so much the better, and the strength should5 not exceed from 16 to $2 \cdot 2$ degrees of Baume, otherwise it will destroy the colour of the animals. Any mucous or other sub-, stance should be carefully removed, and dirt taken away. The animal should not reach the bottom of the bottle, is it is liable to decay by touching the bottle. M. Peron directs that the specimen should be attached to a flat piece of cork, by which means it is held suspended in the spirits, and thus several may be placed in the same vessel, without injuring each other. But the most simple method is to put the specimen in a net, or linen bag; and if these are attached to cork they will remain suspended in the vessel. A slight incision should be made in the abdomen, to allow the spirits to reach the internal cavities, so that it may prevent decay. A day or two after the animals are placed in the bottles, it will be necessary to fill them up again, as part of the liquor will have been absorbed by the specimen. The corks should then be luted with the composition mentioned at page 120. Corks are to be preferred to every thing else for stoppers. Before applying the luting, the coik must be perfectiy dry, otherwise. it will not adhere. The luting is first heated to the boiling point, and well stirred from the bottom, with a piece of $\mathrm{rag}$ attached to a small stick, and the luting may be applied with this all over the cork. A piece of strong linen is then tied over the cork, and if the bottles are large, a piece of wire should be crossed over them, and the whole must then be coated over with pitch.

The traveller, or naturalist, will be best informed in regard to the animals which are peculiar to the different quarters of the globe, by consulting a natural history; for example the Regne Animal of Curier, or Goldsmith's Animated Nature, brought down to the present time. The latter, of course, will be the best allapted to the purpose of the Linglish realer. 


\section{OF THE VEGETABLE KINGDOM.}

The introduction of foreign plants and seeds into Europe is of the utmost consequence, not only in a scientific point of view, bat because many of them prove of the uimost utility to mankind. First then, the introduction of plants in a living state is of much importance, and if it is inconvenient to transport these, their seeds ought to be procured.

The strictest attention ought to be paid to the local situation in which the plants grow; the particular quality of the soil ; whether of a sanly or clayey, or calcareous or regetable mould; whether in moist or dry situations; its uses in the comntry where it is found, whether as food or medicine; and every thing else connected with its history.

The coffee trees were first introluced into the green houses of the gard:n of plants, at Paris, and from thence transported to the American Islands. And more recently, the bread-fruit tree was sent from France to Cayenne, where it has thriven in a remarkible manner, and proved a blessing to the inhabitants of that couniry. In the like manner have many of the most ueful and oruamental wook's of our forests and lawns been introluced. The seeds of plants should be frocured when they are in a periectly ripe state, to insure their propagation. They should be put in separate paper's ; that is, each species by irself; with a memorandum stiting whether it be a tree or an herb-its native country-the natire of the soil-its elevation above the sea, and its native name.

When seeds are ripe, they are easily separated from the ylanis; but when it is found that they are not perfectly ripe, and the travelier cannot remain in the neighbourhood till they are so, a branch nay be brought away with the seeds adhering, which will assist, in ripening them.

The bags containing seeds should be packed in cases corcred with pitch to prevent the entrance of damp, insects, or mice, to destroy them. M. de Candolle packed the seeds which he procured in moist countries in powdered charcoal, which effectually prevented the effects of damp.

Seeds which are of an oily nature, are most liable to lose their gerninating faculty; of this kind are those of coffee, 
tea, and oaks: to prevent this, these seeds should be placed in sandy earth, two inches of this earth should be laid on the bottom, and the seeds put at a little distance ftom each other, they are then covered with a layer of earth one inch in thickness, and proceed in this mamer till the box is filled within six or eight inches of the top, and the remainder filled up with sand. The box must not be too tightly covered, as it is of consequence that the air should penetrate the carth. Indeed, there ought to be an opening at the top, with a trellis cover of brass wire, to prevent the intrusion of mice; this was the manner in which M. M. Michaux, senr. and jumr. transporied nearly the whole of the Forth American oaks to France. During the passage the seeds will germinate, and their embryos will be developed, and all that is required is to place them in fresh soil congenial to their habits. The same method must be adopted with stone fruits, such as waluuts, plumbs, and nectarines; as also with laurels and myrtes, and more particularly those syecies which have to be transported across the equatorial seas.

For the preservation of the seed's of pulpy fruits, a different mode must be pursued. These seeds are pritectly ripe when the fruit inlicates the first stages of putrefaction, the seeds must then be removed, thoroughly dried, and placed in paper bags for preservation.

Dined Plants. - These are collected for the formation of herbariums, and are of much use in enabling the botanist to describe and distinguish new species. By means of these alone, the naturalist can determine all the characters of the plants, and thus form a classification of the regatable kingdom. Besides the leaves and stem of the plant, its roots should also be procured if possible.

Fruits in a ripe state preserved in spirits are extremely use ful for comparison with those which we raise in Europe. Resins, gums, and all other substances which are likely to prove useful in the arts or medicine, ought to be procured.

The plants intended for an herbarium. must be gathered both in the flower and fruit; they must be laid out in as natural a manner as possible beiween leaves of paper, with a board placed over them, and some stones or othe: weights for pressure, to prevent the leares from curling ujon drying. This fiessure must be applied till they are perfectly (irs, and they 
should be examined every day or two, to see that they are lying properly, and to prevent them from sticking to the paper. In most climates, artificial heat becomes necessary to facilitate their drying, so that mouldiness may not ensue. For this pur pose, each plant is placed between two or three sheets of paper, and after placing several layers of these above each other, they are put into an oven which is half cooled. There is no danger of the colours giving way, as might be supposed, from this rapid drying; when this operation is completed the plants are put in clean paper, each species being in a separate leaf.

Bulbous plants are very difficult to dry from the quantity of moisture contained in them, and, indeed, often vegetate after they are in an herbarium; to prevent which, they ought to be plunged in boiling water for about a minute, and then placed between two leaves of brown paper, when they will dry rapidly, as the boiling water will have destroyed the vegetative functions. We must, however, avoid immersing the blossoms. The same notes must be put with each plant, as recommended at page 128; besides these, the height of the plant, the colours of its flowers, and its odour, should be attended to.

When the herbal of a country is formed, it ought to be packed in a large box and a little cotton with oil of petroleum placed beside it, or a little oil of turpentine; the box should be covered with pitch, as before directed.

The genus and species of many of the different kinds of wood used in commerce, are still unknown to Botanists; it is therefore desirable that specimens of these should be sent home of ten inches or a foot long, and the whole breadth of the tree if possible, as also transverse sections; these ought to be accompanied with a branch of the tree containing the leaves, and of flowers and fruit besides.

It is not enough to bring home a single specimen of objects of natural history, but as many as can conveniently be stowed by the traveller; these will be found very useful to other naturalists, and by exchanging them for other duplicates, will add greatly to the value of a collection; and, besides, our specimens are liable to accidents and decay, so that, in many points of view, duplicates will be found very useful. 


\section{GENERAL REMARKS ON BOTANY.}

As we advance towards the equatorial regions, we find that the plants exhibit larger features; so that the paper which we require for an herbarium must be from eighteen to twenty inches long and twelve inches wide. Several planks ought to be procured for pressing-boards; these should be formed of two thin ones glued together to prevent warping fiom the damp of the plants in pressing. The thread of the wood ought to run lengthwise in that which is placed next the paper, and transverse on the outer side. A press should be obtained for squeezing them, or weights and stones may be used for that purpose; others make use of a series of leather straps with buckles. The Botanist should have a book of blotting-paper in his botanical excursions for collecting plants, as it is much better for absorbing the moisture of the fresh plant; besides this, a tin botanizing box of from fifteen to eighteen inches in length, and from six to eight inches in breadth: this box is about two inches to two and a half in depth, and curved, that is, the lid is concave and the bottom convex, to each end should be attached a strong wire for passing a strap through, so that it may be carried like a knapsack ; it ought to be japanned outside to prevent it from wasting. A small box of the same shape for carrying in the pocket, will also be found useful for small plants, this may be about seven and a half inches long and five broad. A small trowel, with the blade six inches long and two and a half broad, will be found extremely useful for digging up the roots of plants; it should be oblong and acutely shaped, as in the following figure :-

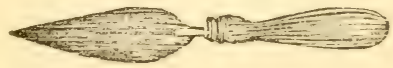

Another instrument for procuring the branches of trees, is an indispensable appendage to the botanist. The upper edge of which is sharpened for cutting branches of trees, or specimens of the wood from the larger trunks of trees. The lower 
edge on one side is sliarp for cutting those branches which are out of reach, and the other side is to serve as a hook for pulling down branches, that specimens may be obtained of the fruit, flowers, and leaves, of high trees. (See plateV., fig. 14.)

When the botanist has arrived at a place where he is to be some time stationary, the plants collected are removed from the boxes, and each placed between a separate piece of dry blotting paper, and two or more sheets shotild intervene betwixt every plant. The whole should then be put between the boards, and well strapped together, and placed in a dry and warm situation. The plaper oughit to be changed every day for some time, to prevent mouldiness from the damp.

Tender and marine plants should be placed in a plate of pure water, and a piece of strong white paper introduced beneath them, and the plants can then be nicely arranged, and then taken out to dry, which is done by raising them slowly in an oblique direction, and when they are half dried they must be placed between paper, and subjected to pressure. When the plants are of a very tender nature, they should be placed on talk, or glass.

Seeds which are proluced in pods ought to be kept in these, and to prevent them from opening, a thread nust be tied round them.

It is of great consequence to have specimens of the trunks of trees with their bark entire. Stumps of a foot in length are necessary to exhibit these properly; that is, if they do not exceed a foot in diameter. But if the trunk exceeds that size, a branch of about that dimension must be chosen. But if the branches difier from the trunk in extcrnal structure, which they frequently do, the trunk itself must be chosen. Let it be cut half or a quarter through, and make a longitudinal section of that portion; that is, it should be cut out of the trunk; but in all cases extending from the pith to the bark.

Fungi of a fleshy nature must be preserved in spirits, in the same manner as fruits.

Cryptogamic botany which has, till late years, been much neglected, is now exciting general interest. Many of these plants are parisites, existing on living regetables, and appear like spots, or excrescences on leaves, stems \&:. These shoulu 
be brought home adhering to their natural situations; and unless the species of the tree on which they grow is known to the traveller, a specimen brancis should be imported at same time.

It is of consequence also, to observe which way climbing and parasitical plants bind round the stems to which they adhere, that is, to ascertain whether they are dextral or sinistral plants. The naturalist must suppose himself in the place of the stem, placing himself with his face tumed towards the south pole, and then mark whether they ascend to the right or left. Those whose head twists in the same direction which the sun appears to move in, are dextral plantz.

\section{GEOLOGY AND MINERALOGY.}

Every mineral from the most common clay or sancl, to the gem, ought to be collected.

Specimens of rocks, such as giraniie, porphyry, limestone, slate, \&c., should, if possible, be broken from fixed rocks, and not from loose masses, which are generally decayed. In selecting the specimens, one set ought to represent the different varieties of appearance presented by the rock in the fresh state; another the rock in is different states of decomposition. It is not sufficient for the geologist to conient himself with yossessing a simple specimen of any mountain rock. For he will find that they present considerable variety of structure in different districts, and these are very interesting to be brought together for comparison. By an accumulation of tilese, we may be assisted in coming to certain conclusions concerning their primary formation, and other geological facts.

When the specimens of simple minerals or rocks contain crystals, they ought to be wrapped in fue paper, and then in cotton, and afterwarils in several folts of strong wiappingpaper.

The specimens of rocks ought, if possible, never to be less than four inches square, and one inch in thickness, and of a square form. As soon as they have been prepared, they slionld be labelled, and put in several folds of strong wrapping-paper to prevent firiction. When paper cannot be procured, moss, or other soft regetable substances, ray lie substituted for it. 
The sands of the deserts, steppes, and rivers, ought to be carefully collected. The sands of rivers often contain precious stones and metals, and hence become interesting objects to the naturalist. The sands of deserts and steppes throw much light, on the nature of the surrounding country, and are much prized by the geologist.

Numerous mineralized, animal, and vegetable remains, oc cur imbedded in strata of different kinds. All these ought to be very carefully collected and preserved. Abundance of shells, in a fossil or petrified state, are found in limestone; of vegetables, in slate, clay, sand-stone, \&c.; and numerous bones, and even whole skeletons of quadrupeds, birds, amphibious animals, fishes, and also insects, occur in rocks of various descriptions.

The mineralogist ought to provide himself with hammers of various sizes. One for common use of two pounds weight; others, three, four, and six pounds weight. He ought to have various chissels, differing in form and size. Likewise, a set of small boring-irons. A mariner's compass, small magnifying glass, goneometer, and blow-pipe, ought also to form part of his equipment. That admirable instrument, the Simpiesometer, invented and sold by Mr Adie of Edinburgh, for ascertaining the altitude of places, should also be possessed by every traveller and naturalist; as also the Thermometer, the Hyrometer, or Dew Point instrument, the Photometer, and the Kilinometer, all made by the same gentleman. Nor should the mineralogist neglect to provide himself with a strong bag, in the form of that used by sportsmen, which ought to be lined with strong leather covered with wax-cloth, and the outside of some durable cloth.

Besides these, there are many other instruments required by naturalists, a complete set of which will be found in the Appendix, with their prices; and these are all made by $\mathrm{Mr}$ Adie, optician and instrument maker to his Majesty, one of the first in his line in this or any other country.

To illustrate the past and present condition of mankind, the various articles of antiquity, dresses of different nations, implements of agriculture, warlike instruments of nations and cribes, ought also to be collected, 


\section{EXPLANATION OF THE PLATES.}

\section{PLATE I.}

Fig. 1. exlibits the skeleton of the Falco Pulumbarius, or Goshawk, and shows the manner in which it is supported by a small iron rod; and also the names of the bones. a.-Ball of the Ulna.

b, b, b.-The rertebrie of the ncck, or cervical veriebra.

d, $\}$ The Sternum.

e, e.-The Tarsus.

f, f.-The Fibula.

g.-The Tibia.

h, h.-The metacarpal bones.

$\mathrm{i}, \mathrm{j}$.-The Ulna.

m. -The Pelvis.

n.-The Os Coccygis.

q. -The Clavicle.

s. - Vertebræ of the back.

t. - The Os Humeri.

Fig. 2.- Skeleton of a Horse, sliowing the manner in which it is supported; and also the names of the bones.

A.-The head.

a.-The posterior maxillary or jaw bone.

b.-The superior maxillary, or upper jaw.

c.-The orbit of the eye.

d.- The nasai bones, or bones of the nose.

e.-The suture, dividing the pratial bones below from the occipital bones above.

f.-The inferior maxilary hone, contaning lis: "uyer incisors, or cutting teeth. 
B.-The seven Cervical Vertebre, or bones of the neck. C. - The eighteen Dorsal Vertebri, or bones of the back. D.-The six Lumbar Vertebre, or bones of the loins.

E.-The five Sacral Vertebre, or bones of the haunch. F.-The Caudal Vertebra, or bones of the tail, the usual number being fifteen; sometimes, however, they vary. G.-The Scapula, or shoulder blade.

H.-The Sternum, fore part of the chest or breast-bone.

I. - The Costie, or ribs, seven or eight of which articulating with the Sternum, are called the true ribs, and the remaining ten, or eleven, which are united together by carti lage, are called the false ribs.

J.-The Humerus, or bone of the arm.

K. - The Radius, or bone of the fore arm.

L.-The Ulna, or elbow, with its process, the olecranon.

M, M.-The Carpus, or knee, consisting of seven bones.

N, N.-The Metacarpal, or shank bones. The large Metacarpal, or camion, or shamk in front; and the smaller Metacarpal, or splent bone behind.

g. - The fore pastern and footy consisting of the Os Suffraginis, or the upper and longer pastern bone, with the sesamoid bones behind, articulating with the cannon and greater pastern; the Os Coronx, or lesser pastern; the Os Pedis, or coffin bone; and the Os Naviculæ, or navicular shuttle bone, not seen, and articulating with the smaller pastern and coffin bones.

h. - The corresponding bones of the hind feet.

O, O.-The small metacarpal, or splent-bones.

P.-The pelvis, or haunch, consisting of three portions, the ilium, the ischium, and the pubis.

Q.-The femur, or thigh-bones.

$R, R .-T h e$ patella placed on the stifle joint.

S, S.-The tibia and fibula; the latter is a small bone be hind. These are also called the ham bones.

' ', T.-The bones of the tarsus, or hock, six in number.

U, U.-The metatarsals of the hind leg, called shank, or cannon bones.

W, W.-The os calcis, or point of the hock.

$\mathrm{X}, \mathrm{X}, \mathrm{X}, \mathrm{X}$. - The sesamoid, or fetlock bones. 


\section{PLATE II.}

Fig. 1.-The common Perch, showing the manner in which the paper is attached for the purquse of extending the fins. a, Pectoral fin.

b, Ventral fin.

c, Anal fin.

d, First dorsal fin.

e, Second dorsal fin.

Fig. 2 exhibits the manner of inserting the wires in mounting a Cat.

Fig. 3. -The wires as they are put together before being placed in the skin; a, the tail wire; b, c, head and neck wire ; $d$, $\mathrm{e}$, and $\mathrm{f}, \mathrm{leg}$ wires.

Fig. 4.-Wire employed for forming a double cross in the larger quadrupeds.

Fig. 3, exhibits the manner of articulating the joints of the larger quadrupeds, in setting up skeletons. $a$, an iron plate; $b$ is the nut which tightens the screw of the iron peg; $c$ is the head of the second iron peg, the nut and screw of which are the same as that shown in front, and is placed behind.

\section{PLATE III.}

Fig. I shows the manner of holding the hands in the operation of skinning a bird.

Fig. 2 shows the manner of suspending a bird by one limb, for the purpose of skinning. Described page 29 .

Fig. 3 exhibits Mr Bullock's method of insering the wires in setting up a bird. See page 36 .

Fig. 4 shows the manner of pinning up a bird after it has been mounted, to keep the feathers in their proper fusition till they are fully dried. See page 35. 


\section{PLATE IV.}

Fig. 1 shows the manner of setting Lepidopterous insects, as is fully described page $81 ; a, a, a, b, b, e, f, g$, and $h$, different braces made of card.

Fig. 2.-The setting needle.

Fig. 3.-This figure exhibits the method of setting the Orlhoptera, Dictyoptera, Hemiptera, and Omoptera, as described at page $80, \& c . \quad b, \& c$, are braces of card. In all specimens set in this way, the pin must be passed through the midlle of the back, and near the thorax; the wings are kept extended by means of braces.

Fig. 4.- Hethod of setting Coleoptera, with the wings closed and in a crawling position; the legs are kejt in the attitude designed, by the aid of pins applied as necessity requires. The tarsi are kept flat on the setting-board by card-braces. The pin by which the animal is transfixed is introduced through the right elytron. See page 81 , \&c.

Figs. 5 and 6.-These minute insects which are so small that there is difficulty in piercing with a pin, are placed on a small triangular piece of paper or card, as shown in these figures.

Fig. 7.-An msect net complete. For its uses and description, ste page 76 .

Fig. 8.-A Net Rod. See description, page 76.

Fig. 9.-A Hoop-Nit for aquatic insects. See description, page 76.

Fig. 10.-Breeding Cage for insects. See description, page 87.

Fig. 11.-Phial for collecting insects. See page 77.

Fig. 12.-Setting-Needle. See page 77.

Fig. 13.-A Digger. See pag̨e 77.

Fig. 14.-A pair of small brass plicrs.

Fig. 15.-A setting-needle, with a camel hair pencil places at one end. 


\section{PLATE V.}

Figs. 1 and 2,-A Geological Hamier, which should be. about two pounds weight, as described at page 136 .

Fig. 3.-A Small Geological pocket Hammer, of about one pound weight.

Fig. 4.-A large Hammer for rocks, of at least six poumds weight.

Fig. 5.-Triangular Net for fishing large fresh water Shells, which are sunk in mud. See description, pange 105.

Fig. 6.-A Trn-Spoon for fishing fresh water Shells, described at page 105 .

Fig. 7.-A Small Sieve for microscopic marine Shells. Described at page 110 .

Fig. 8.-The oval and head-wires of a Bird separated. See page 35.

Fig. 9.-The tail-bearers separated. See page $3 \dot{0}$

Fig. 10. - The body-wire, the head-wire, the tail-bearer, and legs connected. See page 35 .

Fig. 11.-A leg-wire separated. See page 3.5.

Fig. 12.-Forceps, or Flappers, for catching Butterflies, or other insects, when seated upon leaves or flowers. This exhibits a front view of the instrument. Described at page 78 .

Fig. 13. - Side view of Forceps.

Fig. 14.-An instrument for the use of travellers, for procuring branches of trees, fruits, \&c. Described at page 133.

\section{PLA'TE VI.}

Fig. 1.-Blade of a Scalpel for separating the skin of Quadrupeds, Birds, \&c.

Fig. 2.-Blade and handle of a differently shaped Scaipel.

Fig 3.-A pair of Scissors used in skinning, \&c.

Fig. 4.-Round Pincers.

Fig. 5.- Cutting Pincers for wire.

Fig. 6.-Pair of large Forceps.

Fig. 7.-Pair of small Forceps.

Fig. 8. - A triangular Bodkin, or A wl.

Figs. 9 and 10.-Circular Bodkins, 


\section{A P P E N D IX.}

I HAVE already stated as my opinion, that no method will ever be devised by which man can be preserved, so as to be fit for placing in a museum. I still adhere to that opinion, although a highly important discovery has recently been made by two celebrated chemists of Chaillot in France, the Monsrs. Capron and Boniface, by which they can preserve the human figure in a manner superior to any mode hitherto practised.

By a process which these chemists keep secret, and to which they have given the name of "Mcmification," they have succeeded, after passing a number of years in experiments, in so modifying and perfecting the known process of preserving bodies, as to reduce them to nummies, leaving all the forms unaltered. All the elements of disorganization which show themselves in the human body so soon after death, are completely destroyed, and not only the external body, but all the viscera, the lungs, the heart, the liver, and even the brain, are perfectly preserved. The operation requires but a very few days, after which the dead bodies may be preserved in a room or a vault, or interred in the ordinary way, without being accessible to worms. They may also be exposed to all the variations of the air, either in a standing or sitting position, without undergoing any alteration. The inventers do not intend to make their process public, but it may be adopted even by those who reside at a considerable distance from Paris, as a body placed in a leaden coffin or bathing tub, and completely surrounded by ice, may be kept uninjured for twenty days, and the operation may still be performed. At a late meeing of the Academie des Sciences, a human body and also two hearts preserved in this manner, were exhibited, and the process appeared perfect. The discoloured state of the skin, occasioned 
by the scar of an oid wound, was even fully perceptible; and although these preparations had been completed several weeks, not the slightest approach to change of any kind was observable.

\section{LIST OF BOOKS FOR ATTITLDES OF QUAD- RUPEDS AND BIRDS.}

The works in which Birds arc regresented in the most lively and natural manner, are,--

1. Audubon's Illustrations of American Ornithology. This admirable, but expensive book, excels all others, for the picturesque beauty, and natural character which that excellent draughtsman and zealous naturalist has given to his birds, - the result of long and patient study in the woods. There the auhor became acquainted with the habits and economy of the feathered tribes of that rast couniry, and has portrayed them in all their variety of attitude.

2. The Gardens and Menagerie of the Zoological Society, delineated, 2 rols. Vol. Jst, Quadrupeds-vol. 2d, Birls. These are executed in a masterly style from the drawing of Harcey. The attitules of both quadrupeds and birds are skilfully managed.

3. Curier, F. and Geofroy St Hilaire, Histoire Naturelle des Mammiferes, folio. These beautiful plates are executed from original drawings, made from the living suljects in the Jardin des Plantes at Paris, by eminent artists, kept at the establishment for the purpose of drawing these oljects.

4. Wilson's American Ornithology, the edition edited by Captain Brown, medium folio. In this edition, the attitudes of the birds are considerably altered.

5. Eewick's Quadrupeds, 1 rol. Sro., and British Birds, 2 rols. Sro. These are fathitul renresentations of the origimals, and frequently powsessing much spitrit in the attitudes.

METEOROLOGY.

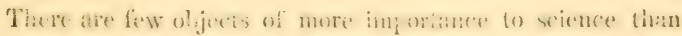


Meteorological olsservations, made, in various countries, on the earth's surface. No opportunity ought therefore to be lost in making these observations. The instruments required for observing the Meteorological phenomena of any climate, are, The Portable or Adie's Patent Sympiesometer, the Thermometer, Hygrometer, and Compass. The former instrument is used to determine the pressure of the atmosphere, the altitude of any situation above another, or above the level of the sea. To obtain the altitudes from the Barometer, observation tables are required. The Sympiesometer gives the altitudes, without the use of tables, and only requires a single process of subtraction and multiplication.

Besides the common use of the Thermometer, namely to ascertain the temperature of the air, it may be used for finding the temperature of springs, \&c., from which a knowledge of the heights may be deduced.

The Reflecting Compass is a very useful instrument to travellers. With this instrument the variations of the magnetic needle may be found, at any part of the globe, and the relative position of objects determined.

\section{LIST OF INSTRUIIENTS USED BY NATURALISTS AND TRAVELLERS.}

Made and sold by Mr Alexander Adie, Optician and Mathematical Instrument Maker to the King, No. 58, Princes' Street, Edinburgh.

Adie's Barometer or Syipiesometer, for measuring heights \&c., from $£ 33$ s. to $£ 1212 \mathrm{~s}$.

Thermometers, from $8 \mathrm{~s}$. to $18 \mathrm{~s}$.

Higrometers, or Dew Point instrument, from $£ \mathrm{~L} 5$ s. to £2 2s.

Kunometers, for finding the dip of stratified rocks, from 10s. 6d. to £3 3s.

Photometers, from $£ 1$ s. to $£ 22 \mathrm{~s}$.

The Compass Box, from 3s. $6 \mathrm{~d}$. to $10 \mathrm{~s}$.

The Reflecting Compass, from $£ 2$ 2s. to $£ 21$ ?s. 6 d. 
The Microscope. These may be had in the form of simple lenses, from 1s. 6il. to 7s.--Or mounted in brass as a compound and single Microscope, from £I 16s. to $£ 7$ s.

The Microscope is a very generally useful and interesting instrument to the observers of nature, and particularly to the Botanist, the Cristallographist, and Mineralogist.

Great improvements have been made of late years by the use of garnet in forming lenses of very high powers. These are now made so high as $\frac{1}{100}$ of an inch focus.

The Spherical, or bird eye object glass, by Coddington, forms a very fine compound or single Microscope, having a large field, great distinctness, and very high power.

The Microscope doubled, prepared by the late Dr Wollaston, forms also a very powerful instrument, with these lenses. The minute lines on the scales of the wing of the White Butterfly and Podura, distant from each other less than the $\frac{1}{\mathbf{8} 0,000}$ of an inch, are most distinctly seen.

All these forms of lenses are attached to the best Microscopes; also Micrometers divided upon glass to $\frac{1}{1000}$ of an inch, by which very small objects may be measured.

BALANCE, for ascertaining the specific gravity of minerals; may be had good, of a small size, for $£$ l ls. Blowplpes, for fusing minerals, from 2s. to Ss. Mineralogical Hammers, of varions sizes. Furceps, Platinum Cups, Callipeirs, Parallel Rules, and Proportional Compasses, \&c. \&c.

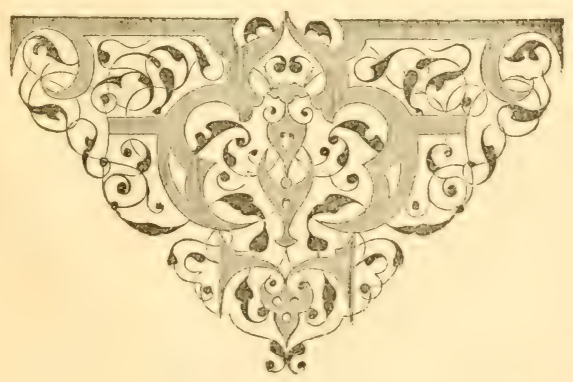





\section{N DEX.}

THE CLASSES ARU PRINTED IN CAPITALS, AND THE ORDERS IN SNALL CAPIXAL9

A

ACAI,EPHA,

Adie's Instruments for Natural. ists,

AlCYONES,

ALEC'TURIDES,

ANISODACTYLI,

Annealed Iron, receipt for making,

Ant Eaters,

Antelopes,

A pes, mode ot preserving,

Arachnides,

Armadillos,

Arsenical composition,

Asterias,

Attitudes of Birds, remarks on, alarm,

Eagles and Vultures,

\section{B}

Balistes,

Bars, for supporting the larger animals, Hippopotamus,

Horse, \&e.

Bats, of stuffing,

Bears, where found,

Becœur's method of stuffing 13irds, 37

BIMANA,

Bison,

Boards, for fixing Quadrupeds on,

Bones, how to prepare, colour of, vary in some animals, mode of articulating,

Books of Plates for studying attitudes,

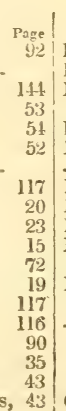

65

17,99

$1+3$
Page

Bitany, general remarks on, $\quad$ list

Braces for seting luserts, 79

Brain, method of removing, from birds' skulls,

Brass pliers,

Breeding of Insects,

- cages for, Insects, s7

Buffalo, $2: 3$

Buinous roots, $1: 3: 3$

Bullork's method of stufting birds, 36

Burchell's moite of preserving small serpents,

Buttertlies and Moths, how to kill,

\section{C}

Casks for preserving fish, their jize,

Cassowary, manner of mounting,

Caterpillars,

Cathartes papa, 49

Caution as to not over stuffing Onadrupeds, \&e.

Centre wire of 13irds, 36

Cement, receipt for, 117

CrTacea, 24

Chase, directions for, $\quad 100$

- - precautious ior preserving animals in,

CHeiroptera, 15

Chopped cotton, its u e, 23

Coots, how to remedy smallnes; of neck of, in skimuing, 26

Coleopteruus Insucts, 79

Colour, chanıihility in the skin of certain birds' heads nccounted for, te 


CoLnMBE,
Corrosive sublimate, solution of,
Crocodiles,
Cryptogamic botany, observa-
tions on,
CRUSTACEA,
CURSOREs,
Cuttle Fish,

Deer,

Diadon,

Digger for Insects,

Diptera,

Dolphin,

Drawers for Insects, how to cork, 89

Dredge, described, how to fish with,

Dried Insects, how to relax, Plants, remarks on, Skins, mode of mounting,

Ducks, how to remedy smaliness of neck, in skinning,

\section{E}

\section{Echini,}

ECHINODERMATA,

EDENTATA,

Education of a Taxidermist, what it ought to be,

Eels,

Eggs of Birds, manner of preserving,

Insects,

Elephant, how mounted at the Jardin de's Plantes,

Elk,

Enamel eyes, first method of making,

Entomological net,

ENTOZOA,

Epidermis of Shells, how removed,

Extended wings, birds mounted witin,

Eyes, Enamel, how to make,

- of Birds, colour to be noted,

- of Quadrupeds, directions for inserting,

\section{F}

Fan-:orceps,

Fat, in Cetaceous animals, truublesome in stuffing,

Feather by feather, how to mount birds in that manner,

FERE,

Fish, mode of skinning, stufting,
Fishes,

Flamingn,

61 Flour paste, Receipt for,

Flying Lemur, attitude of,

Fresh water Shelis, how to fish for,

Frogs,

Fun ri, fleshy, how to preserve, 135

Grallatores,

Granivorous Bires,

Grease in Feathers, how to remove,

91 Greasy spots in Skins, how to remove,

Gryllus,

Gum paste, receipt for,

Galeopithecus Volans, method of stufting,

Gangui, an instrument for fishing Shells, tions for collecting specimens o specimens of,

Hares,

Head and neck of Quadrupeds, what required in stufhing,

Heaths and common, what Insects frequent,

Hedgehogs,

120 Hermit Crab,

122 Hoop and Aquatic Net for In. sects,

Human head, a fine preparation of one,

Hunting-Box for Insects,

\section{I \& J}

INFUSORIA,

INERTES.

INSECTS,

Insects, British, where to collect,

- Cabinet, its dimensions,

_ How to preserve when sent home, Time of the year when most plentiful,

\section{INSECTIVorous BIRIS,}

Instruments used in the Chase.

Birds, in mount $\mathrm{n}$. 
Intestinal Worms,

instructions to Travellers-Animal Kingdom,

INVERTEBRATE ANIMALS, $6 \tau$

Journal, how to be kept,

King of Vultures,

L

Labels, mode of attaching them to Animals,

Lampreys,

Land Shells,

Larvæe,

Legs of Quadrupeds, mode of fixing,

Legs, attention required in the position of those of Birds,

Leg-wires in Quadrupeds, their length,

Lemur, flying,

LEPIDOPTERA,

Lobsters,

Luting for rendering Bottles airtight,

Madrepores,

Harine Shells, M

Marshes, what

Marsupialia,

IIauge's method of skinning Birds,

Meadows, what Insecte frequent, 113

Model made at Paris for mount. ing an Elephant,

Model too large, and how it was remedied,

Mollusca,

Molluscous animals, how caught, 110

Mnnkeys,

Moss, decayed trees, \&c, what Insects frequent them,

MYRIAPODA,

\section{$\mathrm{N}$}

Natural Skeletons made by IVasps,

Natural Skeletons made by Ants,

Neck of Birds, to prevent too much relaxation in, while dry. ing,

Nests, on their preservation,

Neuroptera,

Nicolas' method of inserting wires in mounting Quadrupeds,

Nose, Lips, and Paws, to he well imbued with the preservative.

\section{$\mathrm{O}$}

Cil, its use in cleaning Shells,

78

111 Oily matter in Butterflies, MIoths Pago \&e. \&ce, how to extract it,

OMNIYOROUS BIRDs,

Oruitherynohos rufus,

Ostrich, 20

Owis, $\quad 50$

- where likely to be caught, 100

Pachyderyata,

Packing of Birds,

128 objects of Natural His.

63 tory. 12

10ิt. Paguras Bernhardus,

$86^{\circ}$ Palmipedes, 5?

Paper paste, gummed, receipt for, $11 \mathrm{~s}$

Pearl ashes, receipt for solutiou of, 117

Plial for insects,

11 Pill boxes, their use in collect. ing insects,

Pinnatipedes,

Plaster of Paris casts, for forming the shoulders of quadrupeds,

Platypus, Duck-hilled

Pocket larya box,

135 Pollen powder, 119

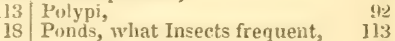

Porcupine, 19

39 Porpoise, 24

Precautions necessary in packing Birds, 27

21 in skinning Fish, 61

Prussic acid, to be used with caution,

Pupa of Insects,

Quadrumana,

\section{Q}

Quills, their use in collecting Insects.

R

96

Rake, described,

RAPACES,

Red Varnish,

56 Relaxing dried Insects,

REPTILES,

Ruitch, Dr, his excellent pre.

RUMINANTIA,

\section{S}

9 Salt's method of packing Birls' skins,

14 Sand pits, Insects which frequent them,

Scorpions,

Sea fowls, attention required in skinning,
106

$4 \mathrm{~S}$

119

83

60

if 
Sea Urchins,

Secds, instructions regardiug,

Serpents,

Setting boards for Insects,

Sharks, and preserving Insects,

Shells, their value,

how to polish,
Gangui used in fishing

Simples, in preserving Insects,

not $t_{0}$ be depended on,

Skeleton wires for Birds,

Skeletoms, how to prepare,

___ of Birds recommended to be imported, artificial,

_ natural, made by Wasps, 96

Skin of Eleplant, immense weight of,

Skinning Birds, at the Jardin des

\section{Plantes, \\ - Quadrupeds, large Biras,}

Skins of large animals, lonw to manage while traveling,

Slivers of flax and tow, their use,

Slotlis,

Snakes, cautions regarding them,

Solution of Gum Arabic, receipt fur,

Spatangus,

- how to pack,

Specimens of wood, directions concerning,

Spiders, preservation of,

Spirits, the strength of, for preserving Animals,

Star Fish,

$2 \geq 130$

Stuckbury's method of preserv. ing $\mathrm{H}$ ish,

Stufling Birds,

Bullock's method,

104

58

39

69

106

85

46

94

27

97

65

6

29

103

10

19

108

91

91

132

66
Page

90. Stuffing Birds, Mauge's method, 38

131 - Watertun's method, 39

$61^{-}$a Cat, 10

78 - Fish, 65

61 - Quadrupeds,

77 - at the Jardin des Plantes, 10

65 Support of Birds, described, 34

Tail-bearer of Birds,

T

Tetraodon,

Toads,

'lortoises, how to skin,

Fow and flax stiver,

'Travellers, instructions to,

U \& V

arnish, low to prevent it from cracking and falling off,

Varnishes, different colours and uses,

Vegetable kingdom,

Unio Margaritifera,

Urus,

28 Vultures,

Walrus,

Waterion's general directions for Birds,

104

$7 \cdot 2$

90

32

36

37 ZYGOHACTYLOUS BiRDS

38
39
10
65
8
10
34

33

65

(i)

(i)

(io

$1 \div 0$

$1 \cdot 25$

Insects, fethod of skinning Birds, opinion as to the edueation of a l'axidermist, Weatherhead's mode of preserving caterpillars,

Wires used in mounting Quadrupeds,

Wires used in stufling Birds,

Woodpeckers, smailuess of their heads, how to remedy in skinnivg,

\section{Z}

THE END.

EDINBURGII:

FULLARTON AND MLACNAB, PRINTERS, LEITH WALK. 



SMITHSONIAN INSTITUTION LIBRARIES 